\title{
Examining the Reversibility of Long-Term Behavioral Disruptions in Progeny of Maternal SSRI Exposure
}

\author{
DSusan E. Maloney, ${ }^{1,2}$ - Shyam Akula, ${ }^{1,2}$ Michael A. Rieger, ${ }^{1,2}$ Katherine B. McCullough, ${ }^{1,2}$ Krystal \\ Chandler, ${ }^{1,2}$ (1) Adrian M. Corbett, ${ }^{3}$ Audrey E. McGowin, ${ }^{4}$ and (1)Joseph D. Dougherty ${ }^{1,2}$
}

DOI:http://dx.doi.org/10.1523/ENEURO.0120-18.2018

${ }^{1}$ Department of Genetics, Washington University School of Medicine, St. Louis, MO 63110, ${ }^{2}$ Department of Psychiatry, Washington University School of Medicine, St. Louis, MO 63110, ${ }^{3}$ Department of Neuroscience, Cell Biology and Physiology, Wright State University, Dayton, $\mathrm{OH} 45435$, and ${ }^{4}$ Department of Chemistry, Wright State University, Dayton, $\mathrm{OH} 45435$

\section{Visual Abstract}
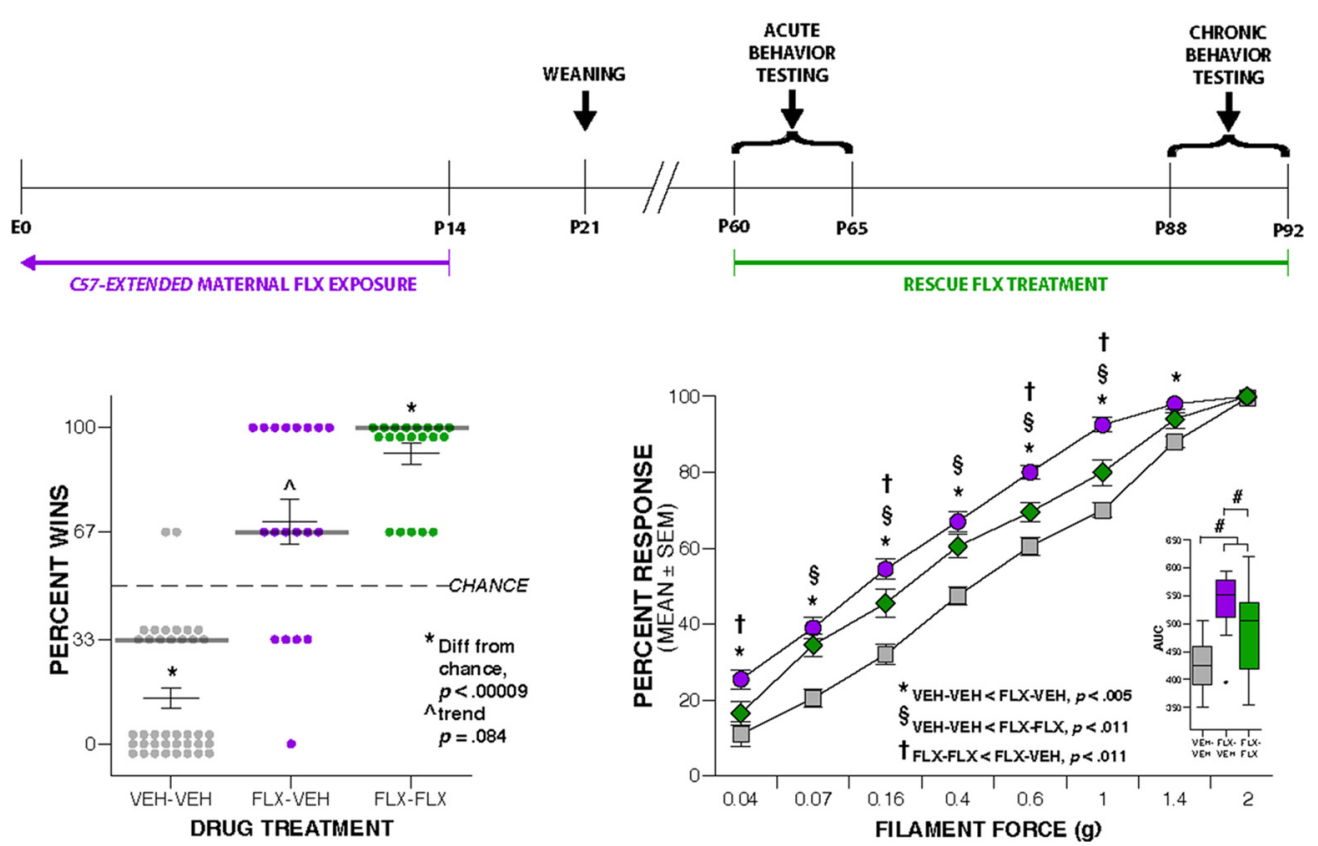

\section{Significance Statement}

Human epidemiological studies suggest that taking antidepressants during pregnancy may increase risk autism spectrum disorder (ASD) in offspring. Since only women with a diagnosis take antidepressants, there is substantial debate on whether all increased ASD risk is contributed by the diagnosis, or if medication has an additional influence. We reasoned empirical studies in a reduced system might provide some indication if there was biological basis for such an influence. Our mouse studies show that, in the absence of other maternal manipulations or stressors, maternal selective serotonin reuptake inhibitor (SSRI) exposure alone can alter the behavioral circuits for sensory, social, and repetitive behaviors, relevant to ASD, in a mammalian brain, and that some of these changes are reversible by SSRI re-exposure. 
Serotonergic dysregulation is implicated in numerous psychiatric disorders. Serotonin plays widespread trophic roles during neurodevelopment; thus perturbations to this system during development may increase risk for neurodevelopmental disorders. Epidemiological studies have examined association between selective serotonin reuptake inhibitor (SSRI) treatment during pregnancy and increased autism spectrum disorder (ASD) risk in offspring. It is unclear from these studies whether ASD susceptibility is purely related to maternal psychiatric diagnosis, or if treatment poses additional risk. We sought to determine whether maternal SSRI treatment alone or in combination with genetically vulnerable background was sufficient to induce offspring behavior disruptions relevant to ASD. We exposed C57BL/6J or Celf6 ${ }^{+/-}$mouse dams to fluoxetine (FLX) during different periods of gestation and lactation and characterized offspring on tasks assessing social communicative interaction and repetitive behavior patterns including sensory sensitivities. We demonstrate robust reductions in pup ultrasonic vocalizations (USVs) and alterations in social hierarchy behaviors, as well as perseverative behaviors and tactile hypersensitivity. Celf6 mutant mice demonstrate social communicative deficits and perseverative behaviors, without further interaction with FLX. FLX re-exposure in adulthood ameliorates the tactile hypersensitivity yet exacerbates the dominance phenotype. This suggests acute deficiencies in serotonin levels likely underlie the abnormal responses to sensory stimuli, while the social alterations are instead due to altered development of social circuits. These findings indicate maternal FLX treatment, independent of maternal stress, can induce behavioral disruptions in mammalian offspring, thus contributing to our understanding of the developmental role of the serotonin system and the possible risks to offspring of SSRI treatment during pregnancy.

Key words: autism; fluoxetine; sensory sensitivity; serotonin; social behavior; SSRI

\section{Introduction}

Dysregulation of the serotonin (5-hydroxytryptamine; $5-\mathrm{HT})$ system is implicated in numerous psychiatric disorders (Nordquist and Oreland, 2010). This system innervates the entire CNS, allowing $5-\mathrm{HT}$ to influence a variety of behavioral functions including: sleep-wake cycle, perception, appetite, aggression, sexual behavior, sensorimotor activity, pain sensitivity, mood, and learning and memory (Lucki, 1998; Smythies, 2005). During prenatal development, $5-\mathrm{HT}$ is one of the earliest neuromodulators to become active, and 5-HT levels, the expression of the $5-\mathrm{HT}$ transporter, and 5-HT receptors are at their peak, allowing 5-HT to modulate critical neurodevelopmental processes such as neurogenesis, neuroapoptosis, dendritic refinement, cell migration, and synaptic plasticity (Sodhi and Sanders-Bush, 2004; Whitaker-Azmitia, 2010). During this time, the placenta is a transient source of $5-\mathrm{HT}$

Received March 27, 2018; accepted June 7, 2018; First published July 2, 2018. The authors declare no competing financial interests.

Author contributions: S.E.M. and J.D.D. designed research; S.E.M., S.A., K.B.M., K.C., A.M.C., and A.E.M. performed research; S.E.M., M.A.R., A.M.C., and A.E.M. analyzed data; S.E.M., M.A.R., and J.D.D. wrote the paper.

This work was supported by the W. M. Keck Fellowship in Molecular Medicine from Washington University in St. Louis (S.E.M.), the McDonnell Center for Systems Neurosciences (J.D.D.), and National Institutes of Health Grants 5U01MH109133-02 and 5R00NS067239. J.D.D. is a National Alliance for Research on Schizophrenia and Depression Independent Investigator.

Acknowledgements: We thank Andreas H. Burkhalter, Ph.D., Rinaldo D'Souza, Ph.D., Durga P. Mohapatra, Ph.D., Karen L. O’Malley, Ph.D., and Steven K. Harmon for access to equipment and training; Matthew Reisman, Ph.D., for advice and discussion; and Rayden Hollis, M.A., for equipment construction.

Correspondence should be addressed to Dr. Joseph D. Dougherty, Department of Genetics, Washington University School of Medicine, Campus Box 8232, 660 South Euclid Avenue, St. Louis, MO 63110-1093, E-mail: jdougherty@wustl.edu.

DOI:http://dx.doi.org/10.1523/ENEURO.0120-18.2018

Copyright @ 2018 Maloney et al.

This is an open-access article distributed under the terms of the Creative Commons Attribution 4.0 International license, which permits unrestricted use, distribution and reproduction in any medium provided that the original work is properly attributed. for the fetal forebrain until the forebrain is innervated by 5-HT-producing raphe fibers (Muller et al., 2016). Increased 5-HT transfer from the placenta has been shown to blunt 5-HT axonal outgrowth within the fetal forebrain (Goeden et al., 2016). Thus, alterations to 5-HT activity from either exogenous maternal or endogenous fetal sources can impact circuit development, possibly increasing risk for psychiatric disorders.

$5-\mathrm{HT}$ is a dominant target for treatment in many psychiatric conditions through frequently prescribed medications such as selective serotonin reuptake inhibitors (SSRIs). SSRIs have become the first-line pharmacotherapy for mood disorders in pregnant women (Andrade et al., 2008) and are among the most commonly prescribed medications in this population, with frequency estimates in the United States at 5-13\% (Cooper et al., 2007; Andrade et al., 2008; Ramos et al., 2008). As the number of pregnant women taking antidepressants has increased, so has the number of studies investigating their safety and effects during pregnancy. Initial studies on neonatal outcomes reported no gross abnormalities (Misri et al., 2000); however, adverse outcomes like low birth weight and respiratory distress were reported (Oberlander et al., 2006). Sufficient time has accrued since SSRIs were introduced that human epidemiological studies are now able to assess the impact of SSRI use during pregnancy on risk of offspring psychiatric disorder diagnoses. The initial focus has been on autism spectrum disorder (ASD), likely because of the young age at onset and because $5-\mathrm{HT}$ dysregulation has been implicated in ASD: $30 \%$ of ASD patients exhibit elevated 5-HT levels in whole-blood platelets (Benza and Chugani, 2015), changes to 5-HT can either worsen or alleviate certain symptoms (McDougle et al., 1993, 1996; Hollander et al., 2005), increased 5-HT axons are observed postmortem (Azmitia et al., 2011), and PET studies demonstrate altered 5-HT synthesis in vivo (Chugani et al., 1999, 1997). A meta-analysis of the recent epidemiological studies examining this possible SSRI-ASD 
Table 1. Cohort sample sizes distributed between sexes, and behavioral tests

\begin{tabular}{|c|c|c|c|c|c|c|c|c|c|c|}
\hline \multirow{3}{*}{$\begin{array}{l}\text { Cohort } \\
\text { Celf6-Extended }\end{array}$} & \multicolumn{3}{|c|}{ FLX exposed } & \multicolumn{5}{|c|}{ Vehicle exposed } & \multirow[b]{2}{*}{ Litters } & \multirow[b]{3}{*}{$\begin{array}{l}\text { Behavioral tests } \\
\text { Developmental milestones and reflexes, } \\
\text { sensorimotor battery, social approach, } \\
\text { marble burying, T-maze, 1-h locomotor } \\
\text { activity }\end{array}$} \\
\hline & Genotype & Males & Females & Total & Litters & Males & Females & Total & & \\
\hline & Celf6 $^{+/+}$ & 11 & 12 & 23 & & 10 & 9 & 19 & & \\
\hline & Celf6 ${ }^{+/-}$ & 33 & 23 & 56 & 19 & 32 & 19 & 51 & 17 & \\
\hline & Celf6 ${ }^{-/-}$ & 13 & 12 & 25 & & 15 & 14 & 29 & & \\
\hline C57-Extended & C57BL/6J & 14 & 16 & 30 & 4 & 16 & 19 & 35 & 5 & $\begin{array}{l}\text { Juvenile play, marble burying, T-maze, } \\
\text { tube test, von Frey assessment }\end{array}$ \\
\hline Long Prenatal & C57BL/6J & 7 & 13 & 20 & 3 & 16 & 9 & 25 & 4 & $\begin{array}{l}\text { Developmental milestones and } \\
\text { reflexes, social approach, T-maze, } \\
\text { marble burying, tube test }\end{array}$ \\
\hline Short Prenatal & C57BL/6J & 10 & 13 & 23 & 4 & 9 & 13 & 22 & 3 & \\
\hline Rescue & C57BL/6J & $\begin{array}{l}9+\mathrm{VEH} \\
10+\mathrm{FLX}\end{array}$ & $\begin{array}{l}10+\text { VEH } \\
10+\text { FLX }\end{array}$ & $\begin{array}{l}19 \\
20\end{array}$ & 9 & $19+$ VEH & $20+$ VEH & 39 & 7 & $\begin{array}{l}\text { von Frey assessment, T-maze, tube } \\
\text { test, 1-h locomotor activity }\end{array}$ \\
\hline
\end{tabular}

link reported a significant case-control association between maternal antidepressant use and ASD risk in offspring. This remained when adjusted for maternal psychiatric history (Odds Ratio [OR], 1.52; 95\% Confidence Intervals [Cl], 1.09-2.12; Mezzacappa et al., 2017), although parallel analysis of existing cohort studies did not quite show independence from psychiatric history (HR, 1.26; 95\% Cl, 0.91-1.74). Likewise, two additional studies provide evidence supporting (OR 1.45; $95 \% \mathrm{Cl}$, 1.13-1.85; Rai et al., 2017), and not clearly supporting (OR 1.23; 95\% Cl 0.96-1.57; Viktorin et al., 2017), an effect of antidepressant usage independent from maternal diagnosis. Thus, although inconsistent in rejecting the null hypothesis, the Cls reported also clearly do not reject a modest independent effect of magnitude on par or above that typically seen for common genetic variants in psychiatric disease (ORs $\sim 1.1$; Schizophrenia Working Group of the Psychiatric Genomics Consortium, 2014). Regardless, direct causality and biological mechanisms cannot be inferred from epidemiological studies. However, animal studies can provide clear indication as to whether transient SSRI exposure, independent of maternal psychiatric stress, can alter long-term behaviors in mammals and provide ready access to related neurobiology.

We developed a rodent model of maternal SSRI exposure, in the absence of maternal stress, to determine whether drug alone induces behavioral disruptions related to the core symptoms of ASD in offspring. As genetic factors are clearly an important causation of ASD (Geschwind, 2008), it is likely that environmental contributions to ASD risk interact with existing genetic susceptibility (Hertz-Picciotto et al., 2006; Klei et al., 2012). It has been suggested that environmental factors that might modulate social behavior or language could tip the balance toward ASD in children with genetic vulnerability (Geschwind, 2008). As we initially thought SSRI exposure alone might be a relatively modest factor, we also exposed Celf6 mutant mice, which exhibit a subtle ASD-like phenotype (Dougherty et al., 2013), to maternal SSRI and analyzed offspring behavior for possible potentiation of the ASD-like phenotype. The Celf6 mutant was ideal for this gene $x$ environment experiment because this model already shows subtle ASD-related deficits, specifically decreased early social communicative behavior and a resistance to change behavior patterns (Dougherty et al., 2013), which allows for possible further disruption to other social and repetitive behaviors with the addition of FLX. Further, Celf6 is enriched in 5-HT-producing cells and, when deleted, results in a decrease in brain 5-HT levels (Dougherty et al., 2013). Thus, we hypothesized that early exposure to FLX may interact synergistically on the 5-HT system to further disrupt behavior in mice with this genetically vulnerable background. We also examined the impact of adult SSRI reexposure on ameliorating these disruptions to better understand their mechanism: if persistent alterations in 5-HT activity levels are playing a key role in these behavioral abnormalities, pharmacotherapy should reverse them. If not, it would indicate underlying behavioral circuits were permanently altered by maternal SSRI exposure. Overall, across multiple exposure durations, we found strong evidence supporting the hypothesis that transient exposure to SSRIs has long-term consequences on behaviors relevant to ASD symptoms. Furthermore, while a subset of these consequences are reversible with acute or chronic adult SSRI re-exposure, other phenotypes are exacerbated. Thus, maternal SSRI exposure has complex, long-lasting effects on the serotonergic system in the mammalian brain.

\section{Materials and Methods}

\section{Animals}

All animal procedures were performed in accordance with the Washington University in St. Louis animal care committee regulations. Mice were house in translucent plastic cages measuring $28.5 \times 17.5 \times 12 \mathrm{~cm}$ with corncob bedding and standard lab diet and water freely available. The colony room lighting was a 12/12 h light/dark cycle; room temperature $\left(\sim 20-22^{\circ} \mathrm{C}\right)$ and relative humidity $(50 \%)$ were controlled automatically. All mice used in this study were maintained and bred in the vivarium at Washington University in St. Louis and were all grouphoused. The C57BL/6J wild-type (WT) inbred strain (https:// www.jax.org/strain/000664; RRID: IMSR_JAX:000664) and the Celf6 mutant line (https://www.jax.org/strain/028389; RRID :IMSR_JAX:028389) were used in this study. Five separate cohorts of mice were used based on maternal drug exposure duration and mouse line: Celf6-Extended, C57-Extended, Long Prenatal, Short Prenatal, and Rescue (Table 1). Celf6 mutant mice were generated on the C57BL/6 background 
by deletion of exon 4 of the Celf6 gene as previously described (Dougherty et al., 2013). For the Celf6-Extended cohort, heterozygous breedings pairs were used to generate Celf6 ${ }^{+/+}$, Celf6 $^{+/-}$, and Celf6 ${ }^{-/-}$littermates (Table 1). Offspring were genotyped using standard reagents and primers for amplification of the region spanning exons 3 and 4: forward, ATCGTCCGATCCAAGTGAAGC and reverse, CTCCTCGATATGGCCGAAGG. C57BL/6J breeding pairs were used to generate the C57-Extended, Long Prenatal, Short Prenatal, and Rescue cohorts (Table 1). The C57Extended cohort served to replicate and extend the findings from the Celf6-Extended cohort. Mice were examined for ultrasonic vocalization (USV) production, developmental milestones, and reflexes, and subsets were used for further behavioral assessment.

\section{Maternal SSRI exposure}

In most countries, fluoxetine (FLX, Prozac) was the first SSRI to become available for clinical use (Hiemke and Härtter, 2000). Therefore, FLX is likely to be the mostrepresented antidepressant in the epidemiological studies of SSRI use during pregnancy. To mimic the 5-HT system in human mothers already taking an antidepressant before pregnancy, dams were exposed to FLX at least one week before mating. FLX crosses the placental barrier at a rate in mice comparable to that in humans (Noorlander et al., 2008). To avoid inducing unwanted maternal stress that can occur with daily injections, which has been shown to have adverse effects on the developing brain (Matrisciano et al., 2013), FLX was administered orally through drinking water sweetened with $1 \%$ saccharin to mask unpleasant drug taste. Control dams received $1 \%$ saccharin-only water (VEH). FLX capsules (20 mg each; Camber Pharmaceuticals, Inc) were dissolved into water containing $1 \%$ saccharin sodium salt hydrate (Millipore Sigma). The FLX dose used in this study was equivalent to the maximum recommended human dose (MRHD) of 80 $\mathrm{mg} / \mathrm{d}$ on a $\mathrm{mg} / \mathrm{m}^{2}$ basis (Marken and Munro, 2000). The dose calculations are based on equivalent surface area dosage conversion factors (Freireich et al., 1966) and approximate drinking water consumed daily (Bachmanov et al., 2002). Average drug water intake per day was recorded throughout the study to monitor drug exposure levels. The FLX water was prepared so that each mouse would consume $48 \mathrm{mg} / \mathrm{d}(16 \mathrm{mg} / \mathrm{kg} / \mathrm{d}$ based on a $30-\mathrm{g}$ mouse) or $6.5 \mathrm{ml} / \mathrm{d}$ of $0.074 \mathrm{mg} / \mathrm{ml} \mathrm{FLX} \mathrm{in} 1 \%$ saccharin water. Females of the same drug group were co-housed to reduce stress induced by isolation housing, and placed into the cage of a single-housed male for breeding. On detection of a vaginal plug following breeding, the females were removed from the male to isolate maternal drug exposure effects and avoid paternal drug exposure. Three drug exposure durations were used. Extended exposure continued until postnatal day $(P) 14$, the age just before pups begin to consume food and water, to avoid direct drug exposure in the pups. Long Prenatal exposure lasted until birth of the pups, and Short Prenatal exposure was stopped at embryonic day (E)16 (Fig. 1A).

\section{Adult SSRI re-exposure}

At P60, FLX or VEH was administered orally through drinking water sweetened with $1 \%$ saccharin. All parameters and dosing were as described above. Average drug water intake per day was recorded throughout the study to monitor drug exposure levels.

\section{HPLC}

Reverse-phase HPLC with fluorescence detection was used to separate and quantify FLX and its major active metabolite norfluoxetine (NFLX) in mouse brain tissue according to previously published methods (Unceta et al., 2010; Corbett et al., 2012). P9 mouse pups and adult dams exposed to extended FLX or VEH were deeply anesthetized via isoflurane, killed via rapid decapitation, and the brain extracted and flash frozen in $-70^{\circ}$ isopentane and stored at $-80^{\circ} \mathrm{C}$ until HPLC preparation.

\section{Reagents and materials}

Fluoxetine hydrochloride (FLX; lot \#SLBL4347V) and its primary active metabolite, norfluoxetine hydrochloride (NFLX), were purchased from Sigma-Aldrich. Sodium acetate buffer $(0.050 \mathrm{M})$ was prepared from sodium acetate (Fisher Scientific, Inc.) and glacial acetic acid (VWR brand). Borate buffer $(0.1 \mathrm{M})$ was prepared from boric acid, $\mathrm{H}_{3} \mathrm{BO}_{4}$ (Sigma) and sodium hydroxide (Fisher Scientific). Solvents were HPLC-grade acetonitrile (Pierce) and water purified using a Milli-Q system (Millipore Corporation). Stir bar sorptive extraction (SBSE) was performed using GERSTEL-Twister sorptive stir bars (GERSTEL Gmbh \& Co. KG) obtained from Agilent Technologies. The stir bars are $10-\mathrm{mm}$ long and are coated with a $0.5-\mathrm{mm}$ film thickness of polydimethylsiloxane (PDMS). Extractions were conducted in Fisherbrand $21 \times 70-\mathrm{mm}$ amber glass vials. Desorptions were performed in Varian $4.0-\mathrm{ml}$ clear glass vials with PTFE/sil septa containing Agilent $400-\mu l$ glass inserts.

\section{Sample preparation}

Approximately $100-\mathrm{mg}$ samples of brain tissue $( \pm 0.1$ $\mathrm{mg}$ ) were weighed. One milliliter of purified water was added to each sample before homogenization. Four control samples were spoked with FLX and NFLX to yield a final concentration of 120 and $150 \mathrm{ng}$ of FLX and NFLX, respectively.

\section{Instrumentation}

Chromatographic separations were conducted on a Varian ProStar HPLC system with Galaxie software, a Varian ProStar Model 410 autosampler, and a Hitachi Model L-2485 Elite LaChrom fluorescence detector. The fluorescence detector was set at $228 \mathrm{~nm}$ (excitation) and $284 \mathrm{~nm}$ (emission). Separations of $100-\mu$ l injections were achieved on a GRACE Platinum C18 reverse-phase column $(250 \times 4.6 \mathrm{~mm}, 5-\mu \mathrm{m}$ particle size). The mobile phase consisted on a 30:70 (v:v) of $0.050 \mathrm{M}$ sodium acetate buffer $(\mathrm{pH} 4.5)$ and acetonitrile delivered isocratically at a flow rate of $1.0 \mathrm{ml} / \mathrm{min}$. The retention times for NFL and FLX were 10.0-10.9 and 11.7-12.0 min, respectively.

\section{Method validation}

Individual stock solutions were prepared of $160 \mathrm{mg} / \mathrm{l}$ of FLX and $200 \mathrm{mg} / \mathrm{l}$ of NFLX in acetonitrile by weighing 1-2 
A

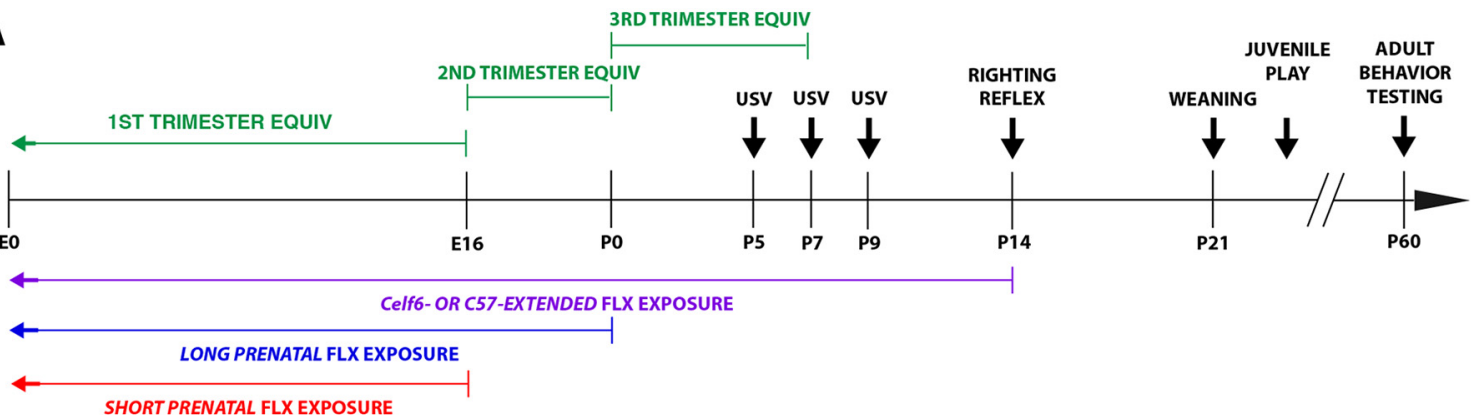

B

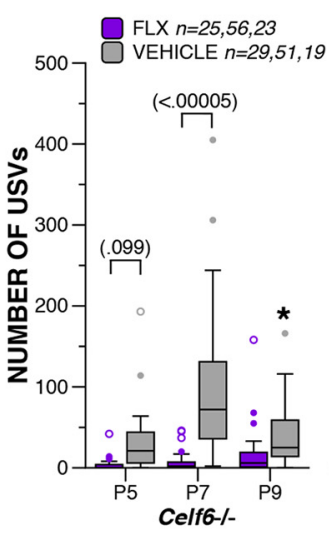

C
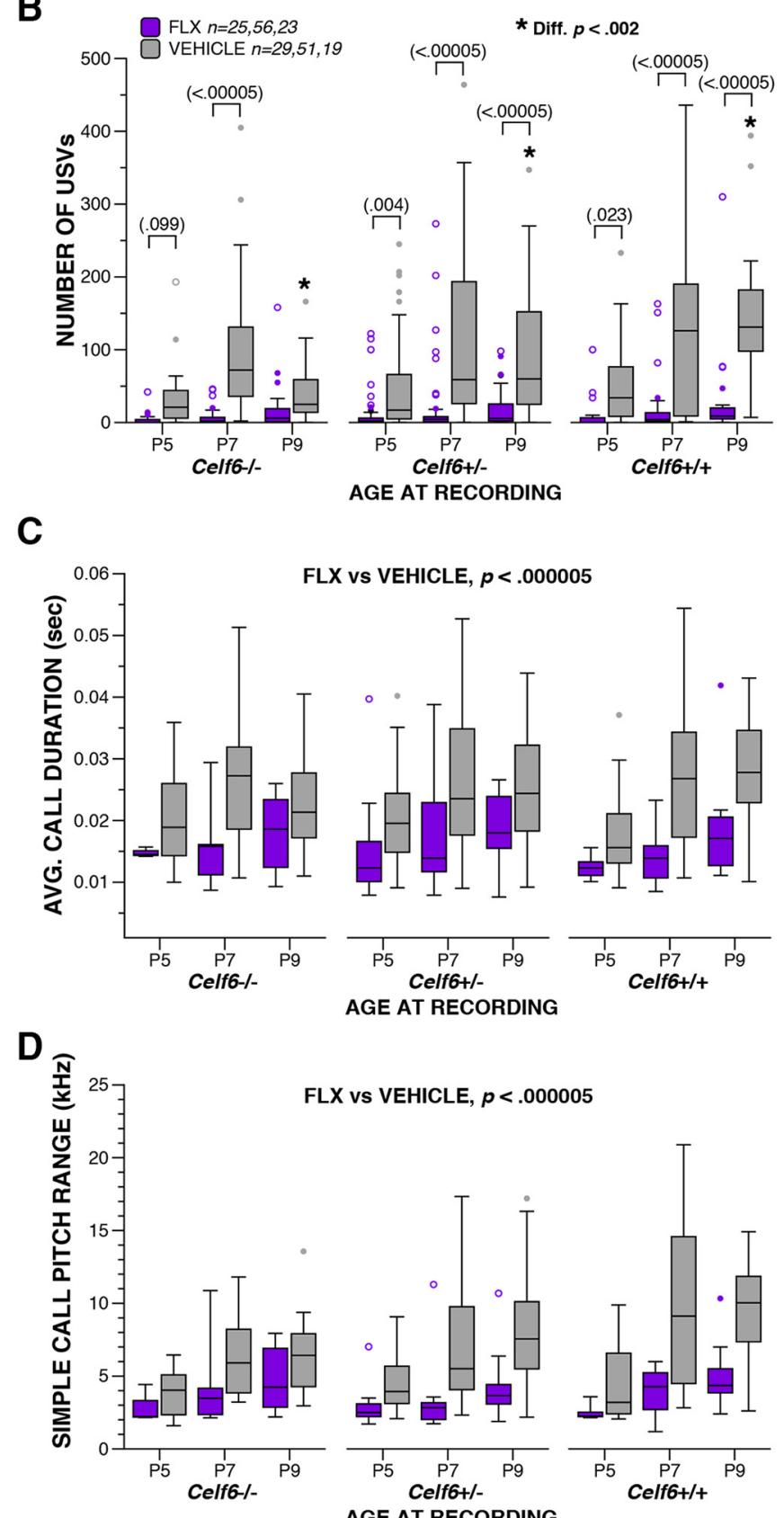

AGE AT RECORDING

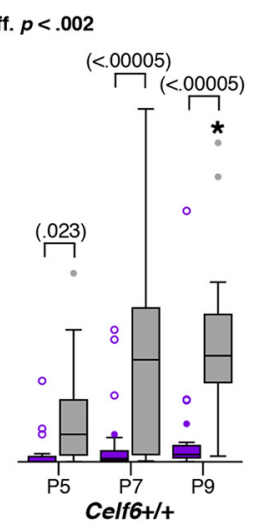

E

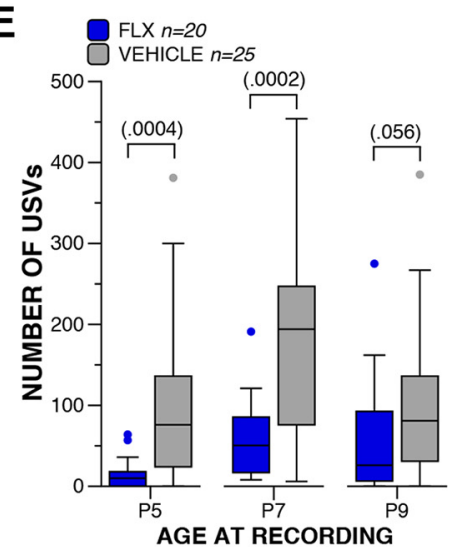

$F$

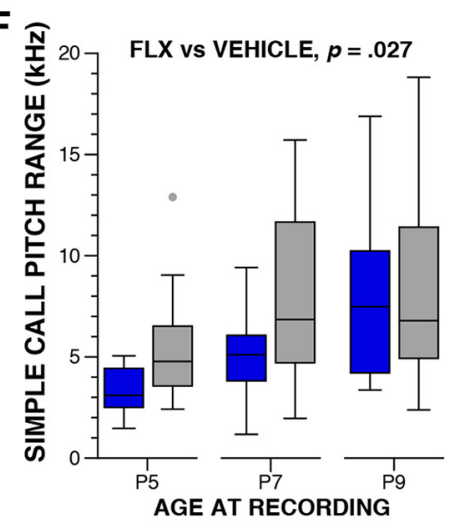

G

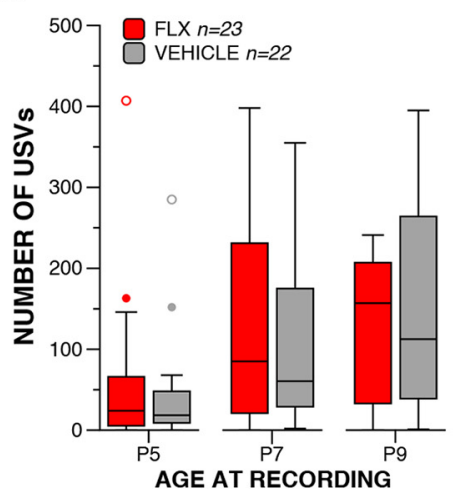

Figure 1. Maternal FLX throughout pregnancy alters early communicative behavior. $\boldsymbol{A}$, Schematic of the paradigm for maternal FLX exposure, with approximate equivalents in brain development to human pregnancy, and the mouse age for each behavioral test. $\boldsymbol{B}$, Boxplot of number of USVs at P5, P7, and P9 from Celf6-Extended FLX and VEH Celf6 mutant and WT littermates (drug, $p<$ 
continued

0.000005; age $\times$ drug $\times$ genotype interaction, $p=0.049$ ); $*$ denotes significant difference at $p<0.002$ between P9 VEH-exposed Celf6 mutant and WT littermates. $\boldsymbol{C}, \boldsymbol{D}$, Boxplots of number average USV duration $(\boldsymbol{C}$; drug, $p<0.000005)$ and pitch range of simple USV calls ( $\boldsymbol{D}$; drug, $p<0.000005)$ at P5, P7, and P9 from Celf6-Extended FLX and VEH Celf6 mutant and WT littermates. $\boldsymbol{E}$, Boxplot of number of USVs at P5, P7, and P9 from Long Prenatal FLX and VEH mice (drug, $p=0.0001$ ). $\boldsymbol{F}$, Boxplot of pitch range of simple USV calls from Long Prenatal FLX and VEH pups (drug, $p=0.027$ ). G, Boxplot of number of USVs at P5, P7, and P9 from Short Prenatal FLX and VEH mice (drug, $p=0.840$ ). For boxplots, thick horizontal lines signify respective group medians, boxes are 25th-75th percentiles, whiskers are $1.5 \times I Q R$, closed and open circles depict outliers.

$\mathrm{mg}$ of each solid standard to a $10.00 \mathrm{ml}$ and diluting with acetonitrile. The solutions were stored in the freezer at $-20^{\circ} \mathrm{C}$. A mixed stock solution of FLX and NFLX was prepared in acetonitrile by combining $5 \mathrm{~mL}$ of each individual stock solution in to a vial for a final concentration of 80 and $100 \mu \mathrm{g} / \mathrm{ml}$, respectively, and stored in the dark at $-20^{\circ} \mathrm{C}$. Calibration standard solutions were prepared in acetonitrile and ranged from 0.016 to $10 \mu \mathrm{g} / \mathrm{ml}$. Calibration curves were linear over the entire range of calibration with $R^{2}$ for FLX and NFLX ranging from 0.9998 to 0.9999 . The limit of detection for FLX was 16 parts-per-billion (ppb) and for NFLX was 20-ppb concentration in solution. When calculated as tissue concentration and corrected for recovery, the limits of detection were $164 \mathrm{ng} / \mathrm{g}$ for FLX and $320 \mathrm{ng} / \mathrm{g}$ for NFLX.

\section{SBSE of FLX and NFLX}

Before use, each Gerstel stir bar was washed with acetonitrile for $20 \mathrm{~min}$ in a $15-\mathrm{ml}$ vial with the magnetic stirrer set at $300 \mathrm{rpm}$ at $75^{\circ} \mathrm{C}$, rinsed with purified water, and patted dry with a lint-free tissue. One $\mathrm{mL}$ of $0.1 \mathrm{M}$ borate buffer was added to each brain tissue sample and a stir bar was added. Each sample was stirred at $300 \mathrm{rpm}$ at $75^{\circ} \mathrm{C}$ for $45 \mathrm{~min}$ and allowed to cool to room temperature. The stir bar was removed with a magnet on the outside of the extraction vial. The stir bar was rinsed with purified water and patted dry with a lint-free tissue. For desorption, the stir bar was placed into a 2-ml sample vial with a glass vial-insert into which $0.350-\mathrm{ml}$ acetonitrile had been added. Vials were capped and the analytes desorbed by magnetic agitation at $300 \mathrm{rpm}$ and at $75^{\circ} \mathrm{C}$ for $30 \mathrm{~min}$. Each vial was cooled slightly before opening to remove the stir bar with a magnet on the outside of the vial. The vial caps were replaced and the samples analyzed.

\section{Behavioral tasks}

Multiple behavioral assays across the same domain were employed to adequately determine presence of behavioral disruptions. Experimenters were blinded to experimental group designations during behavioral testing. Experimenters were all female, except during Celf6Extended developmental assessments in which one female and one male experimenter each collected data. No effect of experimenter sex was observed for those data. Order of and age at testing were chosen to minimize effects of stress and previous testing. Developmental reflexes and milestones assessment of the Celf6-Extended, Long Prenatal, and Short Prenatal cohorts occurred on P5-P14. Adult behavioral testing for all cohorts began at P60. Adult behavioral testing of the Celf6-Extended cohort included a battery of sensorimotor measures, fol- lowed by the social approach test, marble burying, spontaneous alternation T-maze, and the 1-h locomotor activity task. Mice in the C57-Extended cohort were assessed in the juvenile interaction task P22-P30, and adult behavioral testing included marble burying, spontaneous alternation T-maze, the tube test of social dominance, and the von Frey assessment of tactile sensitivity. Both the Long Prenatal and Short Prenatal cohorts were tested as adults in the social approach test, followed by spontaneous alternation T-maze, marble burying, and the tube test of social dominance. Following initiation of FLX or VEH re-exposure at $\mathrm{P} 60$, mice in the Rescue cohort were immediately tested for tactile sensitivity in the von Frey assessment, spontaneous alternation T-maze, tube test of social dominance, and the 1-h locomotor activity test to assess acute effects of re-exposure. After three weeks of re-exposure, all mice were retested in the same tasks to assess chronic effects of re-exposure on behavior. The Rescue cohort was not tested before re-exposure, such that no testing occurred during the pre-weaning period or juvenile development.

\section{Maternal isolation-induced USV recording}

USVs are considered a strongly conserved affective and communicative display that elicits maternal search and retrieval responses, nursing, and caretaking, and is used in the rodent literature to model early communicative deficits (Haack et al., 1983). Playback experiments demonstrated lactating dams respond rapidly with searching behavior to pup isolation calls. In addition, these dam behaviors are dependent on acoustic call features, such as duration and frequency, suggesting these features have communicative value (Wöhr et al., 2008). This behavior has a distinct developmental trajectory, allowing its use for the study of both early communication and neurobehavioral development in infant rodents (Branchi et al., 2001). USV production due to maternal isolation in the C57BL/6J mouse pup normally peaks just after P7, disappearing completely by P14 (Rieger and Dougherty, 2016).

For this study, USV recording occurred on P5, P7, and P9. Dams were removed from the home cage and placed into a clean standard mouse cage for the duration of testing. Pups in the home cage were placed into a warming box (Harvard Apparatus) for at least 10 min before the start of testing to control temperature. Skin surface temperature was recorded immediately before placement in the USV recording chamber via a noncontact HDE Infrared Thermometer to ensure consistent temperatures as lower body temperature of the pup is known to increase USV production (Branchi et al., 1998). Differences in temperature between FLX and VEH pups were not detected, 
indicating the differences in USV production were not secondary to thermoregulation differences. For recording, pups were individually removed from the home cage and placed into an empty standard mouse cage $(28.5 \times 17.5$ $\times 12 \mathrm{~cm}$ ) inside a sound-attenuating chamber (Med Associates). USVs were obtained using an Avisoft UltraSoundGate CM16 microphone, Avisoft UltraSoundGate $416 \mathrm{H}$ amplifier, and Avisoft Recorder software (gain $=2$ $\mathrm{dB}, 16$ bits, sampling rate $=250 \mathrm{kHz}$ ). Pups were recorded for $3 \mathrm{~min}$, after which they were weighed and returned to their home cages inside the warming box. Tissue from a toe was also collected at this time on P5 for genotyping. Frequency sonograms were prepared from recordings in MATLAB [frequency range $=25-120 \mathrm{kHz}$, FFT (Fast Fourier Transform) size $=512$, overlap $=50 \%$, time resolution $=1.024 \mathrm{~ms}$, frequency resolution $=488.2$ $\mathrm{Hz}$, and individual syllables and other spectral features were identified and counted from the sonograms according to a previously published method (Dougherty et al., 2013; Rieger and Dougherty, 2016; Maloney et al., 2018), adapted from validated procedures (Holy and Guo, 2005).

\section{Developmental reflexes and milestones assessment}

Mice were evaluated at several time points for achievement of physical and behavioral milestones of development. A visual check for the presence of detached pinnae was done at P5, and eye opening at P14. Weight was measured at P5, P7, P9, and P14, concurrent with USV recordings and righting reflex testing. To assess surface righting reflex at $\mathrm{P} 14$, each mouse was placed in a $50-\mathrm{ml}$ conical tube containing a lid with a hole. When the belly of the mouse was facing down, the conical tube was quickly turned $180^{\circ}$ in a smooth motion placing the mouse on its back. The time for the mouse to right itself with all four paws underneath its belly was recorded up to $60 \mathrm{~s}$. Each mouse received three trials, which were averaged for analysis.

\section{Juvenile social interaction}

Full-contact social behaviors were assessed through juvenile interactions using a procedure adapted from previously published methods (Peñagarikano et al., 2011). Mice were tested between P22-P30 and were paired with an age- and sex-matched C57BL/6J stimulus mouse derived from standard mouse breeding. All mice were weighed before testing. The procedure consisted of three consecutive 10-min trials. During trial 1 , the stimulus mouse was habituated to the testing chamber. For trial 2, the test animal was habituated to the chamber while the stimulus mouse was placed in a holding chamber lined with clean corn cob bedding. For the third trial, the stimulus mouse was placed back into the testing chamber with the test mouse and their interactions were recorded for $10 \mathrm{~min}$. The testing chamber was cleaned with $70 \%$ ethanol between test animals and the corn cob bedding was replaced. The test apparatus was a transparent enclosure $(25 \times 15 \times 12 \mathrm{~cm})$ containing a layer of clean corn cob bedding on the floor and surrounded by a clear acrylic enclosure measuring $28 \times 17.5 \times 37.5 \mathrm{~cm}$. A 4-cm diameter hole on the top of the enclosure allowed for placement of a digital video camera (Sony HDR-Cx560V
High Definition Handycam camcorder) to record scenes inside the apparatus. The apparatus was housed inside a custom built sound-attenuating chamber $(70.5 \times 50.5 \times$ $60 \mathrm{~cm}$ ), which was equipped with two LED infrared lights (Crazy Cart 48-LED CCTV infrared Night Vision Illuminator) to allow for capture of social behaviors in darkness.

Video files in MPG format were acquired in $360 \times 240$ or $544 \times 362$ pixel resolution with a frame rate of 25 or 30 frames per second. Videos were minimally post-processed to key only grayscale images, remove associated audio track, and convert to $\mathrm{AVI}$ containers before tracking. Simultaneous supervised tracking of both the stimulus and experimental animals was performed in MiceProfiler (de Chaumont et al., 2012) on the Icy platform, with scale value of 0.35 and pixel intensity threshold used to identify mice optimized for each video as necessary to ensure most accurate tracking. This software allows for experimenter supervision of tracking through manual intervention and frame-by-frame correction, and was validated previously by comparing results obtained with MiceProfiler to those obtained by human visual inspection. Social contact data were similar between supervised tracking with MiceProfiler and the experimenter-obtained values (de Chaumont et al., 2012). In the current application, manual corrections of tracking was performed as necessary through the course of each video. Two videos were excluded due to unexpected differences in zoom and resolution, and 11 other videos were excluded, because one mouse left the field of view for a portion of the ten minute testing time.

Tracked videos were then processed using a custom pipeline in MATLAB as follows. MiceProfiler data points for each frame and $<\mathrm{x}, \mathrm{y}\rangle$ positions of head, center of mass ("body"), and tail were parsed from the XML tracking data, pixel coordinates were converted to centimeters using the real world size of the testing apparatus, and frame number converted to time in seconds using the frame rate. Occasionally isolated frames contained missing data points occur where MiceProfiler does not record a value, and these were recorded as $\mathrm{NaN}$ (not-a-number) in MATLAB. Because of these occasional missing values, and jitter which occurs during tracking, data were smoothed using a 11-point moving average smooth, which resulted in more accurate tracking within MiceProfiler. After smoothing, positional values for head, body, and tail were used to estimate two-dimensional kinematics, using the first difference approximation for derivatives: velocity, acceleration, and jerk. Vectors defined by the head and tail positions were used to determine relative orientation of the two mice in the field of view, and final processed data contained the following variables by frame: distance traveled, length of body axis (head-to-tail) and direction (radians) with respect to the field of view (coordinate system $<0,0\rangle$ in lower left), the direction (radians) and magnitude of each 2D component of motion (velocity, acceleration, jerk) for each animal, and inter-animal parameters (angle between both animals and between their velocity vectors, all pairwise distances in $\mathrm{cm}$ between head, body, tail), from which total distance traveled and average speed $(\mathrm{cm} / \mathrm{s})$ were determined. Thresholds of $3.502 \mathrm{~cm}$ for headto-head distance and $3.125-$ or $3.145-\mathrm{cm}$ head-to-tail 
distance were used to define head sniffing and anogenital sniffing behaviors, respectively. These thresholds were determined through examination of the histogram of all head-to-head and head-to-tail distances across all videos and verified by manual inspection of video after applying threshold. After thresholding, bouts of behavior were scored as frames with distances below threshold, and bouts separated by 35 frames or less $(\leq 5.10$ or $\leq 0.17 \mathrm{~s})$ were merged. From these, fraction of total frames for each behavior, as well as number and average duration of bouts of behavior were determined. Measures of overall activity per mouse, such as distance traveled and average speed, were also extracted.

\section{Social approach}

The social approach task was used to quantify sociability and preference for social novelty, and as previously described (Moy et al., 2004; Dougherty et al., 2013). Sociability was defined here as a tendency to pursue social contact. Preference for social novelty was defined as pursuing social contact with a novel conspecific as compared to a conspecific from a previous interaction. The social approach testing apparatus was a rectangular clear acrylic box divided into three separate chambers each measuring $19.5 \times 39 \times 22 \mathrm{~cm}$ including clear acrylic dividing walls with rectangular openings measuring $5 \times 8$ $\mathrm{cm}$ to allow for movement between chambers, which could be shut off by sliding down clear acrylic doors. This clear acrylic apparatus was housed inside a custom built sound-attenuating chamber $(70.5 \times 50.5 \times 60 \mathrm{~cm})$, lit with LED Flex Ribbon Lights (Commercial Electric, Home Depot) to provide $\sim 20$ lux illumination in the chamber. A small stainless steel conspecific cage (Galaxy Pencil/Utility Cup, Spectrum Diversified Designs, Inc), measuring 10 $\mathrm{cm}$ in height and $10 \mathrm{~cm}$ in diameter at its base, was placed in each outer chamber, and had vertical bars that allowed minimal contact while preventing fighting. A CCTV camera (SuperCircuits) connected to a PC computer running the software program ANY-maze (Stoelting Co.; RRID: SCR_014289) tracked the movement of the mouse within the apparatus (Dougherty et al., 2013; Miranda et al., 2015) and time spent in each investigation zone surrounding the conspecific cages. The investigation zones encompassed an area of $2 \mathrm{~cm}$ around the conspecific cages. Only the head was tracked in the investigation zone to quantify intention to investigate the conspecific. Total distance traveled was also ascertained as an index of general activity levels. The entire apparatus was cleaned between animals with a $2 \%$ chlorohexidine diacetate solution (Nolvasan, Zoetis). The conspecific cages were cleaned with $70 \%$ ethanol solution between each mouse.

The social approach task consisted of four, consecutive 10-min trials. For the first trial, the mouse was placed in the middle chamber with the doors to the outer chambers shut and allowed $10 \mathrm{~min}$ to habituate to the apparatus. During the second trial (habituation trial), the mouse was allowed to freely investigate and habituate to all three chambers for 10 min. Performance of the mouse during the third trial (sociability trial) allowed for the evaluation of sociability to an unfamiliar, sex-matched conspecific
(C57BL/6J) placed in one conspecific cage versus an empty conspecific cage. Again, the mouse was allowed to move freely within the apparatus for $10 \mathrm{~min}$. During the fourth trial (preference for social novelty trial), the now familiar conspecific remained in the apparatus, and a new, unfamiliar sex-matched conspecific (C57BL/6J) was placed in the other conspecific cage. The mouse was allowed to move freely within the apparatus for $10 \mathrm{~min}$, and the mouse's preference for social novelty was quantified. Placement of conspecifics was counterbalanced.

\section{Tube test of social dominance}

Under laboratory conditions, mice begin to develop social hierarchy behaviors at six weeks of age, which result in dominance ranks within their social groups (Hayashi, 1993). The tube test of social dominance allows for examination of social dominance rank between two pairs of mice after eight weeks of age and was adapted from previously described methods (Wang et al., 2011). The apparatus consisted of a clear acrylic tube measuring $3.6 \mathrm{~cm}$ in diameter and $30 \mathrm{~cm}$ in length. This task spanned 5 consecutive days. On days 1 and 2, each mouse was exposed to the test apparatus to habituate the animals to the testing tube and to walking through the testing tube to the other side. This was conducted from each side of the tube. On days $3-5$, dominance bouts were conducted with sex-matched pairs of FLX and VEH mice, avoiding cage mate pairings. A new pair was used for each bout such that each mouse was paired with three distinct partners, and side of entry was alternated. On each day, male bouts were conducted first, followed by female bouts. For each bout, a small acrylic divider was placed in the center of the tube, prohibiting the animals from crossing the center, and each mouse was allowed to enter the tube from one end. Once the animals met in the center, the divider was lifted and the bout lasted 2 min or until one animal was backed out of the tube by the other (all four paws exiting the tube). The animal remaining in the tube was the winner of the bout (dominant) and the animal that was backed out was the loser of the bout (subordinate). The bouts were recorded with a USB camera connected to a PC laptop (Lenovo) and subsequently scored by an observer. The percentage of bouts won was calculated for each mouse, and compared between groups. The acrylic tube was cleaned with a $2 \%$ chlorohexidine diacetate solution (Nolvasan, Zoetis) between each bout.

\section{Marble burying task}

Marble burying behavior in mice serves as a proxy for repetitive and perseverative digging behavior (AngoaPérez et al., 2013), and our procedure was adapted from these previously described methods. The apparatus was a transparent enclosure $(47.6 \times 25.4 \times 20.6 \mathrm{~cm})$ housed within a sound-attenuating chamber $(70.5 \times 50.5 \times 60$ $\mathrm{cm}$ ), lit with LED Flex Ribbon Lights (Commercial Electric, Home Depot) to provide 20 lux illumination. Each enclosure was filled with $3 \mathrm{~cm}$ of clean, autoclaved corncob bedding. Using a template, 20 clear marbles were placed in five rows of four. For testing, the mouse was placed in the center of the enclosure, and allowed to freely explore for $30 \mathrm{~min}$. The animal was then removed and two inde- 
pendent observers scored buried marbles. A marble was considered buried when at last $2 / 3$ of it was covered by bedding. The average score between the two observers was used for analysis. The correlation between observers' scores for all marble burying experiments in this study was $r>.92, p=0.000$. In between animals, new fresh, autoclaved bedding was used and all marbles were cleaned thoroughly with $70 \%$ ethanol.

\section{Spontaneous alternation T-maze}

The spontaneous alternation T-maze was used to assess perseverative exploratory behavior and was adapted from previously published methods (Peñagarikano et al., 2011). Testing was conducted under dim overhead lighting. The apparatus was made of opaque acrylic and comprises a $20 \times 8.7 \mathrm{~cm}$ start chamber with two radiating arms, each measuring $25 \times 8.7 \mathrm{~cm}$. Removable doors were used to sequester the animal in the start box, or either maze arm. Testing consisted of 10 consecutive trials, each lasted 2 min or until the animal made an arm choice. For each the first trial, the animal was placed in the start box with the door closed for 2 min to habituate to the apparatus. The door was then removed and the animal allowed to explore either the right or left arm of the maze. An arm choice was determined when the animal entered the arm with all four paws. Then the door to that arm was closed, and the animal allowed to explore it for 5 $\mathrm{s}$. The door was again lifted and the animal was allowed to return to the start box and the door shut. If the animal did not quickly move back to the start area, it was gently guided by placement of a hand or object behind the animal, yet avoiding picking the animal up by the tail and moving back to the start chamber as this can result in a negative association with that arm and impact the spontaneous alternation. After $5 \mathrm{~s}$, the start box door was again lifted to start the next trial. If no arm choice was made after $2 \mathrm{~min}$, the animal was gently guided back to the start box. After 10 consecutive trials, the animal was returned to its home cage and the apparatus cleaned thoroughly with a $2 \%$ chlorohexidine diacetate solution (Nolvasan, Zoetis). Each of the two trials was scored as an alternation, a non-alternation or no choice trial. The number of non-alternations and percentage of trials alternating were compared between groups.

\section{Tactile sensitivity assessment with von Frey filaments}

The tactile sensitivity task assessed reflexive, mechanical sensitivity to a punctate stimulus (von Frey filaments), and was conducted as previously described (Mickle et al., 2015). The testing apparatus consisted of a metal grid surface elevated $63.5 \mathrm{~cm}$, which allowed access to the plantar surface of the animals' paws. On top set individual acrylic boxes $(10 \times 10 \times 10 \mathrm{~cm})$ open on the bottom and opaque on three sides to prevent visual cues between animals. All mice were acclimated to the testing room 30 min before habituation and testing. On days 1 and 2, all mice were habituated to the testing apparatus for $1 \mathrm{~h}$. On day 3 , mice were allowed to acclimate to the testing apparatus for 30 min before start of testing. Eight different von Frey hair filaments (applying 0.04-2 g of force; North Coast Medical and Rehabilitation Products) were applied to the plantar surface of each animal's hind paw and withdrawal responses were recorded. Presentations started with the lowest filament strength $(0.04 \mathrm{~g})$ and increased to the maximum filament strength $(2 \mathrm{~g})$. Each filament was applied to the plantar surface of each hind paw five times, and the number of paw withdrawal responses was recorded as percentage of responses. To evaluate the changes in paw withdrawal responses to the whole range of filaments over the testing duration, the area under the curve (AUC) was calculated for each animal.

\section{One-hour locomotor activity}

A 1-h locomotor activity/exploration test was conducted to assess the general activity, exploratory behavior, and emotionality of the mice. This test also served as a control test to identify any differences in general activity that may interfere with the interpretation of cognitive, social, and/or emotionality tests. The mice were evaluated over a 1-h period in transparent enclosures $(47.6 \times 25.4$ $\times 20.6 \mathrm{~cm})$. A digital video camera connected to a PC computer running ANY-maze (Stoelting Co.; RRID: SCR_014289) tracked the movement of the animal (Palanisamy et al., 2011; Dougherty et al., 2013) within a $33 \times$ $11-\mathrm{cm}$ central zone and a bordering $5.5-\mathrm{cm}$ peripheral zone. General activity variables (distance traveled and time at rest) along with measures of emotionality, including "time spent," "distance traveled," and "entries made into the central zone," as well as "distance traveled in the peripheral zone" were analyzed. Each enclosure was cleaned with $70 \%$ ethanol solution between each mouse.

\section{Sensorimotor battery}

Balance, strength, and coordination were evaluated by a battery of sensorimotor measures. The battery included walking initiation, ledge, platform, pole, and inclined and inverted screen tests. An observer manually recorded time in hundredths of a second using a stopwatch for each test. Two trials were conducted for each test and the average of the two yielded a single time, which was used in the analyses. To avoid exhaustion effects, the order of the tests during the first set of trials was reversed for the second set of trials. The order of the tests was not counterbalanced between animals so that every animal experienced each test under the same conditions. All tests lasted a maximum of $60 \mathrm{~s}$, except for the pole test, which lasted a maximum of $120 \mathrm{~s}$. The tests are described below.

The walking initiation test assessed the time taken by a mouse to move out of a small area. The mouse was placed on a flat surface inside a square measuring $21 \times$ $21 \mathrm{~cm}$, marked on the surface of a supply cart with white tape. The time for the mouse to leave the square was recorded, i.e., all four limbs concurrently outside of the square. Basic balance ability was assessed by the performance on the ledge and platform tests. The ledge test required the mouse to balance on a clear acrylic ledge, measuring $0.50 \mathrm{~cm}$ wide and standing $37.5 \mathrm{~cm}$ high. Time the mouse remained on the ledge was recorded. During the platform test, the mouse used basic balance ability to remain on a wooden platform measuring $1.0 \mathrm{~cm}$ thick and 
$3.3 \mathrm{~cm}$ in diameter and elevated $27 \mathrm{~cm}$ above the floor. The time the mouse was able to balance on the platform was recorded. The pole test was used to evaluate fine motor coordination. The mouse was placed head upward on a vertical pole with a finely textured surface and the time taken by the mouse to turn downward $180^{\circ}$ and climb to the bottom of the pole was recorded. The $60^{\circ}$, $90^{\circ}$, and inverted screen tests assessed a combination of coordination and strength. The mouse was placed head oriented downward in the middle of a mesh wire grid measuring 16 squares per $10 \mathrm{~cm}$, elevated $47 \mathrm{~cm}$ and inclined to $60^{\circ}$ or $90^{\circ}$. The time required by the mouse to turn upward $180^{\circ}$ and climb to the top of the screen was recorded. For the inverted screen test, the mouse was placed head oriented downward in the middle of a mesh wire grid measuring 16 squares per $10 \mathrm{~cm}$, elevated 47 $\mathrm{cm}$, and, when it was determined the mouse has a proper grip on the screen, it was inverted to $180^{\circ}$. The time the mouse was able to hold on to the screen without falling off was recorded.

\section{Experimental design and statistical analysis}

All statistical analyses were performed using the IBM SPSS Statistics software (v.24; RRID: SCR_002865) except where otherwise stated. Sample sizes, including litter numbers, for each cohort can be found in Table 1. Before analyses, all data were screened for missing values, fit between distributions and the assumptions of univariate analysis, and homogeneity of variance. ANOVA, including repeated measures (rmANOVA) and mixed model, was used to analyze the behavioral data where appropriate, with main factors of sex and drug exposure. As litter size can influence behavior, and our samples included littermates, we also conducted accompanying analyses of covariance (ANCOVAs) with litter size as the covariate, and report any discrepancies between the results. Linear mixed modeling was used to analyze datasets containing missing values, including spectral or temporal USV features which cannot be assessed if $<10 \mathrm{USV}$ s/session are produced. For non-normal distributions, equivalent nonparametric tests were used when available. The HuynhFeldt adjustment was used to protect against violations of sphericity/compound symmetry assumptions where appropriate. Multiple pairwise comparisons were subjected to Bonferroni correction when appropriate; $\chi^{2}$ goodness of fit test was used to assess categorical variables. Tukey's HSD or the Games-Howell method were used as post hoc tests. Probability value for all analyses was $p<$ 0.05 except where otherwise stated. Test statistics and other analysis details for each experiment are provided in Tables 2, 4-6, including observed power and effect sizes (Cohen, 1988).

\section{Results}

\section{Development of SSRI maternal exposure models}

To determine the potential of maternal SSRI exposure to induce behavioral disruptions in offspring reminiscent of ASD symptomatology, we exposed mouse dams to FLX during gestation and lactation and examined offspring behaviors during development, the juvenile stage, and adulthood (Fig. 1A; Table 1). We included both C57BL/6J line and the Celf6 mutant line to examine the influence of FLX exposure alone or in combination with a genetically vulnerable background. We also examined different pre- and postnatal durations of FLX to establish periods of vulnerability. Epidemiological studies are inconsistent regarding the trimesters of pregnancy most vulnerable to SSRI-induced ASD risk. To address this, we used three FLX durations, corresponding to periods of brain development approximating the trimesters of human pregnancy. Our designation of "Extended FLX" corresponded to the entire duration of the pregnancy and a recommended period of nursing (one year) in humans (E0-P14; Dobbing and Sands, 1979; Levitt, 2003). Both Celf6 and C57BL/6J mice were exposed for this duration (Celf6-Extended and C57-Extended). "Long Prenatal" (E0-P0) exposure approximated the first and second trimesters of human pregnancy. "Short Prenatal" (E0-E16) approximated the first trimester of human pregnancy (Fig. $1 A)$. Only C57BL/6J mice were used for prenatal-only exposures. Overall, our experimental design enabled analysis of both gene $\times$ environment interaction and exposure duration effects on behaviors relevant to the symptoms of ASD.

\section{Maternal FLX disrupts early communicative behavior in pup offspring}

We examined developmental behavior, physical milestones and reflexes in our FLX mice. Quantification of USV production and features served to assess neurodevelopmental progress as well as to examine early affective and communicative behavior known to influence maternal care behavior (Haack et al., 1983). At P5, P7, and P9, we observed robust decreases in USVs when FLX lasted through pregnancy. No influence of sex was observed for developmental analyses, therefore all data reported below are collapsed for sex. Output from statistical tests is fully reported in Table 2. Specifically, Celf6-Extended exposure to FLX reduced USVs independent of Celf6 genotype $\left(p<0.000005^{\mathrm{a}}\right.$; Fig. $\left.1 B\right)$, yet an interaction with genotype was also observed $\left(p=0.049^{b}\right)$. Celf6 mutation reduced USVs in VEH-exposed pups $\left(p<0.000005^{\mathrm{cb}}\right)$, replicating previous work (Dougherty et al., 2013). Further post hoc tests revealed FLX-induced USV reduction at each age across all mice $\left(p<0.024^{\mathrm{d}}\right)$, except for P5 and P9 Celf6 ${ }^{-1-}$ mice when USVs were already low due to mutation. Robust reductions in the duration time of calls $p<$ $0.000005^{\mathrm{e}}$; Fig. $1 C$ ) and the pitch range of simple calls pups $\left(p<0.000005^{f}\right.$; Fig. $1 D$ ) were observed in FLX. Celf6 mutation did not influence spectral or temporal features of USVs alone or through an interaction with extended FLX.

Since the impact of FLX alone was so strong, and independent of Celf6 mutation in the Celf6-Extended cohort, we examined the impact of prenatal-only exposure to FLX on USV in C57BL/6J mice. Long Prenatal exposure to FLX also reduced USVs $\left(p=0.0001^{\text {g; }}\right.$ Fig. $\left.1 E\right)$. This FLX-induced reduction occurred at P5 and P7 $(p<$ $\left.0.0005^{\mathrm{h}}\right)$, with a trend at P9 $(p=0.056 \mathrm{f})$. Examination of spectral and temporal features showed Long Prenatal exposure only altered the pitch range of simple calls $(p=$ 
Table 2. Statistical summary for Figures 1, 2

\begin{tabular}{|c|c|c|c|c|c|c|c|c|}
\hline \multirow{18}{*}{$\begin{array}{l}\text { Variable } \\
\text { Number of USVs }\end{array}$} & & Comparison & Data structure & Statistical test & Output & $p$ value & Post hoc power & Effect size \\
\hline & a & Celf6-Extended, drug (FLX vs vehicle) & Non-normal & Two-way rmANOVA & $F_{(1,197)}=80.854$ & $p<0.000005$ & 1 & 0.641 \\
\hline & $\mathrm{b}$ & Celf6-Extended, age $\times$ drug $\times$ genotype interaction & Non-normal & Two-way rmANOVA & $F_{(3.66,360.87)}=2.478$ & $p=0.049$ & 0.667 & 0.160 \\
\hline & c & Vehicle at P9 Celf6 $6^{+/+}$vs Celf6 ${ }^{+/-}$vs Celf6 ${ }^{-/-}$ & Non-normal & Simple main effect & $F_{(2,591)}=15.454$ & $p<0.000005$ & 0.967 & 0.422 \\
\hline & d & Celf6 ${ }^{+/+}$at P5 FLX vs vehicle & Non-normal & Simple main effect & $F_{(1,591)}=5.214$ & $p=0.023$ & 0.625 & 0.095 \\
\hline & d & Celf6 ${ }^{+/+}$at P7 FLX vs vehicle & Non-normal & Simple main effect & $F_{(1,591)}=24.168$ & $p<0.000005$ & 0.998 & 0.201 \\
\hline & d & Celf6 ${ }^{+/+}$at P9 FLX vs vehicle & Non-normal & Simple main effect & $F_{(1,591)}=32.669$ & $p<0.000005$ & 1 & 0.234 \\
\hline & d & Celf6 ${ }^{+/-}$at P5 FLX vs vehicle & Non-normal & Simple main effect & $F_{(1,591)}=8.307$ & $p=0.004$ & 0.821 & 0.119 \\
\hline & d & Celf $^{+/-}$at P7 FLX vs vehicle & Non-normal & Simple main effect & $F_{(1,591)}=53.427$ & $p<0.000005$ & 1 & 0.301 \\
\hline & $d$ & Celf6 $^{+/-}$at P9 FLX vs vehicle & Non-normal & Simple main effect & $F_{(1,591)}=35.638$ & $p<0.000005$ & 1 & 0.246 \\
\hline & d & Celf6 $^{-/-}$at P5 FLX vs vehicle & Non-normal & Simple main effect & $F_{(1,591)}=2.724$ & $p=0.099$ & 0.378 & 0.071 \\
\hline & d & Celf6 $^{-/-}$at P7 FLX vs vehicle & Non-normal & Simple main effect & $F_{(1,591)}=24.936$ & $p<0.000005$ & 0.999 & 0.204 \\
\hline & d & Celf6 $^{-/-}$at P9 FLX vs vehicle & Non-normal & Simple main effect & $F_{(1,591)}=1.380$ & $p=0.241$ & 0.217 & 0.045 \\
\hline & $\mathrm{g}$ & Long Prenatal, drug (FLX vs vehicle) & Non-normal & One-way rmANOVA & $F_{(1,43)}=18.013$ & $p=0.0001$ & 0.986 & 0.647 \\
\hline & $\mathrm{h}$ & P5 FLX vs vehicle & Non-normal & Simple main effect & $F_{(1,43)}=14.689$ & $p=0.0004$ & 0.963 & 0.585 \\
\hline & $\mathrm{h}$ & P7 FLX vs vehicle & Non-normal & Simple main effect & $F_{(1,43)}=16.678$ & $p=0.0002$ & 0.979 & 0.622 \\
\hline & $\mathrm{i}$ & P9 FLX vs vehicle & Non-normal & Simple main effect & $F_{(1,43)}=3.874$ & $p=0.056$ & 0.486 & 0.301 \\
\hline & $\mathrm{k}$ & Short Prenatal, drug (FLX vs vehicle) & Non-normal & One-way rmANOVA & $F_{(1,43)}=0.041$ & $p=0.840$ & 0.052 & $<0.000$ \\
\hline Average duration & e & Celf6-Extended, drug (FLX vs vehicle) & Normal & Linear mixed model & $F_{(1,211.820)}=31.223$ & $p<0.000005$ & {$[0.005,0.010]$} & \\
\hline \multirow{2}{*}{$\begin{array}{l}\text { Simple call pitch } \\
\text { range }\end{array}$} & $f$ & Celf6-Extended, drug (FLX vs vehicle) & Normal & Linear mixed model & $F_{(1,170.380)}=38.155$ & $p<0.000005$ & \multicolumn{2}{|c|}{$[1895.15,3675.32]$} \\
\hline & j & Long Prenatal, drug (FLX vs vehicle) & Normal & Linear mixed model & $F_{(1,44.068)}=5.256$ & $p=0.027$ & \multicolumn{2}{|l|}{$[251.10,3901.71]$} \\
\hline \multirow[t]{29}{*}{ Weight } & $\mathrm{k}$ & Celf6-Extended, age (P5 vs P7 vs P9 vs $\mathrm{P} 14$ ) & Normal & Two-way rmANOVA & $F_{(1.46,286.7)}=2670.61$ & $p<0.000005$ & 1 & 3.673 \\
\hline & $\mathrm{m}$ & Celf6-Extended, drug (FLX vs vehicle) & Normal & Two-way rmANOVA & $F_{(1,197)}=56.921$ & $p<0.000005$ & 1 & 0.537 \\
\hline & $\mathrm{n}$ & Celf6 $^{+/+}$at P5 FLX vs vehicle & Normal & Simple main effect & $F_{(1,788)}=8.087$ & $p=0.005$ & 0.811 & 0.101 \\
\hline & $\mathrm{n}$ & Celf6 $^{+/+}$at P7 FLX vs vehicle & Normal & Simple main effect & $F_{(1,788)}=8.008$ & $p=0.005$ & 0.807 & 0.101 \\
\hline & $\mathrm{n}$ & Celf6 $^{+/+}$at P9 FLX vs vehicle & Normal & Simple main effect & $F_{(1,788)}=13.699$ & $p=0.0003$ & 0.959 & 0.132 \\
\hline & $n$ & Celf6 $^{+/+}$at P14 FLX vs vehicle & Normal & Simple main effect & $F_{(1,788)}=34.952$ & $p<0.000005$ & 1 & 0.209 \\
\hline & $\mathrm{n}$ & Celf6 $^{+/-}$at P5 FLX vs vehicle & Normal & Simple main effect & $F_{(1,788)}=14.860$ & $p=0.0001$ & 0.971 & 0.139 \\
\hline & $n$ & Celf6 ${ }^{+/-}$at P7 FLX vs vehicle & Normal & Simple main effect & $F_{(1,788)}=18.036$ & $p=0.00002$ & 0.989 & 0.150 \\
\hline & $\mathrm{n}$ & Celf6 $^{+/-}$at P9 FLX vs vehicle & Normal & Simple main effect & $F_{(1,788)}=21.454$ & $p<0.000005$ & 0.996 & 0.167 \\
\hline & $n$ & Celf6 $^{+/-}$at P14 FLX vs vehicle & Normal & Simple main effect & $F_{(1,788)}=42.427$ & $p<0.000005$ & 1 & 0.232 \\
\hline & $\mathrm{n}$ & $\mathrm{Celf6}^{-/-}$at P5 FLX vs vehicle & Normal & Simple main effect & $F_{(1,788)}=7.462$ & $p=0.006$ & 0.779 & 0.095 \\
\hline & $\mathrm{n}$ & Celf6 $^{-/-}$at P7 FLX vs vehicle & Normal & Simple main effect & $F_{(1,788)}=8.869$ & $p=0.003$ & 0.845 & 0.105 \\
\hline & $\mathrm{n}$ & Celf6 ${ }^{-/-}$at P9 FLX vs vehicle & Normal & Simple main effect & $F_{(1,788)}=12.822$ & $p=0.0004$ & 0.947 & 0.128 \\
\hline & $\mathrm{n}$ & Celf6 $^{-/-}$at P14 FLX vs vehicle & Normal & Simple main effect & $F_{(1,788)}=18.815$ & $p=0.00002$ & 0.991 & 0.153 \\
\hline & q & Celf6-Extended, litter (FLX vs vehicle) & Non-normal & Mann-Whitney $U$ & $U_{(203)}=4723.5$ & $p=0.301$ & $\mathrm{~N} / \mathrm{A}$ & 0.01 \\
\hline & $\mathrm{k}$ & Long Prenatal, age (P5 vs $\mathrm{P} 7$ vs $\mathrm{P} 9$ vs $\mathrm{P} 14$ ) & Normal & Two-way rmANOVA & $F_{(2.26,97.31)}=1231.23$ & $p<0.000005$ & 1 & 5.330 \\
\hline & $\mathrm{m}$ & Long Prenatal, drug (FLX vs vehicle) & Normal & Two-way rmANOVA & $F_{(1,43)}=20.887$ & $p=0.00004$ & 0.994 & 0.697 \\
\hline & $\mathrm{n}$ & P5 FLX vs vehicle & Normal & Simple main effect & $F_{(1,172)}=4.163$ & $p=0.043$ & 0.528 & 0.157 \\
\hline & $\mathrm{n}$ & P7 FLX vs vehicle & Normal & Simple main effect & $F_{(1,172)}=12.029$ & $p=0.0007$ & 0.932 & 0.264 \\
\hline & $\mathrm{n}$ & P9 FLX vs vehicle & Normal & Simple main effect & $F_{(1,172)}=27.769$ & $p<0.000005$ & 0.999 & 0.402 \\
\hline & $\mathrm{n}$ & P14 FLX vs vehicle & Normal & Simple main effect & $F_{(1,172)}=31.829$ & $p<0.000005$ & 1 & 0.430 \\
\hline & q & Long Prenatal, litter (FLX vs vehicle) & Non-normal & Mann-Whitney $U$ & $U_{(45)}=228$ & $p=0.595$ & N/A & 0.01 \\
\hline & $\mathrm{k}$ & Short Prenatal, age (P5 vs P7 vs P9 vs P14) & Normal & Two-way rmANOVA & $F_{(1.64,70.58)}=892.959$ & $p<0.000005$ & 0.954 & 4.554 \\
\hline & o & Short Prenatal, drug (FLX vs vehicle) & Normal & Two-way rmANOVA & $F_{(1,43)}=25.719$ & $p=0.000008$ & 0.999 & 0.773 \\
\hline & $\mathrm{p}$ & P5 FLX vs vehicle & Normal & Simple main effect & $F_{(1,172)}=5.273$ & $p=0.023$ & 0.627 & 0.176 \\
\hline & $\mathrm{p}$ & P7 FLX vs vehicle & Normal & Simple main effect & $F_{(1,172)}=13.753$ & $p=0.0003$ & 0.958 & 0.283 \\
\hline & $\mathrm{p}$ & P9 FLX vs vehicle & Normal & Simple main effect & $F_{(1,172)}=19.138$ & $p=0.00002$ & 0.992 & 0.333 \\
\hline & $p$ & P14 FLX vs vehicle & Normal & Simple main effect & $F_{(1,172)}=49.019$ & $p<0.000005$ & 1 & 0.534 \\
\hline & $r$ & Short Prenatal, litter (FLX vs vehicle) & Non-normal & Mann-Whitney $U$ test & $U_{(45)}=84.5$ & $p=0.00003$ & N/A & 0.35 \\
\hline \multirow{3}{*}{$\begin{array}{l}\text { Latency to righting } \\
\text { reflex }\end{array}$} & s & Celf6-Extended, drug (FLX vs vehicle) & Non-normal & Two-way ANOVA & $F_{(1,191)}=13.753$ & $p=0.004$ & 0.827 & 0.212 \\
\hline & $\mathrm{t}$ & Long Prenatal, drug (FLX vs vehicle) & Non-normal & Mann-Whitney $U$ & $U_{(45)}=223.0$ & $p=0.545$ & $\mathrm{~N} / \mathrm{A}$ & 0.01 \\
\hline & u & Short Prenatal, drug (FLX vs vehicle) & Non-normal & Mann-Whitney $U$ & $U_{(45)}=187.5$ & $p=0.140$ & $\mathrm{~N} / \mathrm{A}$ & 0.05 \\
\hline
\end{tabular}

Effect size for $F$ tests reported as Cohen's $f$ (Cohen, 1988; interpretation: $0.01=$ small; $0.25=$ medium; $0.40=$ large) and for nonparametric tests reported as $\eta^{2} .95 \%$ confidence intervals reported for linear mixed models.

0.027j; Fig. 1F). Short Prenatal exposure to FLX did not influence pup USV production ( $p=0.840^{\mathrm{k}}$; Fig. $1 G$ ). Taken together, these findings suggest FLX, when continued through pregnancy, induced early communicative deficits in mice in the form of USV reductions, yet FLX limited to early pregnancy did not influence production rate. Further, the effect of FLX on USVs was so robust that we did not have the ability to observe additional interaction with Celf6 mutation.

\section{Developmental assessment of physical milestones and reflexes}

USV suppression may be a consequence of perturbation of specific CNS circuits due to FLX exposure. However, an alternative explanation is that USV is suppressed by a FLX-induced gross developmental delay. To explore this possibility, we examined other developmental traits of
FLX pups. As a measure of general health, we compared the weight of FLX and VEH mice on P5, P7, P9, and P14. Mice in all cohorts increased in weight across developmental time points, as expected $(p<0.000005$; Fig. $2 A-C$ ), yet the duration of FLX exposure influenced weight. All Celf6-Extended and Long Prenatal FLX mice weighed less than VEH pups $\left(p<0.00005^{\mathrm{m}}\right.$; Fig. $\left.2 A, B\right)$ regardless of genotype at each age examined $(p<$ $\left.0.044^{\mathrm{n}}\right)$. Interestingly, Short Prenatal FLX resulted in increased weight compared to VEH ( $p=0.000008^{\circ}$; Fig. $\left.2 C\right)$ at all ages examined $\left(p<0.023^{\mathrm{p}}\right)$. However, these weight differences are less likely a result of the E0-E16 FLX exposure and more likely an indirect result due to decreased litter size in this cohort. Analysis of litter sizes across treatment groups in each cohort revealed no effect of litter size for the Celf6-Extended and Long Prenatal groups ( $p=0.3^{q}$ and $p=0.582^{q}$, respectively; Table 2 ), 

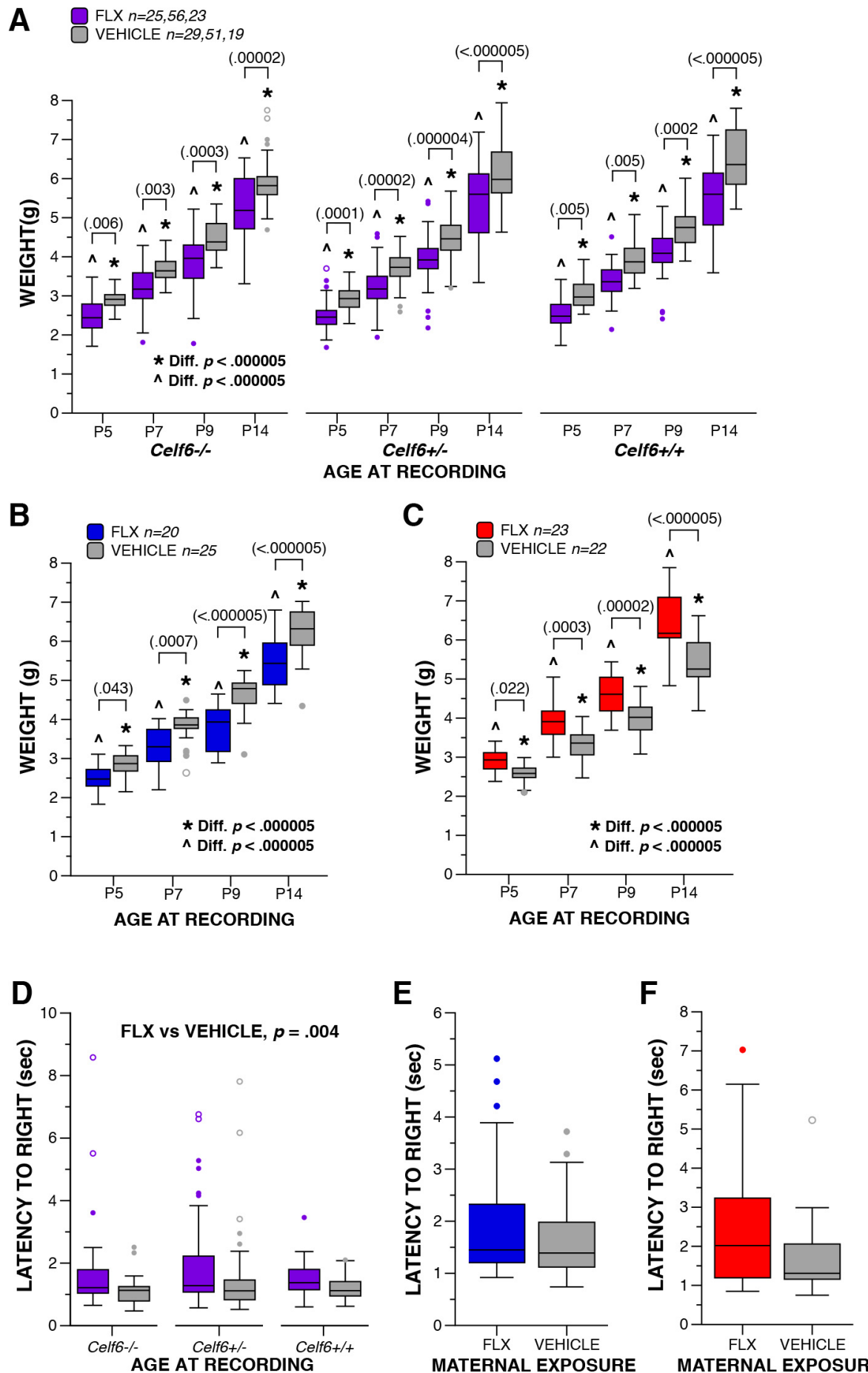

\section{MATERNAL EXPOSURE MATERNAL EXPOSURE}

Figure 2. Maternal FLX exposure decreases weight reduction and alters righting reflex pups. $\boldsymbol{A}-\boldsymbol{C}$, Boxplot of weight at $\mathrm{P} 5$, $\mathrm{P} 7, \mathrm{P} 9$, and P14 of Celf6-Extended ( $\boldsymbol{A}$; drug, $p<0.000005)$, Long Prenatal $(\boldsymbol{B} ;$ drug, $p=0.00004)$, and Short Prenatal $(\boldsymbol{C} ;$ drug, $p=0.000008)$ FLX and VEH pups. All mice gained weight with age. $\boldsymbol{D}-\boldsymbol{F}$, Boxplot of the latency to exhibit a righting reflex at P14 by Celf6-Extended $(\boldsymbol{E}$; drug, $p=0.004)$, Long Prenatal $(\boldsymbol{F}$; drug, $p=0.545)$, and Short Prenatal (G; drug, $p=0.140)$ FLX and VEH pups; $*$ denotes significant difference across ages at $p<0.000005$ within $\mathrm{VEH}$-exposed mice; $\wedge$ denotes significant difference across ages at $p<$ 0.000005 within FLX-exposed mice. For boxplots, thick horizontal lines signify respective group medians, boxes are 25th-75th percentiles, whiskers are $1.5 \times \mathrm{IQR}$, closed and open circles depict outliers.

indicating the weight differences are due to the FLX treatment, and replicating previous findings (Svirsky et al., 2016). However, a significant difference in litter sizes between the FLX- and VEH-exposed Short Prenatal groups was observed $\left(p=0.000006^{r}\right.$; FLX, $M=5.65, S D=1.15$; $\mathrm{VEH}, M=7.55, S D=1.30$ ), indicating the increase in weight in the FLX mice is likely a result of their smaller average litter sizes. The addition of litter size as a covari- 
Table 3. Brain levels of FLX and NFLX $(\mu \mathrm{g} / \mathrm{g})$ from extended exposure dams and $\mathrm{P9}$ pups

\begin{tabular}{lllll}
\hline & FLX & & NFLX & \\
& $M$ & SD & M & SD \\
Dam FLX & 4534.5 & 1540.8 & 6122.5 & 2003.6 \\
Dam VEH & LLOD & LLOD & $<$ LOD & $<$ LOD \\
Pup FLX & 1962.3 & 3398.9 & 1957.0 & 943.8 \\
Pup VEH & KLOD & LLOD & $<$ LOD & $<$ LOD
\end{tabular}

Limit of detection (LOD) was $164 \mathrm{ng} / \mathrm{g}$ for FLX and $320 \mathrm{ng} / \mathrm{g}$ for NFLX.

ate in the model did not change the overall results of weight analyses for the three cohorts. However, the influence of drug on weights only at P5 for the Long and Short Prenatal animals was found to be marginally significant $(p=0.059)$ and non-significant $(p=0.304)$ in the ANCOVA model. Further assessment of developmental milestones revealed that FLX exposure had no effect on the timing of pinna detachment (by P5) or eye opening (by P14; data not shown). To assess early gross locomotor abilities and to evaluate general body strength, we examined righting reflex at P14. When collapsed across genotypes, FLX pups in the Celf6-Extended cohort exhibited a longer latency to right compared to VEH pups $\left(p=0.004^{\text {s; }}\right.$; Fig. 2D). No difference in latency to right was observed in the Long Prenatal cohort ( $p=0.537^{\text {t; }}$ Fig. $2 E$ ), or in the Short Prenatal cohort ( $p=0.137^{\mathrm{u}}$; Fig. $\left.2 F\right)$. The developmental data show age-appropriate physical milestones were achieved, indicating FLX did not induce robust developmental delay; however, developmental reflexes were minimally influenced by FLX and weight was affected across development suggesting FLX exposure did induce some developmental perturbation in pups. Thus, the reduction in USVs cannot be completely decoupled from FLX influence on developmental progression.

To confirm the presence of FLX and its active metabolite NFLX in the pup brains, we examined levels of these compounds in whole brain tissue of P9 pup receiving Extended drug exposure, as well as in the whole brain tissue from dams to compare pups levels to that of direct drug exposure.

Given the half-life of FLX $\left(\sim 6 \mathrm{~h}^{1}\right)$ and its active metabolite NFLX $\left(\sim 15 \mathrm{~h}^{2}\right)$ in vivo, both should be well cleared by the time the juvenile and adult offspring were analyzed. However, we shared the reviewers interest in whether the early postnatal time points might be influenced by ongoing FLX/NFLX in the brain.

To confirm the drug was reaching the developing brain, HPLC was used to measure levels of FLX and its active metabolite NFLX in whole brains of pups exposed to extended maternal FLX exposure. We found FLX and NFLX were both present in the P9 pup brain during maternal FLX exposure, and neither present in the VEHexposed control brains (Table 3). The levels of FLX and NFLX in the pups were $\sim 43 \%$ and $32 \%$, respectively, of that measured in an equal amount of dam brain tissue. These data indicate that FLX and NFLX are active in the offspring brain during maternal exposure, suggesting the 5 -HT system is targeted at this time. Given the half-life of FLX $(\sim 6 \mathrm{~h})$ and its active metabolite NFLX $(\sim 15 \mathrm{~h})$ in vivo, both should be well-cleared by juvenile and adult ages (Holladay et al., 1998; Marken and Munro, 2000). Thus while the alterations in USV behavior might be impacted by the acute levels of FLX and NFLX, the later behavioral alterations must reflect long-term consequences of transient exposure.

\section{Maternal FLX disrupts adult social behaviors}

Deficits in social communication and social interaction are varied among autistic individuals, and include failure to initiate or respond to social interaction, abnormal social approach, and difficulties adjusting behavior to suit various social contexts (American Psychiatric Association, 2013). Therefore, we tested our mice in multiple social behavior assays, each designed to assess a distinct aspect of social behavior. The full-contact juvenile interaction assay was used to assess social interaction behaviors in FLX mice, and in adulthood, we examined social approach behaviors and possible disruptions to behaviors in the specific context of social dominance hierarchies.

Maternal FLX exposure disrupted social approach and specific social hierarchy behaviors in adulthood, but not juvenile social interactions. Significant interactions between sex and drug exposure were not observed, therefore results are reported collapsed across sex. Output from statistical tests is fully reported in Table 4. During the social approach habituation trial, no side bias was observed for any cohort (Fig. 3A-C). In the Celf6-Extended exposure group, when collapsed for genotype, VEH mice spent more time compared to FLX mice investigating both stimuli overall $\left(p=0.020^{v}\right.$; Fig. $\left.3 D\right)$, and more time investigating the social stimulus $\left(p=0.028^{\mathrm{w}}\right)$. Yet, the expected preference for social stimulus was observed for all FLX and VEH Celf6 mutant and WT mice $\left(p<0.022^{\times}\right)$. As Celf6 mutation did not potentiate the impact of FLX on sociability behavior, we continued our examination of social approach behaviors without manipulation of Celf6 genotype for the Long and Short Prenatal cohorts. Long Prenatal exposure resulted in disruptions to sociability $\left(p=0.0004^{y}\right)$. FLX mice failed to display a preference for the social stimulus $\left(p=0.645^{z}\right.$; VEH, $p<0.000005^{\text {aa; }}$ Fig. $3 E$ ), and spent significantly less time investigating the social stimulus compared to VEH mice $\left(p=0.0001^{\mathrm{bb}}\right)$. Short Prenatal exposure did not disrupt sociability $(p=$ $0.962^{\mathrm{CC}}$ ): both FLX and VEH spent more time investigating the social stimulus than the empty cup (FLX, $p=0.001^{\text {dd. }}$ $\mathrm{VEH}, p=0.001^{\mathrm{ee}}$; Fig. $3 F$ ), and a similar time was spent investigating the social stimulus by both groups $(p=$ $\left.0.726^{f f}\right)$. Finally, during the preference for social novelty trial, again the Celf6-Extended cohort VEH mice showed a strong trend for investigating the objects more overall compared to FLX mice $\left(p=0.065^{\mathrm{gg}}\right)$, when collapsed for genotype. For all cohorts, more time was spent investigating the novel mouse compared to the familiar mouse in all cohorts $\left(p<0.045^{\text {hh }}\right.$; Fig. 3G-l). Comparable activity levels were detected for all groups in this task (Fig. 3J-L), ruling out hypoactivity as a confound. Taken together, these data indicate maternal FLX influenced sociability only when continued throughout pregnancy. We did not demonstrate a strong impact of FLX exposure limited to early pregnancy or extended into postnatal development on adult sociability in our mice. 
Table 4. Statistical summary for Figures 3, 4

\begin{tabular}{|c|c|c|c|c|c|c|c|c|}
\hline Variable & & Comparison & $\begin{array}{c}\text { Data } \\
\text { structure }\end{array}$ & $\begin{array}{c}\text { Statistical } \\
\text { test }\end{array}$ & Output & $p$ value & $\begin{array}{c}\text { Post hoc } \\
\text { power }\end{array}$ & $\begin{array}{c}\text { Effect } \\
\text { size }\end{array}$ \\
\hline \multirow{16}{*}{$\begin{array}{l}\text { Sociability } \\
\text { investigation } \\
\text { time }\end{array}$} & $\mathrm{v}$ & Celf6-Extended, drug (FLX vs vehicle) & Normal & Two-way rmANOVA & $F_{(1,111)}=5.608$ & $p=0.020$ & 0.651 & 0.225 \\
\hline & $x$ & Celf6 $^{++}$FLX social vs empty stimulus & Normal & Simple main effect & $F_{(1,111)}=6.983$ & $p=0.009$ & 0.745 & 0.250 \\
\hline & $x$ & Celf6 $^{+/-}$FLX social vs empty stimulus & Normal & Simple main effect & $F_{(1,111)}=5.440$ & $p=0.021$ & 0.638 & 0.222 \\
\hline & $\mathrm{x}$ & Celf6 $^{-/-}$FLX social vs empty stimulus & Normal & Simple main effect & $F_{(1,111)}=7.821$ & $p=0.006$ & 0.792 & 0.266 \\
\hline & $x$ & Celf6 $^{++}$vehicle social vs empty stimulus & Normal & Simple main effect & $F_{(1,111)}=5.998$ & $p=0.016$ & 0.680 & 0.232 \\
\hline & $\mathrm{x}$ & Celf6 $^{+/-}$vehicle social vs empty stimulus & Normal & Simple main effect & $F_{(1,111)}=8.852$ & $p=0.004$ & 0.839 & 0.283 \\
\hline & $x$ & Celf6 $^{-/-}$vehicle social vs empty stimulus & Normal & Simple main effect & $F_{(1,111)}=15.898$ & $p=0.0001$ & 0.977 & 0.378 \\
\hline & w & Social stimulus FLX vs vehicle & Normal & Simple main effect & $F_{(1,222)}=4.895$ & $p=0.028$ & 0.596 & 0.150 \\
\hline & y & Long Prenatal, stimulus $\times$ drug interaction & Normal & One-way rmANOVA & $F_{(1,40)}=14.627$ & $p=0.0004$ & 0.962 & 0.605 \\
\hline & z & FLX social vs empty stimulus & Normal & Simple main effect & $F_{(1,40)}=0.216$ & $p=0.645$ & 0.074 & 0.071 \\
\hline & aa & Vehicle social vs empty stimulus & Normal & Simple main effect & $F_{(1,40)}=28.149$ & $p<0.000005$ & 0.999 & 0.83 \\
\hline & $\mathrm{bb}$ & Social stimulus FLX vs vehicle & Normal & Simple main effect & $F_{(1,80)}=16.659$ & $p=0.0001$ & 0.981 & 0.45 \\
\hline & $\mathrm{cc}$ & Short Prenatal, stimulus $\times$ drug interaction & Normal & One-way rmANOVA & $F_{(1,42)}=0.002$ & $p=0.962$ & 0.050 & 0.007 \\
\hline & dd & FLX social vs empty stimulus & Normal & Simple main effect & $F_{(1,42)}=12.337$ & $p=0.001$ & 0.929 & 0.03 \\
\hline & ee & Vehicle social vs empty stimulus & Normal & Simple main effect & $F_{(1,42)}=11.715$ & $p=0.001$ & 0.917 & 0.03 \\
\hline & $\mathrm{ff}$ & Social stimulus FLX vs vehicle & Normal & Simple main effect & $F_{(1,84)}=0.124$ & $p=0.726$ & 0.064 & 0.03 \\
\hline \multirow{13}{*}{$\begin{array}{l}\text { Social novelty } \\
\text { investigation } \\
\text { time }\end{array}$} & $g g$ & Celf6-Extended, drug (FLX vs vehicle) & Normal & Two-way rmANOVA & $F_{(1,111)}=3.468$ & $p=0.065$ & 0.455 & 0.176 \\
\hline & $\mathrm{hh}$ & Celf6 $^{++}$FLX Fam vs novel stimulus & Normal & Simple main effect & $F_{(1,111)}=8.845$ & $p=0.004$ & 0.838 & 0.28 \\
\hline & $\mathrm{hh}$ & Celf6 $^{+/-}$FLX Fam vs novel stimulus & Normal & Simple main effect & $F_{(1,111)}=7.618$ & $p=0.007$ & 0.781 & 0.26 \\
\hline & $\mathrm{hh}$ & Celf6 $^{-/-}$FLX Fam vs novel stimulus & Normal & Simple main effect & $F_{(1,111)}=11.659$ & $p=0.0009$ & 0.923 & 0.32 \\
\hline & $\mathrm{hh}$ & Celf6 $^{++}$vehicle Fam vs novel stimulus & Normal & Simple main effect & $F_{(1,111)}=5.812$ & $p=0.018$ & 0.666 & 0.22 \\
\hline & $\mathrm{hh}$ & Celf6 $^{+/-}$vehicle Fam vs novel stimulus & Normal & Simple main effect & $F_{(1,111)}=9.616$ & $p=0.002$ & 0.867 & 0.29 \\
\hline & $\mathrm{hh}$ & Celf6 $^{-/-}$vehicle Fam vs novel stimulus & Normal & Simple main effect & $F_{(1,111)}=18.954$ & $p=0.00003$ & 0.991 & 0.41 \\
\hline & $\mathrm{hh}$ & Long Prenatal, stimulus (Fam vs novel cup) & Non-normal & One-way rmANOVA & $F_{(1,40)}=46.742$ & $p<0.000005$ & 1 & 1.08 \\
\hline & $\mathrm{hh}$ & FLX Fam vs novel stimulus & Non-normal & Simple main effect & $F_{(1,40)}=11.365$ & $p=0.002$ & 0.908 & 0.533 \\
\hline & $\mathrm{hh}$ & Vehicle Fam vs novel stimulus & Non-normal & Simple main effect & $F_{(1,40)}=42.911$ & $p<0.000005$ & 1 & 1.037 \\
\hline & $\mathrm{hh}$ & Short Prenatal, stimulus (Fam vs novel cup) & Non-normal & One-way rmANOVA & $F_{(1,40)}=13.815$ & $p=0.001$ & 0.952 & 0.588 \\
\hline & hh & FLX Fam vs novel stimulus & Non-normal & Simple main effect & $F_{(1,40)}=10.119$ & $p=0.003$ & 0.874 & 0.503 \\
\hline & $\mathrm{hh}$ & Vehicle Fam vs novel stimulus & normal & Simple main effect & $F_{(1,40)}=4.307$ & $p=0.044$ & 0.526 & 0.328 \\
\hline \multirow{6}{*}{$\begin{array}{l}\text { Percent tube } \\
\text { test bouts } \\
\text { won }\end{array}$} & ii & C57-Extended FLX, compared to $50 \%$ & Non-normal & One-spl Wilcoxon & $Z=2.418$ & $p=0.016$ & N/A & 0.24 \\
\hline & jj & C57-Extended vehicle, compared to $50 \%$ & Non-normal & One-spl Wilcoxon & $Z=-2.398$ & $p=0.016$ & N/A & 0.24 \\
\hline & $\mathrm{kk}$ & Long Prenatal FLX, compared to $50 \%$ & Non-normal & One-spl Wilcoxon & $Z=-2.356$ & $p=0.018$ & N/A & 0.69 \\
\hline & kk & Long Prenatal vehicle, compared to $50 \%$ & Non-normal & One-spl Wilcoxon & $Z=1.873$ & $p=0.061$ & N/A & 0.44 \\
\hline & ॥ & Short Prenatal FLX, compared to $50 \%$ & Non-normal & One-spl Wilcoxon & $Z=-1.907$ & $p=0.057$ & N/A & 0.20 \\
\hline & $\|$ & Short Prenatal vehicle, compared to $50 \%$ & Non-normal & One-spl Wilcoxon & $Z=1.691$ & $p=0.091$ & $\mathrm{~N} / \mathrm{A}$ & 0.16 \\
\hline \multirow[t]{3}{*}{ Adult weight } & $\mathrm{mm}$ & C57-Extended, drug (FLX vs vehicle) & Normal & Two-way ANOVA & $F_{(1,12)}=0.475$ & $p=0.504$ & 0.097 & 0.199 \\
\hline & $\mathrm{nn}$ & Long Prenatal, drug (FLX vs vehicle) & Normal & Two-way ANOVA & $F_{(1,40)}=8.096$ & $p=0.007$ & 0.793 & 0.44 \\
\hline & ০० & Short Prenatal, drug (FLX vs vehicle) & Normal & Two-way ANOVA & $F_{(1,40)}=1.796$ & $p=0.188$ & 0.258 & 0.212 \\
\hline
\end{tabular}

Effect sample size for $F$ tests reported as Cohen's $f$ (Cohen, 1988; interpretation: $0.01=$ small; $0.25=$ medium; $0.40=$ large) and for nonparametric tests reported as $\eta^{2}$.

As Celf6 genotype did not influence sociability in the social approach task, we chose to examine full-contact social behaviors in C57BL/6J juveniles in a separate C57Extended cohort. We did not observe abnormal social interactions in these mice in the juvenile interaction assay. Specifically, FLX and VEH mice exhibited a comparable number and duration of anogenital and head-to-head sniffing, and sniffing behaviors directed toward FLX and VEH mice by the stimulus partners were also similar (data not shown). Unlike the social approach task, we did not observe altered social behaviors in the juvenile interaction assay. However, in social approach only the FLX mouse has control over timing and duration of interactions, while in juvenile interaction, deficits in social behaviors with FLX treatment could be masked because interactions were also initiated by the unexposed stimulus mouse.

Finally, we examined social hierarchy behaviors in our mice to determine whether maternal FLX exposure influences behavior in this specific social context. Groups of mice display social hierarchies with dominant and submissive group members (Hayashi, 1993), and we assessed this using the tube test for social dominance. For this task, sex-matched mice from different experimental groups are directly compared. Due to the complexity of experimental groups in the Celf6-Extended cohort, we only examined tube test behavior between FLX and VEH mice in the C57-Extended cohort. We observed an interesting influence of FLX duration on dominance. C57Extended FLX resulted in increased dominant behavior (Fig. $4 A$, FLX wins greater than by chance, $p=0.016^{\mathrm{ii}}$; VEH wins fewer than by chance, $\left.p=0.016^{\mathrm{ij}}\right)$. In contrast, both maternal FLX cohorts restricted to prenatal development induced submissive behaviors in adulthood: Long Prenatal FLX resulted in fewer wins relative to chance $(p=$ $0.018^{\mathrm{kk}}$; Fig. 4B). Short Prenatal exposure influenced dominance behavior less strongly, resulting in fewer bouts won than expected by chance by FLX-exposed mice, which did not reach statistical significance ( $p=0.057^{\prime \prime}$; Fig. $4 C$ ). These alterations in dominance were not due to differences in animal size between drug exposure groups as adult weights did not correspond to increased dominance in a simple way. Specifically, at available power we did not detect differences in adult weight in C57-Extended FLX mice $\left(p=0.504^{\mathrm{mm}}\right.$; Fig. $\left.4 D\right)$. Long Prenatal FLX resulted in a decrease in weight compared to VEH, that was independent of $\operatorname{sex}\left(p=0.007^{\mathrm{nn}}\right.$; Fig. $\left.4 E\right)$ and dominance performance. We also did not detect a weight difference among mice of the Short Prenatal cohort $\left(p=0.188^{\circ \circ}\right.$; Fig. $\left.4 F\right)$. Taken together, these data suggest perinatal FLX exposure via the mother influences social behaviors during adulthood, long 
A

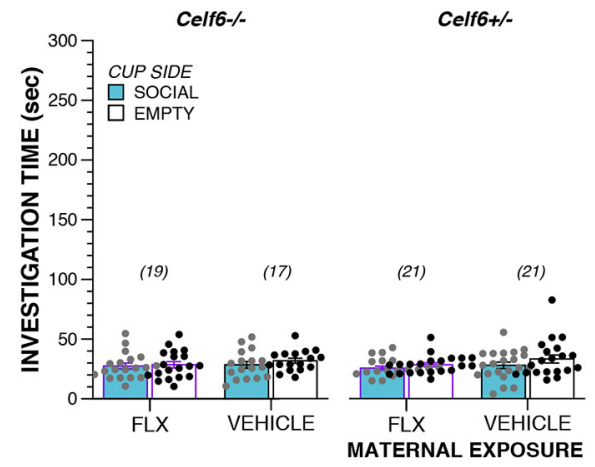

HABITUATION

B

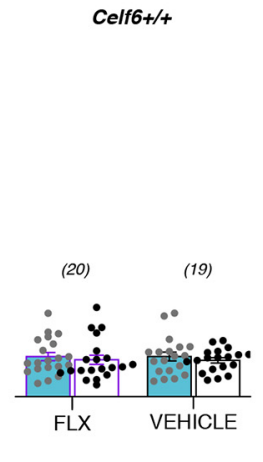

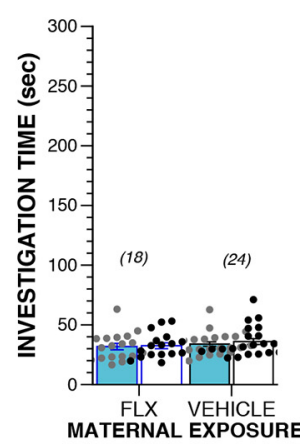

MATERNAL EXPOSURE
C

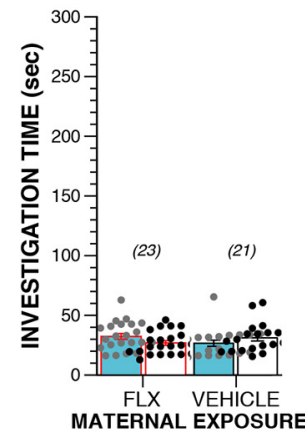

D

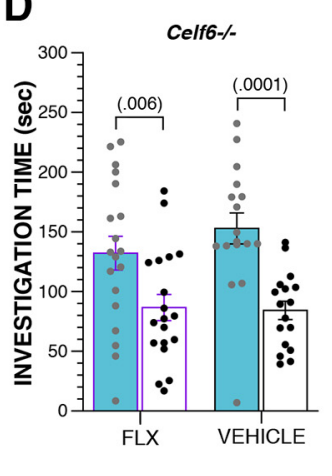

SOCIABILITY

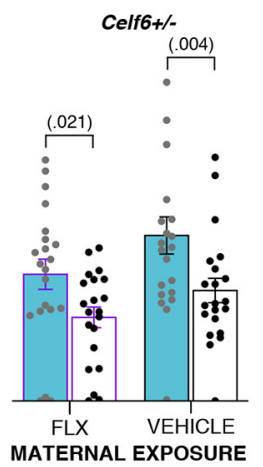

$E$

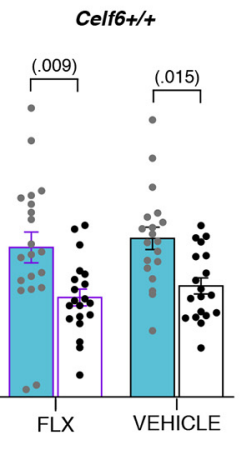

300

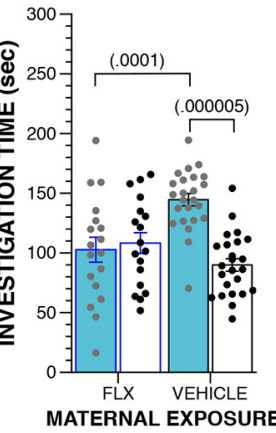

$\mathbf{F}$

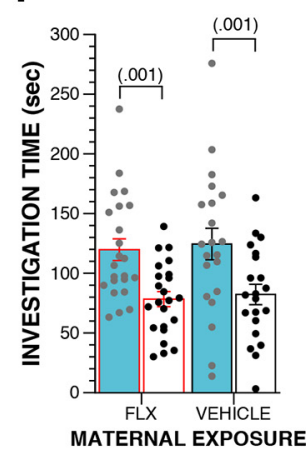

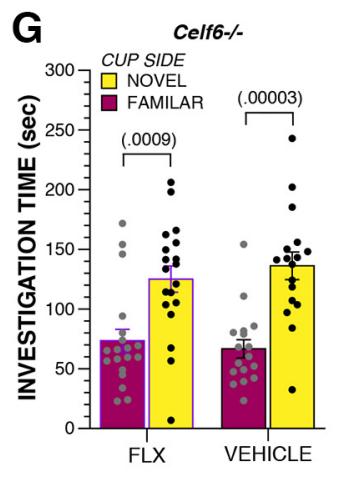
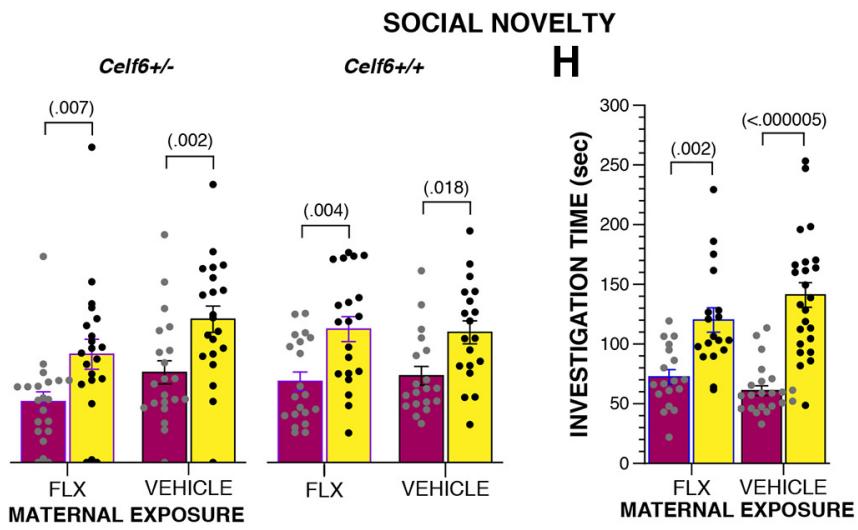

I

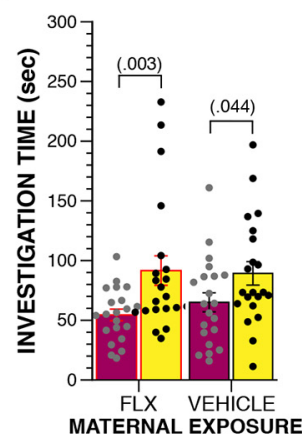

ACTIVITY LEVELS
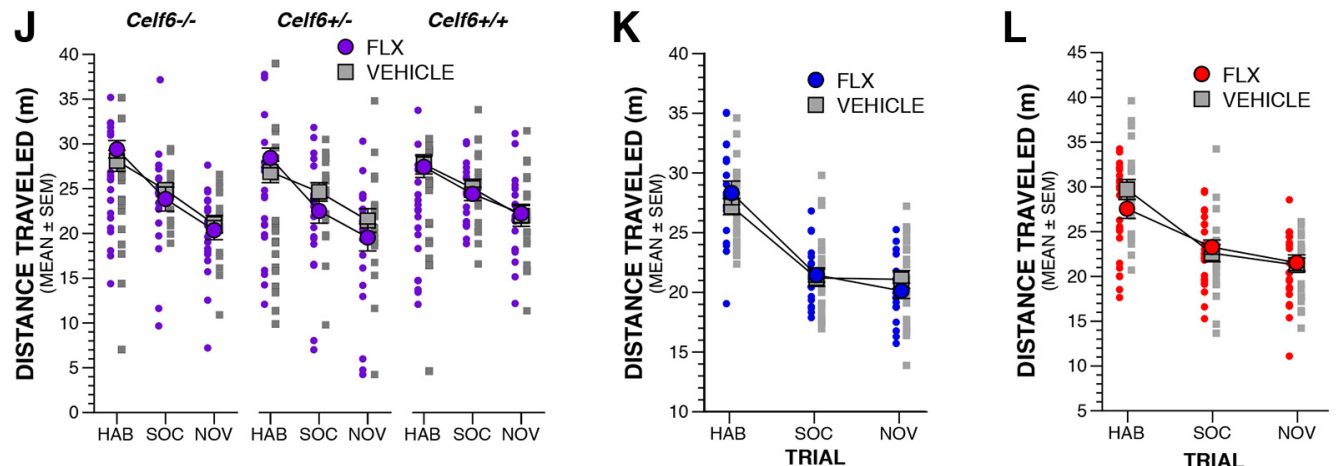

Figure 3. Adult sociability is disrupted by maternal FLX exposure only during pregnancy. $\boldsymbol{A}-\boldsymbol{C}$, Time spent investigating social and empty cup zones during the social approach habituation trial by Celf6-Extended (A), Long Prenatal (B), and Short Prenatal (C) FLX 
continued

and VEH mice. $\boldsymbol{D}-\boldsymbol{F}$, Time spent investigating social and empty cups during the sociability trial of the social approach test by Celf6-Extended $(\boldsymbol{D}$; drug, $p=0.020)$, Long Prenatal $(\boldsymbol{E}$; stimulus $\times$ drug, $p=0.0004)$, and Short Prenatal $(\boldsymbol{F}$; stimulus $\times$ drug, $p=0.962)$ FLX and VEH mice. $\mathbf{G}-\boldsymbol{I}$, Boxplots of time spent investigating cups containing novel or familiar conspecifics during the preference for social novelty trial of the social approach test Celf6-Extended (G; stimulus, $p<0.000005)$, Long Prenatal $(\boldsymbol{H}$; stimulus, $p<0.000005)$, and Short Prenatal $(\boldsymbol{l}$; stimulus, $p=0.001)$ FLX and VEH mice. $\boldsymbol{J}-\boldsymbol{L}$, Distance traveled during the social approach task by Celf6-Extended $(\boldsymbol{J})$, Long Prenatal $(\boldsymbol{K})$, and Short Prenatal $(\boldsymbol{L})$ FLX and VEH mice. Data are mean \pm SEM, with individual data points represented as filled circles/squares (A-I: social/familiar zone, gray; empty/novel zone, black; J-L: FLX, purple/blue/red; WT, gray).

after drug exposure occurred, with specific disruptions to sociability and behavior in the specific context of dominance. Further, prenatal versus postnatal exposure may differentially influence behavioral circuits underlying dominance behaviors.

\section{Extended maternal FLX induces repetitive, restricted patterns of behavior}

Similar to our analysis of social behaviors, we assessed a range of rodent tasks relevant to repetitive and restricted patterns of behavior to fully characterize the in-
A

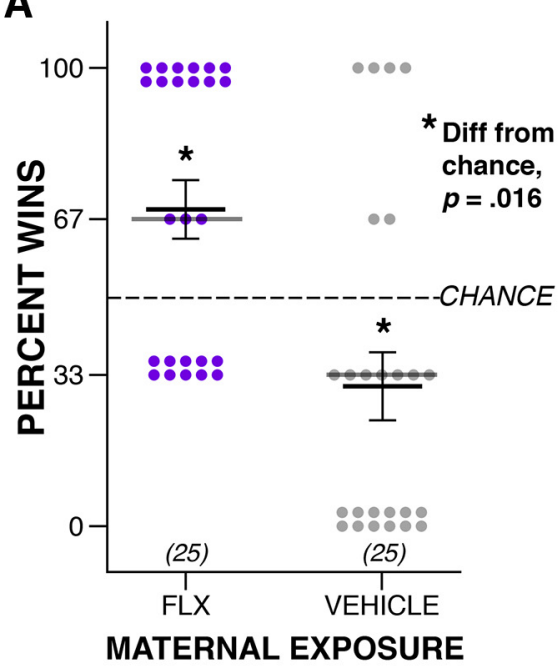

D

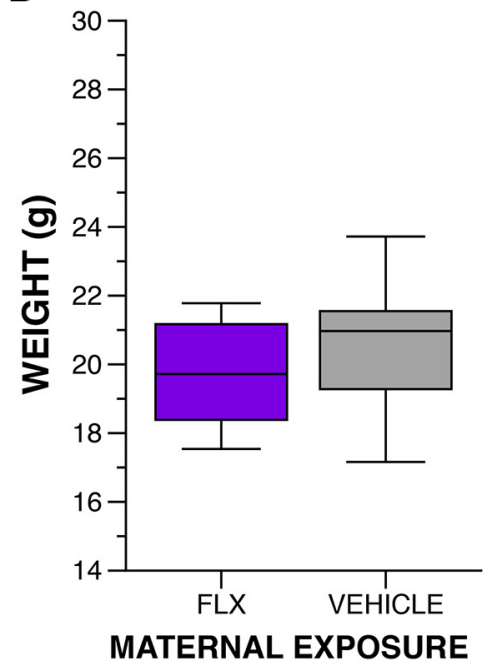

B

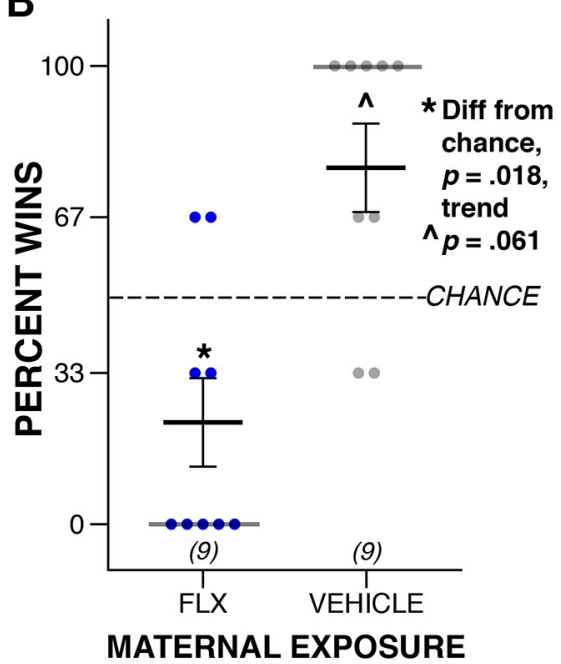

E

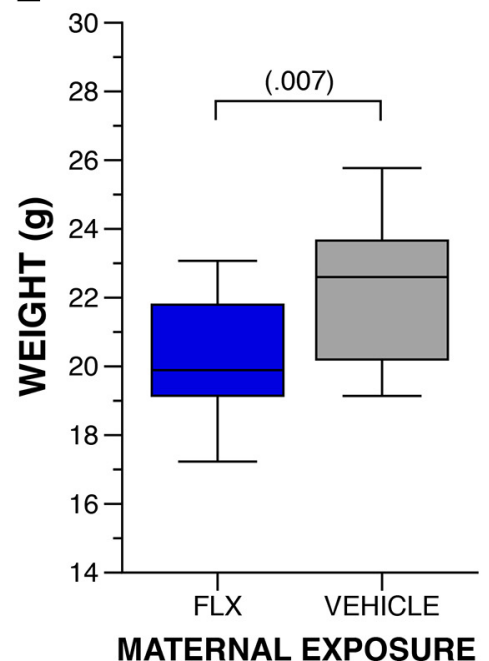

C

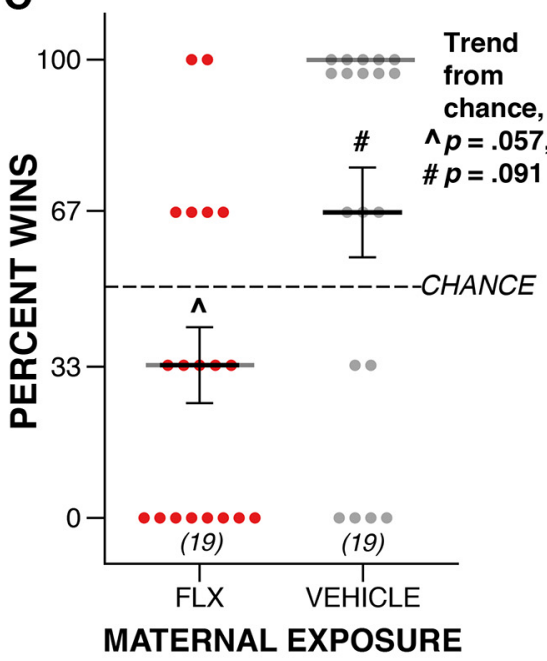

$\mathbf{F}$

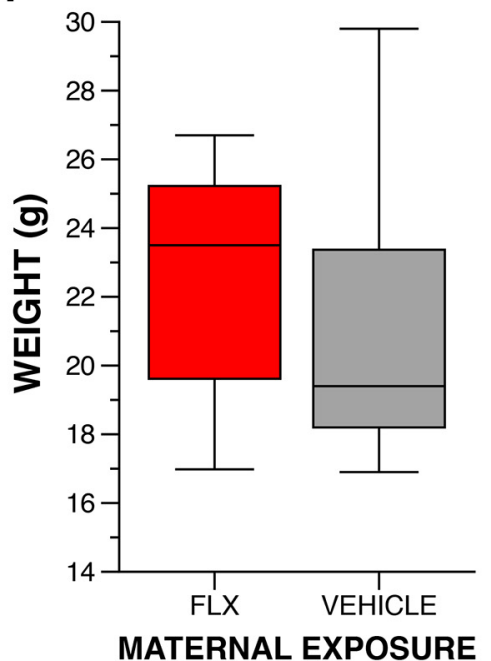

Figure 4. Maternal FLX disrupts adult social dominance behaviors. $\boldsymbol{A}-\boldsymbol{C}$, Dot plots of percentage of wins during tube test of social dominance between FLX and VEH adult mice in the C57-Extended $(\boldsymbol{A} ; *$ denotes significant difference from chance at $p=0.016)$, Long Prenatal $(\boldsymbol{B} ; *$ denotes significant difference from chance at $p=0.018 ; \wedge$ denotes marginally significant difference from chance at $p=0.061)$, and Short Prenatal cohorts $\left(\boldsymbol{C} ;{ }^{\wedge}\right.$ denotes marginally significant difference from chance at $p=0.057 ; \#$ denotes marginally significant difference from chance at $p=0.091)$. Crosshairs represent mean \pm SEM, and dark gray lines represent medians. $\boldsymbol{D}-\boldsymbol{F}$, Boxplots of weight of C57-Extended ( $\boldsymbol{D}$; drug, $p>0.05)$, Long Prenatal $(\boldsymbol{E}$; drug, $p=0.007)$, and Short Prenatal $(\boldsymbol{F}$; drug, $p>0.05)$ FLX and VEH adult mice. For boxplots, thick horizontal lines signify respective group medians, boxes are 25th-75th percentiles, whiskers are $1.5 \times \mathrm{IQR}$, closed and open circles depict outliers. 
Table 5. Statistical summary for Figure 5

\begin{tabular}{|c|c|c|c|c|c|c|c|c|}
\hline \multirow[t]{6}{*}{ Marbles buried } & $\mathrm{pp}$ & $\begin{array}{l}\text { Comparison } \\
\text { Celf6-Extended, genotype }\left(\text { Celf6 }{ }^{+/+} \text {vs }\right. \\
\text { Celf6 }^{+/-} \text {vs Celf) }\end{array}$ & $\begin{array}{l}\text { Data } \\
\text { structure } \\
\text { Normal }\end{array}$ & $\begin{array}{r}\text { Statistical test } \\
\text { Two-way ANOVA }\end{array}$ & $\begin{array}{c}\text { Output } \\
F_{(2,117)}=6.209\end{array}$ & $\begin{array}{c}p \text { value } \\
p=0.03\end{array}$ & $\begin{array}{l}\text { Post hoc } \\
\text { power } \\
0.886\end{array}$ & $\begin{array}{l}\text { Effect } \\
\text { size } \\
0.326\end{array}$ \\
\hline & qq & Celf6-Extended, drug $\times$ genotype interaction & Normal & Two-way ANOVA & $F_{(2,117)}=3.559$ & $p=0.032$ & 0.651 & 0.246 \\
\hline & $\mathrm{rr}$ & Celf6 $^{+/+}$FLX vs vehicle & Normal & Simple main effect & $F_{(1,117)}=14.687$ & $p=0.0002$ & 0.967 & 0.355 \\
\hline & ss & C57-Extended, drug (FLX vs vehicle) & Normal & One-way ANOVA & $F_{(1,63)}=1.080$ & $p=0.303$ & 0.176 & 0.132 \\
\hline & tt & Long Prenatal, drug (FLX vs vehicle) & Normal & One-way ANOVA & $F_{(1,42)}=1.456$ & $p=0.234$ & 0.218 & 0.188 \\
\hline & tt & Short Prenatal, drug (FLX vs vehicle) & Normal & One-way ANOVA & $F_{(1,42)}=0.168$ & $p=0.684$ & 0.069 & 0.063 \\
\hline \multirow{15}{*}{$\begin{array}{l}\text { Percent } \\
\text { alternating } \\
\text { trials }\end{array}$} & ww & Celf6-Extended, drug (FLX vs vehicle) & Non-normal & Two-way ANOVA & $F_{(1,117)}=16.205$ & $p=0.0001$ & 0.979 & 0.373 \\
\hline & ww & Celf6 $^{+/+}$FLX vs vehicle & Non-normal & Simple main effect & $F_{(1,117)}=6.857$ & $p=0.010$ & 0.738 & 0.241 \\
\hline & ww & Celf6 $^{+/-}$FLX vs vehicle & Non-normal & Simple main effect & $F_{(1,117)}=10.292$ & $p=0.002$ & 0.889 & 0.297 \\
\hline & uu & $\begin{array}{l}\text { Celf6-Extended vehicle Celf6 }{ }^{+/+} \\
\text {compared to } 50 \%\end{array}$ & Non-normal & One-spl Wilcoxon & $Z=3.231$ & $p=0.001$ & $\mathrm{~N} / \mathrm{A}$ & 0.55 \\
\hline & uu & $\begin{array}{l}\text { Celf6-Extended vehicle Celf6 }{ }^{+/-} \\
\text {compared to } 50 \%\end{array}$ & Non-normal & One-spl Wilcoxon & $Z=4.228$ & $p=0.00002$ & $\mathrm{~N} / \mathrm{A}$ & 0.81 \\
\hline & uu & $\begin{array}{l}\text { Celf6-Extended vehicle } \text { Celf6 }^{-/-} \\
\text {compared to } 50 \%\end{array}$ & Non-normal & One-spl Wilcoxon & $Z=3.470$ & $p=0.0005$ & N/A & 0.71 \\
\hline & $x x$ & C57-Extended, drug (FLX vs vehicle) & Non-normal & Mann-Whitney $U$ & $U_{(31)}=67.5$ & $p=0.032$ & $\mathrm{~N} / \mathrm{A}$ & 0.15 \\
\hline & vv & C57-Extended, vehicle compared to $50 \%$ & Non-normal & One-spl Wilcoxon & $Z=2.958$ & $p=0.003$ & $\mathrm{~N} / \mathrm{A}$ & 0.55 \\
\hline & vv & C57-Extended, FLX compared to $50 \%$ & Non-normal & One-spl Wilcoxon & $Z=0.608$ & $p=0.543$ & $\mathrm{~N} / \mathrm{A}$ & 0.03 \\
\hline & aaa & Long Prenatal, drug (FLX vs vehicle) & Non-normal & Mann-Whitney $U$ & $U_{(44)}=221.5$ & $p=0.706$ & N/A & $<0.01$ \\
\hline & eee & Long Prenatal, vehicle compared to $50 \%$ & Non-normal & One-spl Wilcoxon & $Z=2.303$ & $p=0.021$ & N/A & 0.22 \\
\hline & fff & Long Prenatal, FLX compared to $50 \%$ & Non-normal & One-spl Wilcoxon & $Z=1.608$ & $p=0.108$ & N/A & 0.14 \\
\hline & bbb & Short Prenatal, drug (FLX vs vehicle) & Normal & One-way ANOVA & $F_{(1,40)}=1.555$ & $p=0.220$ & 0.229 & 0.196 \\
\hline & ggg & Short Prenatal, vehicle compared to $50 \%$ & Normal & One-sample t-test & $t_{(19)}=3.324$ & $p=0.004$ & 0.883 & 0.743 \\
\hline & ggg & Short Prenatal, FLX compared to $50 \%$ & Normal & One-sample t-test & $t_{(21)}=2.541$ & $p=0.019$ & 0.679 & 0.542 \\
\hline \multirow{6}{*}{$\begin{array}{l}\text { No. of non- } \\
\text { alternation } \\
\text { trials }\end{array}$} & yy & Celf6-Extended, drug (FLX vs vehicle) & Non-normal & Two-way ANOVA & $F_{(1,117)}=16.290$ & $p=0.0001$ & 0.979 & 0.373 \\
\hline & yy & Celf6 $^{+/+}$FLX vs vehicle & Non-normal & Simple main effect & $F_{(1,117)}=6.893$ & $p=0.010$ & 0.740 & 0.244 \\
\hline & yy & Celf6 $^{+/-}$FLX vs vehicle & Non-normal & Simple main effect & $F_{(1,117)}=9.267$ & $p=0.003$ & 0.855 & 0.281 \\
\hline & $\mathrm{zz}$ & C57-Extended, drug (FLX vs vehicle) & Non-normal & Mann-Whitney $U$ & $U_{(31)}=72$ & $p=0.054$ & $\mathrm{~N} / \mathrm{A}$ & 0.13 \\
\hline & $\operatorname{ccc}$ & Long Prenatal, drug (FLX vs vehicle) & Non-normal & Mann-Whitney $U$ & $U_{(44)}=171.5$ & $p=0.214$ & $\mathrm{~N} / \mathrm{A}$ & 0.04 \\
\hline & ddd & Short Prenatal, drug (FLX vs vehicle) & Normal & One-way ANOVA & $F_{(1,40)}=1.555$ & $p=0.220$ & 0.229 & 0.196 \\
\hline \multirow{5}{*}{$\begin{array}{l}\text { Percent } \\
\text { response } \\
\text { trials }\end{array}$} & hhh & $\begin{array}{l}\text { C57-Extended, drug } \times \text { filament } \\
\text { interaction }\end{array}$ & Non-normal & One-way rmANOVA & $F_{(7,98)}=3.113$ & $p=0.005$ & 0.932 & 0.472 \\
\hline & iii & $0.16 \mathrm{~g}$ filament FLX vs vehicle & Normal & Simple main effect & $F_{(1,112)}=4.104$ & $p=0.045$ & 0.519 & 0.19 \\
\hline & iii & $0.4 \mathrm{~g}$ filament FLX vs vehicle & Normal & Simple main effect & $F_{(1,112)}=13.053$ & $p=0.0005$ & 0.948 & 0.34 \\
\hline & iii & $0.6 \mathrm{~g}$ filament FLX vs vehicle & Normal & Simple main effect & $F_{(1,112)}=13.357$ & $p=0.0004$ & 0.952 & 0.35 \\
\hline & jjj & C57-Extended AUC, drug (FLX vs vehicle) & Non-normal & Mann-Whitney $U$ & $U_{(16)}=15.5$ & $p=0.096$ & $\mathrm{~N} / \mathrm{A}$ & 0.19 \\
\hline
\end{tabular}

Effect size for $F$ tests reported as Cohen's $f$ (Cohen, 1988; interpretation: $0.01=$ small; $0.25=$ medium; $0.40=$ large), for $t$ tests as Cohen's $d$ (interpretation: 0.2 = small; $0.5=$ medium; $0.8=$ large) and for nonparametric tests reported as $\eta^{2}$.

fluence of FLX on this symptom domain. In humans, these symptoms can manifest: as stereotyped or repetitive motor movements, use of objects, or speech; insistence on sameness, inflexible adherence to routines or patterns; or highly restricted interests. This domain also includes hyper- or hypo-reactivity to sensory input (American Psychiatric Association, 2013). In our mice, we used the marble burying task to examine compulsive digging, spontaneous alternation T-maze to test inflexible adherence to behavior patterns (perseveration), and von Frey filaments to gauge reactivity to tactile stimulation. Output from statistical tests for this section is fully reported in Table 5.

Mice compulsively dig in bedding, and this behavior is perturbed in models of obsessive-compulsive disorder and ASD (Angoa-Pérez et al., 2013). Therefore, we examined digging in our mice using buried marbles as a proxy for compulsive digging. In the Celf6-Extended cohort, Celf6 genotype alone decreased compulsive digging $(p=$ $\left.0.001^{\mathrm{pp}}\right)$. In addition, FLX treatment reduced digging in Celf $^{+/+}$mice (drug $\times$genotype interaction, $p=0.032^{\text {qq; }}$;

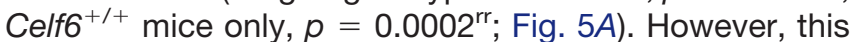
effect on WT mice did not replicate in the C57-Extended cohort $\left(p=0.303^{s s}\right.$; Fig. $\left.5 B\right)$. The reason behind this lack of replication is unclear. While the Celf6 mice were back- crossed for many generations on to the C57BL/6J strain, it is possible there are subtle effects due to genetic drift in the Celf6 colony. In the Long Prenatal and Short Prenatal cohorts, no difference in number of buried marbles was observed $\left(p=0.234^{\mathrm{tt}}\right.$ and $p=0.684^{\mathrm{tt}}$, respectively; Fig. $5 C, D)$. These data suggest that postnatal, but not prenatal, FLX may influence compulsive digging, but the impact of background strain on this effect requires further examination.

In spontaneous alternation in the T-maze, we examined whether the mice alternated which arm was explored between consecutive trials at a rate greater than chance (50\%), which would suggest the mice demonstrated a typical exploration pattern and did not perseverate. We also examined if this percentage alternation was different between groups to understand if there was an effect of maternal FLX exposure on typical exploration patterns. We observed differences in the effect of FLX depending on whether exposure was prenatal only or extended postnatally. Extended FLX exposure induced perseverative behavior in this task as observed through percentage alternations that were no different from chance in the FLX-exposed mice. VEH mice from both Celf6-Extended and C57-Extended cohorts showed percentage of alternations better than chance $\left(p<0.002^{\mathrm{uu}}\right.$ and $p=0.003^{\mathrm{vv}}$, 

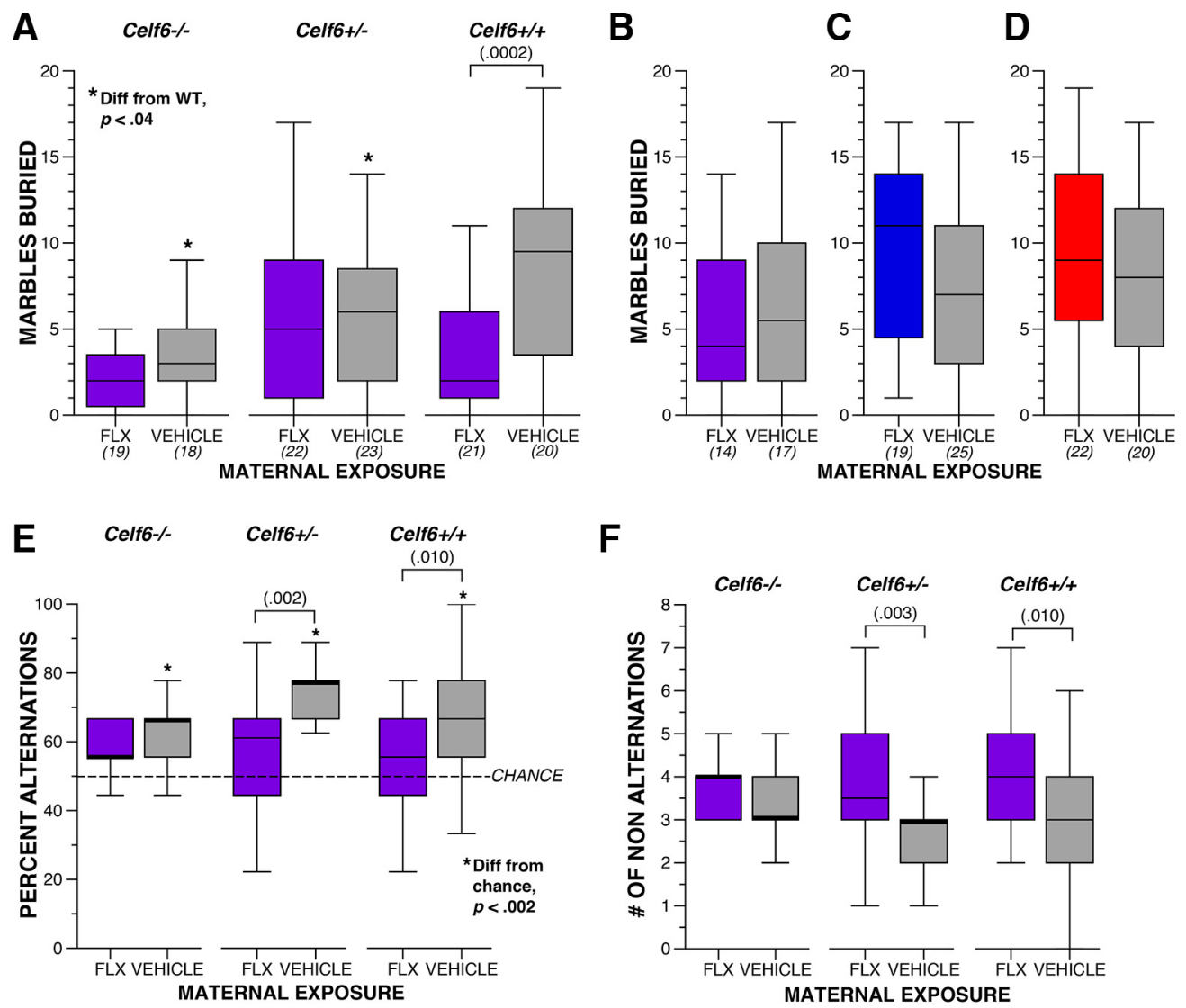

$\mathbf{F}$
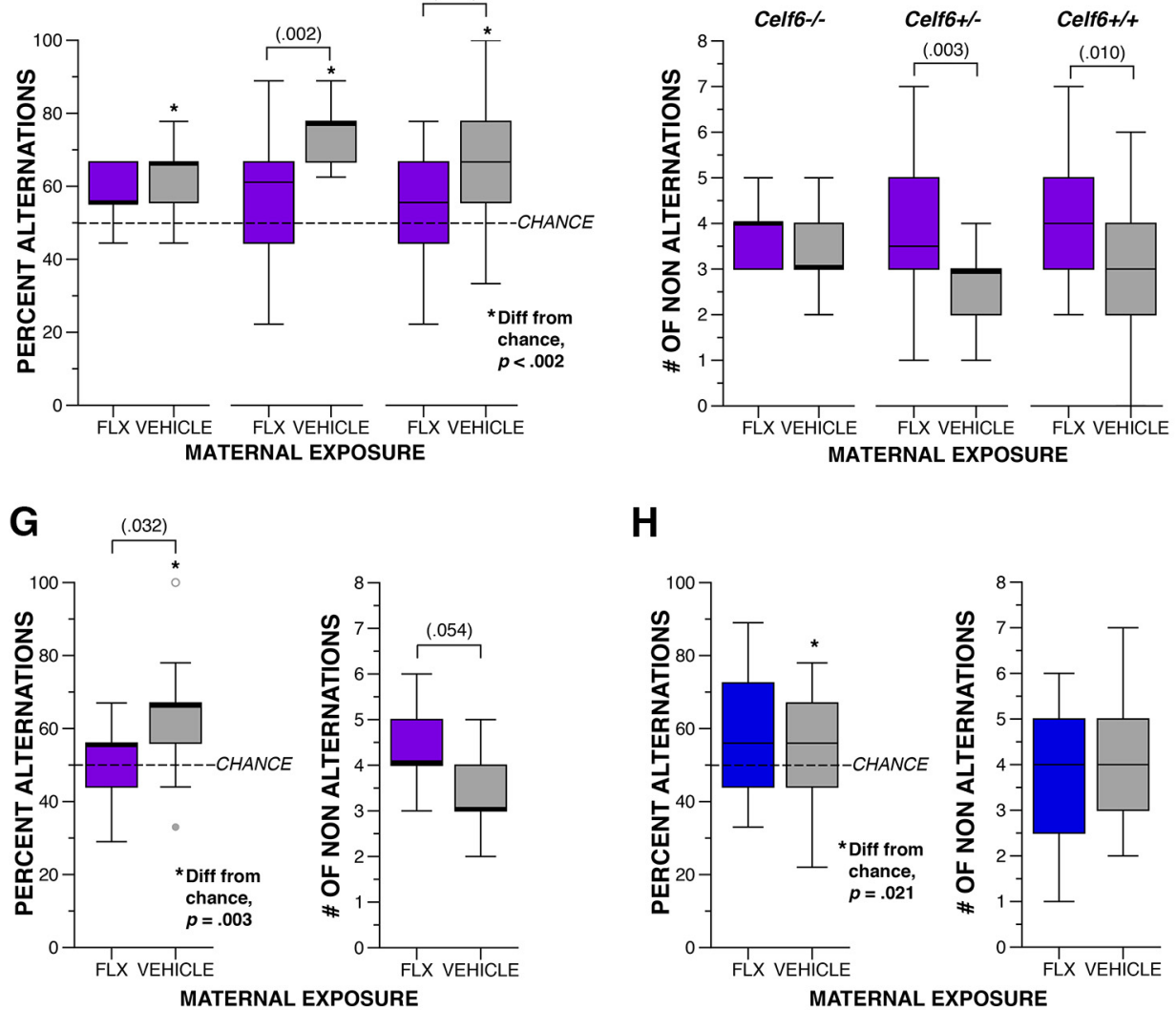

H

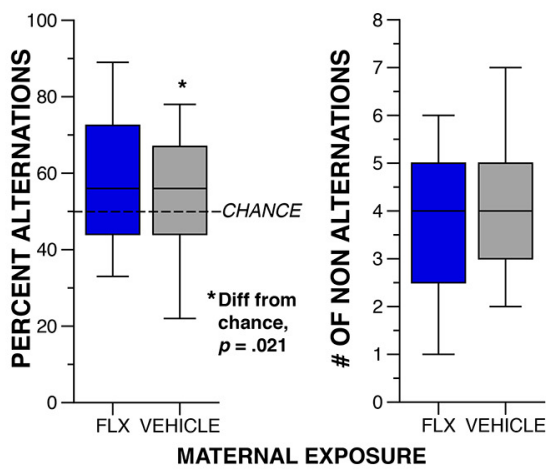

I

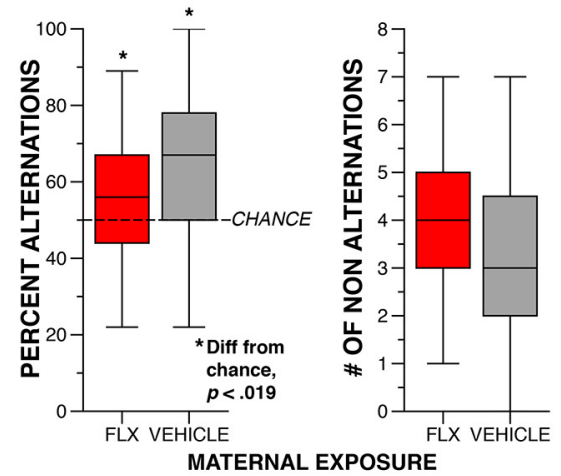

J

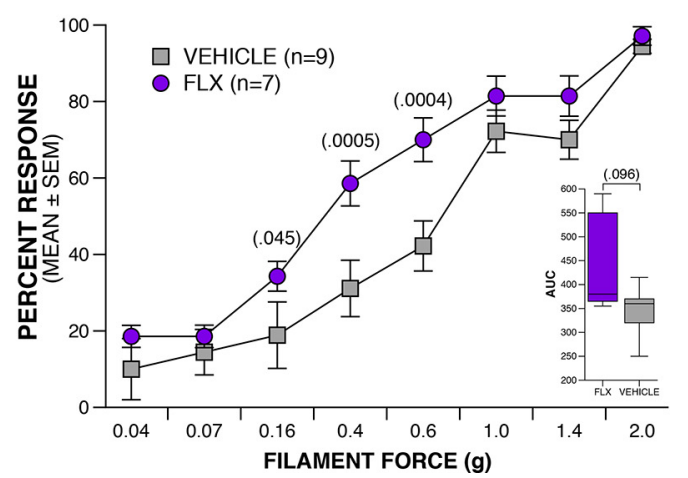

Figure 5. Extended maternal FLX induces repetitive, restricted patterns of behavior and tactile hypersensitivity. $\boldsymbol{A}$, Boxplot of number 
continued

of marbles buried by Celf6-Extended FLX and VEH Celf6 mutant and WT littermates during adulthood (genotype $\times$ drug interaction, $p=0.032 ; *$ denotes significant difference from WT littermates at $p<0.04$ within VEH-exposed mice). $\boldsymbol{B}-\boldsymbol{D}$, Boxplots of number of marbles buried by C57-Extended (B; drug, $p=0.303)$, Long Prenatal $(\boldsymbol{C} ;$ drug, $p=0.234)$, and Short Prenatal $(\boldsymbol{D} ;$ drug, $p=0.684)$ FLX and VEH C57BL/6J mice. $\boldsymbol{E}, \boldsymbol{F}$, Boxplots of percentage alternation trials $(\boldsymbol{E} ; *$ denotes significant difference from chance at $p<$ 0.002) and number of non-alternation trials $(\boldsymbol{F})$ in the spontaneous alternation T-maze for Celf6-Extended FLX and VEH Celf6 mutant and WT littermates (drug, $p=0.0001$ ). G-I, Boxplots of percentage alternation trials and number of non-alternation trials C57Extended $(\boldsymbol{G} ; *$ denotes significant difference from chance at $p=0.003)$, Long Prenatal $(\boldsymbol{H} ; *$ denotes significant difference from chance at $p=0.021)$, and Short Prenatal $(\boldsymbol{I} ; *$ denotes significant difference from chance at $p<0.019)$ C57BL/6J FLX and VEH mice. $\boldsymbol{J}$, Percentage of trials during which a response was elicited by von Frey filament presentation for C57-Extended FLX and VEH C57BL/6J mice (data are mean \pm SEM; filament $\times$ drug, $p=0.005$ ). Inset boxplot represents total AUC for all filaments per drug group. For boxplots, thick horizontal lines signify respective group medians, boxes are 25th-75th percentiles, whiskers are $1.5 \times$ IQR, closed and open circles depict outliers.

respectively; Fig. $5 E, G)$, and greater than that exhibited by FLX-exposed mice $\left(p=0.0001^{\mathrm{ww}}\right.$ and $p=0.032^{\mathrm{xx}}$; Fig. $5 E, G)$. This is also reflected in an increased number of non-alternations in FLX mice (Celf6-Extended main effect of drug, $p=0.0001^{\mathrm{yy}}$; Celf6 ${ }^{+/}, p=0.003$; Celf6 $^{+/+}, p=$ 0.010 ; Fig. $5 F$, and a trend in the C57-Extended cohort, $p=0.054^{\text {zz; }}$ Fig. $5 G$ ). In contrast, Long and Short Prenatal exposure to FLX did not result in percentage alternations different from VEH mice or increased non-alternation trials $\left(p=0.706^{\mathrm{aaa}}, p=0.220^{\mathrm{bbb}}, p=0.214^{\mathrm{ccc}}\right.$, and $p=$ $0.220^{\text {ddd }}$, respectively; Fig. $\left.5 H, I\right)$. While in the Long Prenatal cohort VEH mice exhibited a percentage alternation trials greater than chance $\left(p=0.021^{\text {eee }}\right)$ and FLX-exposed mice did not $\left(p=0.108^{\mathrm{fff}}\right)$, both VEH and FLX mice of the Short Prenatal cohort alternated at a percentage greater than chance $\left(p<0.020^{g 9 g}\right)$ These results suggest that extended FLX exposure is required to induce perseverative behavior.

\section{Maternal FLX results in tactile hypersensitivity}

Because we observed abnormalities in marble burying and T-maze performance only in the Extended exposure cohorts, we further examined FLX influence in this cohort on the sensory reactivity aspect of the restricted and repetitive behavior symptom domain. Previously, tactile processing defects were observed in the Mecp2 and Gabrb3 models of ASD (Orefice et al., 2016). We, therefore, tested tactile sensitivity using the von Frey filaments in a subset of the C57-Extended mice and observed hypersensitivity to tactile stimulation: FLX resulted in an increased percentage of trials with a response to stimulation compared to VEH mice ( $p=0.005^{\text {hhh; }}$ Fig. $5 \mathrm{~J}$ ) for filaments providing $0.16-0.6 \mathrm{~g}$ of force $\left(p<0.046^{\mathrm{iii}}\right)$. AUC was also greater for FLX compared to VEH mice $(p=$ $\left.0.096^{i j}\right)$, although it did not reach statistical significance, indicating a trend for a greater overall response to stimulation across filaments that likely requires a betterpowered sample to observe significance. This tactile hypersensitivity is independent of general activity levels, altered emotionality (anxiogenic behavior), or sensorimotor abilities, as we did not observe differences between Extended FLX and VEH exposure in a 1-h locomotor activity task (distance traveled, center zone time and entries) or on a battery of sensorimotor tasks assessing balance, strength, and coordination (data not shown).

\section{Adult FLX treatment partially rescues tactile hypersensitivity yet exacerbates dominance phenotype induced by maternal FLX exposure}

During brain development, 5-HT regulates the development of its own system through a negative feedback mechanism (Whitaker-Azmitia et al., 1996). Studies have shown persistent alterations to the $5-\mathrm{HT}$ system in adults following developmental SSRI exposure through the dam, including increased 5-HT1a receptor sensitivity, and decreased 5-HT transporter expression, Tph2 levels in the dorsal raphe, and midbrain 5-HT content (Cabrera-Vera et al., 1997; Maciag et al., 2006; Noorlander et al., 2008; Olivier et al., 2011). These findings suggests a disrupted 5-HT system may be mediating the long-term behavioral disruptions in our mice. Indeed, adult alterations to 5-HT activity have been shown to produce similar phenotypes. Tryptophan-depleted diets increased social dominance in the adult mouse (Uchida et al., 2005) and spontaneous alternation rates in adult rats (González-Burgos et al., 1995). Mice null for $L m \times 1 b$, a transcription factor required for differentiation of postmitotic 5-HT neurons, lack central 5-HT and showed reduced responsiveness to von Frey filaments (Zhao et al., 2007). These studies indicate a link between disrupted 5-HT levels and social dominance, alternation rates, and tactile sensitivity. Acute FLX treatment has been shown to increase extracellular 5-HT levels (Malagié et al., 1995), while chronic treatment (lasting at least three weeks) may actually reduce 5- $\mathrm{HT}$ levels through autoreceptor feedback and reduced transportermediated 5-HT recycling (Siesser et al., 2013; Bazhenova et al., 2017). However, the literature on this is inconsistent (Jacobsen et al., 2016). To determine whether altering levels of $5-\mathrm{HT}$ through SSRI treatment can rescue the behavioral deficits we observed in maternally-exposed pups, we treated an independent cohort of C57-Extended mice (Rescue cohort) with FLX through drinking water starting at P60 and examined their behavior following acute $(<5 \mathrm{~d})$ and chronic (more than three weeks) treatment (Fig. 6A). Output from statistical tests for this section is fully reported in Table 6.

Re-exposure with FLX influences tactile sensitivity and social dominance phenotypes induced by maternal FLX exposure, but likely through different mechanisms. The tactile hypersensitivity observed in adult mice exposed to maternal FLX was partially rescued by re-exposure with FLX. No drug $\times$ sex interaction was observed, therefore 
A

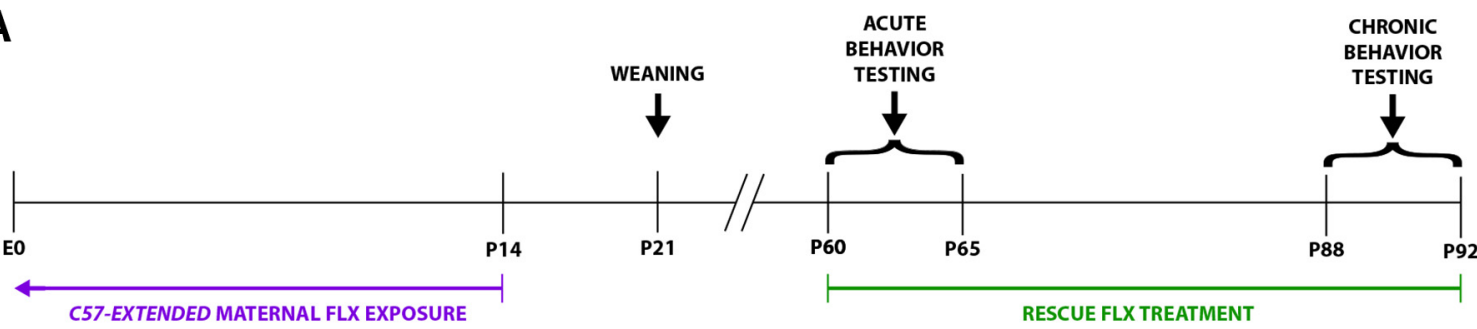

ACUTE

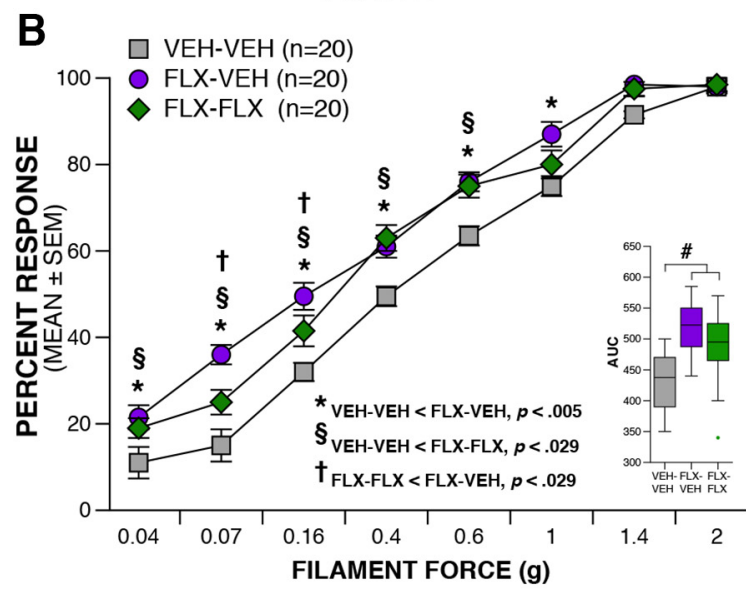

D

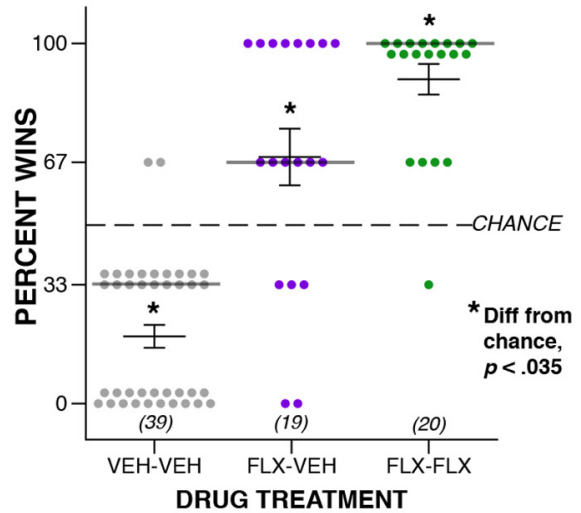

F

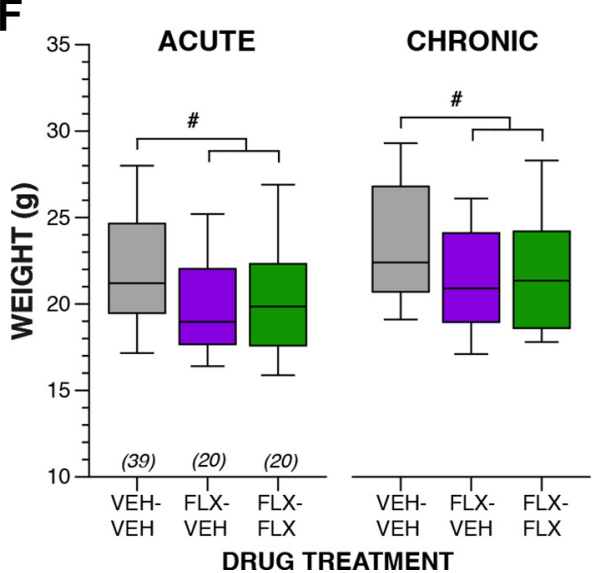

CHRONIC

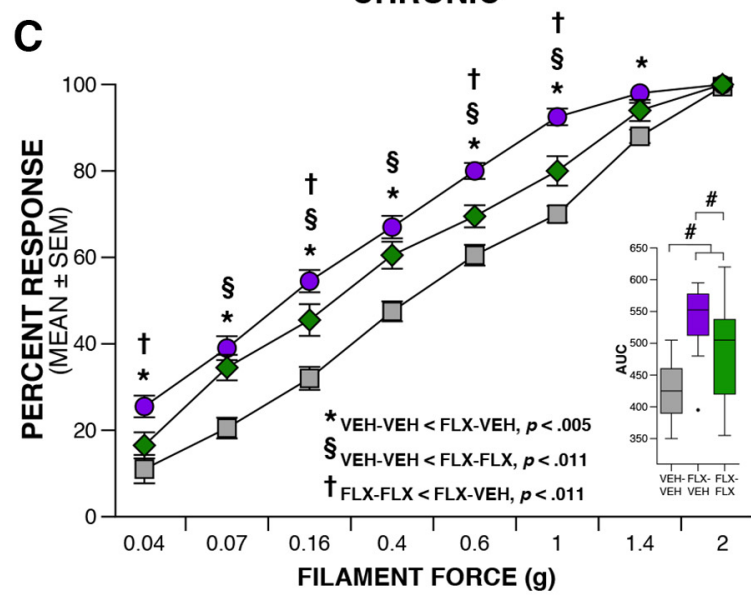

E

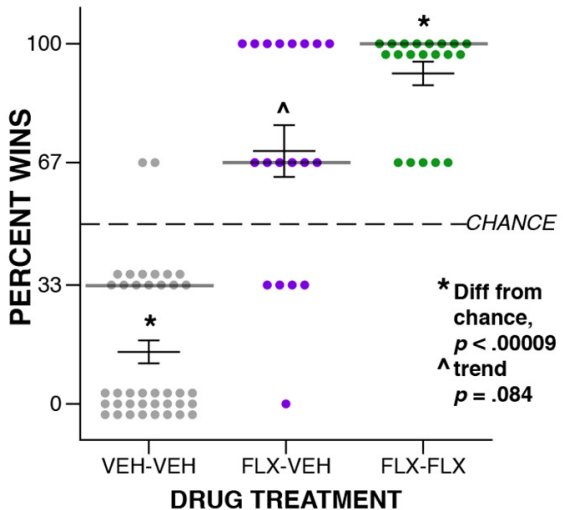

G

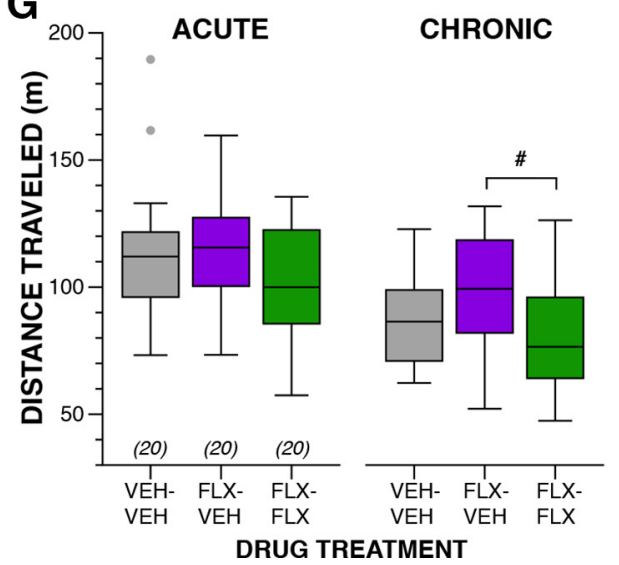

Figure 6. Re-exposure with FLX in adulthood ameliorates tactile hypersensitivity but increases dominance following maternal FLX exposure. $\boldsymbol{A}$, Schematic of treatment paradigm for maternal FLX exposure and behavioral testing following acute and chronic re-exposure with FLX in adulthood. $\boldsymbol{B}, \boldsymbol{C}$, Percentage of trials during which a response was elicited by von Frey filament presentation 


\section{continued}

for Rescue VEH-VEH, VEH-FLX, and FLX-FLX C57BL/6J mice following acute (B; filament $\times$ drug, $p=0.002)$ and chronic $(\boldsymbol{C}$; filament $\times$ drug, $p<0.000005)$ FLX re-exposure (data are mean \pm SEM; $*$ denotes significant difference between VEH-VEH and FLX-VEH; $\S$ denotes significant difference between VEH-VEH and FLX-FLX; $\dagger$ denotes significant difference between FLX-FLX and FLX-VEH). Inset boxplot represents total AUC for all filaments per drug group. $\boldsymbol{D}, \boldsymbol{E}$, Dot plots of percentage of wins during tube test of social dominance between VEH-VEH and VEH-FLX, and between VEH-VEH and FLX-FLX adult mice in the Rescue cohort following acute $(\boldsymbol{D} ; *$ denotes significant difference from chance at $p=0.035)$ and chronic re-exposure $(\boldsymbol{E} ; *$ denotes significant difference from chance at $p<0.00009 ; \wedge$ denotes marginally significant difference from chance at $p=0.084)$. Crosshairs represent mean \pm SEM, and dark gray lines represent medians. $\boldsymbol{F}$, Boxplots of weight of Rescue VEH-VEH, VEH-FLX, and FLX-FLX C57BL/6J mice following acute (drug, $p<0.000005$ ) and chronic (drug, $p<0.000005)$ FLX re-exposure. G, Boxplots of distance traveled during the 1-h locomotor activity test by Rescue VEH-VEH, VEH-FLX, and FLX-FLX C57BL/6J mice following acute (drug, $p=0.070$ ) and chronic (drug, $p<0.020$ ) FLX re-exposure. For boxplots, thick horizontal lines signify respective group medians, boxes are 25th-75th percentiles, whiskers are $1.5 \times \mathrm{IQR}$, closed and open circles depict outliers; \# denotes significantly different Tukey's post hoc comparison.

data are reported collapsed by sex. We replicated in both acute and chronic testing the tactile hypersensitivity observed in the C57-Extended cohort. During acute reexposure, differences in tactile responsiveness were observed between treatment groups $\left(p=0.002^{\mathrm{kkk}}\right)$ for all but the largest two filaments that elicit near $100 \%$ response from all mice $\left(p<0.012^{111}\right.$; Fig. $\left.6 B\right)$, For each of these filaments, the FLX-VEH group exhibited increased percentage of trials with a response to stimulation compared to VEH-VEH mice while the FLX-FLX mice began to show a reduction in responsiveness to presentation of the von Frey filaments providing $0.07-0.16 \mathrm{~g}$ of force compared to FLX-VEH mice. The overall response to stimulation as measured by AUC was not different between FLX-treated groups, although each was greater than that for the VEHVEH mice $\left(p<0.000005^{\mathrm{mmm}}\right)$. After three more weeks of FLX treatment, differences between treatment groups $\left(p<0.000005^{\mathrm{nnn}}\right)$ were now observed for all filaments

Table 6. Statistical summary for Figure 6

\begin{tabular}{|c|c|c|c|c|c|c|c|c|}
\hline Variable & & Comparison & $\begin{array}{l}\text { Data } \\
\text { structure }\end{array}$ & Statistical test & Output & $p$ value & $\begin{array}{l}\text { Post hoc } \\
\text { power }\end{array}$ & $\begin{array}{l}\text { Effect } \\
\text { size }\end{array}$ \\
\hline \multirow{17}{*}{$\begin{array}{l}\text { Percent } \\
\text { response } \\
\text { trials }\end{array}$} & kkk & $\begin{array}{l}\text { ACUTE Rescue, drug } \times \\
\text { filament interaction }\end{array}$ & Non-normal & One-way rmANOVA & $F_{(6.158,351.02)}=2.619$ & $p=0.002$ & 0.981 & 0.303 \\
\hline & III & $0.04 \mathrm{~g}$ filament, drug & Non-normal & Simple main effect & $F_{(2,456)}=4.543$ & $p=0.011$ & 0.772 & 0.139 \\
\hline & III & $0.07 \mathrm{~g}$ filament, drug & Non-normal & Simple main effect & $F_{(2,456)}=16.661$ & $p<0.000005$ & 1 & 0.270 \\
\hline & III & $0.16 \mathrm{~g}$ filament, drug & Non-normal & Simple main effect & $F_{(2,456)}=11.590$ & $p=0.00001$ & 0.994 & 0.225 \\
\hline & III & $0.4 \mathrm{~g}$ filament, drug & Non-normal & Simple main effect & $F_{(2,456)}=8.016$ & $p=0.0004$ & 0.956 & 0.185 \\
\hline & III & $0.6 \mathrm{~g}$ filament, drug & Non-normal & Simple main effect & $F_{(2,456)}=7.286$ & $p=0.0008$ & 0.936 & 0.179 \\
\hline & III & $1.0 \mathrm{~g}$ filament, drug & Non-normal & Simple main effect & $F_{(2,456)}=5.487$ & $p=0.004$ & 0.849 & 0.157 \\
\hline & $\mathrm{mmm}$ & ACUTE Rescue AUC, drug & Normal & One-way ANOVA & $F_{(2,57)}^{(2,400)}=15.887$ & $p<0.000005$ & 0.999 & 0.747 \\
\hline & $\mathrm{nnn}$ & $\begin{array}{l}\text { CHRONIC Rescue, drug } \times \\
\text { filament interaction }\end{array}$ & Non-normal & One-way rmANOVA & $F_{(6.665,13.33)}=4.506$ & $p<0.000005$ & 1 & 0.398 \\
\hline & ০०० & $0.04 \mathrm{~g}$ filament, drug & Non-normal & Simple main effect & $F_{(2,456)}=8.840$ & $p=0.0001$ & 0.971 & 0.196 \\
\hline & ০০০ & $0.07 \mathrm{~g}$ filament, drug & Non-normal & Simple main effect & $F_{(2,456)}=15.357$ & $p<0.000005$ & 0.999 & 0.259 \\
\hline & ০০০ & $0.16 \mathrm{~g}$ filament, drug & Non-normal & Simple main effect & $F_{(2,456)}=21.158$ & $p<0.000005$ & 1 & 0.305 \\
\hline & ০০০ & $0.4 \mathrm{~g}$ filament, drug & Non-normal & Simple main effect & $F_{(2,456)}=16.264$ & $p<0.000005$ & 1 & 0.266 \\
\hline & ০০০ & $0.6 \mathrm{~g}$ filament, drug & Non-normal & Simple main effect & $F_{(2,456)}^{(2,400)}=15.714$ & $p<0.000005$ & 0.999 & 0.261 \\
\hline & ০০০ & $1.0 \mathrm{~g}$ filament, drug & Non-normal & Simple main effect & $F_{(2,456)}=20.966$ & $p<0.000005$ & 1 & 0.303 \\
\hline & ০০০ & $1.4 \mathrm{~g}$ filament, drug & Non-normal & Simple main effect & $F_{(2,456)}=4.179$ & $p=0.016$ & 0.735 & 0.135 \\
\hline & $\mathrm{ppp}$ & $\begin{array}{l}\text { CHRONIC Rescue AUC, } \\
\text { drug }\end{array}$ & Normal & One-way ANOVA & $F_{(2,57)}=20.307$ & $p<0.000005$ & 1 & 0.844 \\
\hline \multirow{2}{*}{$\begin{array}{l}\text { Percent } \\
\text { alternating } \\
\text { trials }\end{array}$} & qqq & ACUTE Rescue, drug & Normal & Two-way ANOVA & $F_{(2,54)}=1.766$ & $p=0.181$ & 0.354 & 0.255 \\
\hline & rrr & CHRONIC Rescue, drug & Non-normal & Two-way ANOVA & $F_{(2,51)}=0.814$ & $p=0.449$ & 0.182 & 0.179 \\
\hline \multirow{6}{*}{$\begin{array}{l}\text { Percent } \\
\text { tube test } \\
\text { bouts won }\end{array}$} & sss & $\begin{array}{l}\text { ACUTE Rescue VEH-VEH, } \\
\text { compared to } 50 \%\end{array}$ & Non-normal & One-spl Wilcoxon & $Z=-5.312$ & $p<0.000005$ & N/A & 0.74 \\
\hline & $\mathrm{ttt}$ & $\begin{array}{l}\text { ACUTE Rescue FLX-VEH, } \\
\text { compared to } 50 \%\end{array}$ & Non-normal & One-spl Wilcoxon & $Z=2.114$ & $p=0.034$ & N/A & 0.25 \\
\hline & vVv & $\begin{array}{l}\text { ACUTE Rescue FLX-FLX, } \\
\text { compared to } 50 \%\end{array}$ & Non-normal & One-spl Wilcoxon & $Z=4.016$ & $p=0.00006$ & N/A & 0.85 \\
\hline & sss & $\begin{array}{l}\text { CHRONIC Rescue VEH-VEH, } \\
\text { compared to } 50 \%\end{array}$ & Non-normal & One-spl Wilcoxon & $Z=-5.533$ & $p<0.000005$ & N/A & 0.81 \\
\hline & uuu & $\begin{array}{l}\text { CHRONIC Rescue FLX-VEH, } \\
\text { compared to } 50 \%\end{array}$ & Non-normal & One-spl Wilcoxon & $Z=1.726$ & $p=0.084$ & N/A & 0.17 \\
\hline & vVv & $\begin{array}{l}\text { CHRONIC Rescue FLX-FLX, } \\
\text { compared to } 50 \%\end{array}$ & Non-normal & One-spl Wilcoxon & $Z=3.934$ & $p=0.00008$ & N/A & 0.81 \\
\hline \multirow[t]{2}{*}{ Weight } & www & ACUTE Rescue, drug & Normal & Two-way ANOVA & $F_{(2,73)}=15.468$ & $p<0.000005$ & 0.999 & 0.652 \\
\hline & www & CHRONIC Rescue, drug & Non-normal & Two-way ANOVA & $F_{(2,73)}=18.850$ & $p<0.000005$ & 1 & 1.814 \\
\hline \multirow[t]{2}{*}{ Distance traveled } & $x x x$ & ACUTE Rescue, drug & Normal & Two-way ANOVA & $F_{(2,54)}=2.787$ & $p=0.070$ & 0.526 & 0.322 \\
\hline & yyy & CHRONIC Rescue, drug & Normal & Two-way ANOVA & $F_{(2,54)}=7.742$ & $p=0.020$ & 0.713 & 0.378 \\
\hline
\end{tabular}

Effect size for $F$ tests reported as Cohen's $f$ (Cohen, 1988; interpretation: $0.01=$ small; $0.25=$ medium; $0.40=$ large) and for nonparametric tests reported as $\eta^{2}$. 
except the largest, for which all mice responded $100 \%$ of the time $\left(p<0.017^{\circ 00}\right.$; Fig. $\left.6 C\right)$. The FLX-FLX mice showed further reduction in responsiveness compared to the FLX-VEH group for filaments providing 0.04, 016, 0.6, and $1.0 \mathrm{~g}$ of force. Analysis of the AUC revealed the overall responsiveness for the FLX-FLX group was now significantly lower than the FLX-VEH group $(p<$ $0.000005^{\mathrm{ppp}}$ ). These data suggest the tactile hypersensitivity induced by maternal FLX exposure can be alleviated by FLX treatment, further supporting a role for the 5-HT system in the circuitry mediating this phenotype.

Despite observing increased perseverative behavior in the spontaneous alternation T-maze for FLX-exposed mice in both the Celf6-Extended and C57-Extended cohorts, we did not replicate this baseline difference in phenotype a third time in the Rescue cohort. During acute and chronic testing, no differences were observed between drug groups for percentage of alternations $(p=$ $0.181^{\text {qqq }}$ and $p=0.449^{\text {rrr }}$, respectively; Table 5) or number of non-alternation trials (data not shown). Thus, it remains unclear if this phenotype, when present, would be reverted by adult FLX treatment.

Surprisingly, the enhanced dominance phenotype observed in mice exposed to maternal FLX was exacerbated by both acute and chronic FLX re-exposure. In the Rescue cohort, the increased dominance observed in the C57-Extended cohort was replicated. The VEH-VEH mice lost more bouts compared to chance $(50 \%)$ during both

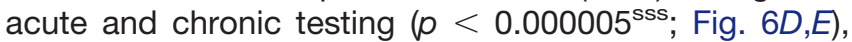
while FLX-VEH mice won more bouts compared to chance, although this failed to reach statistical significance during chronic treatment testing $\left(p=0.034^{\mathrm{ttt}}\right.$ and $p=0.084^{\text {uuu }}$ ). The FLX-FLX group also displayed increased dominance by winning more bouts than expected by chance during both acute and chronic testing $(p<$ $0.00009^{\mathrm{vvv}}$; Fig. $6 D, E$ ). The mean and median differences suggest that the FLX re-exposure further increased the dominance behavior in mice exposed to maternal FLX (acute: FLX-VEH, $M=68.47, M d n=67, S D=34.25$; FLX-FLX, $M=90.05, M d n=100, S D=19.01$; chronic: FLX-VEH, $M=69.89, M d n=66, S D=31.33$; FLX-FLX, $M=91.50, M d n=100, S D=15.10)$. As in the previous cohorts, the dominance phenotypes were not due to increased animal size in the FLX groups, as each actually weighed less than the VEH-VEH group $\left(p<0.000005^{\text {www; }}\right.$; Fig. 6F), with no change between acute and chronic treatment. We also examined the Rescue cohort in the 1-h locomotor activity task to determine whether the behavioral changes observed were due to general differences in activity levels or anxiogenic behavior induced by FLX re-exposure. We found a trend toward a decrease in total distance traveled in the FLX-FLX mice compared to the FLX-VEH mice during acute exposure $\left(p=0.070^{\mathrm{xx}}\right.$; Fig. $6 G)$ that reached statistical significance following chronic exposure $\left(p=0.020^{y y y}\right)$, with no differences in center area variables suggesting no change in anxiety-related behavior (data not shown). ANCOVA with litter size as the covariate yielded a marginally significant effect of drug on distance traveled during chronic re-exposure testing $(p=$ 0.072). We do not interpret these data as hypoactivity in the FLX-FLX group as their activity levels were not different from VEH-VEH mice nor were the FLX-VEH mice hyperactive compared to the control group in any cohort examined. It is possible there is a very small effect of FLX re-exposure on activity that we were underpowered to detect, but which likely does not confound the interpretation of the von Frey assessment or dominance phenotypes. In sum, the results from the Rescue cohort suggest disrupting 5-HT levels during development influenced the role of the 5-HT system in the behavioral circuits responsible for responses to sensory and social stimuli in the von Frey assessment of tactile sensitivity and the tube test of social dominance, respectively. Remarkably, the effects are in the opposite directions, suggesting they are mediated by distinct mechanisms. Specifically, SSRI treatment ameliorated the hypersensitivity to sensory stimuli but further exacerbated the response to social stimuli.

\section{Discussion}

The widespread roles of $5-\mathrm{HT}$ in neurodevelopmental processes are well-described (Sodhi and Sanders-Bush, 2004; Whitaker-Azmitia, 2010), and 5-HT dysregulation in a subset of patients with ASD has been well-documented and often replicated (McDougle et al., 1996, 1993; Chugani et al., 1999, 1997; Hollander et al., 2005; Azmitia et al., 2011; Benza and Chugani, 2015). Here, we examined the behavioral impact of in utero exposure to drugs that impact the 5-HT system. Human epidemiological studies suggest antidepressant use during pregnancy may increase ASD risk in offspring, although challenges remain in adjusting for maternal diagnosis appropriately. With current epidemiological samples, only some analyses confidently demonstrated an effect of SSRI treatment independent of maternal diagnosis, although most were not inconsistent with modest additional risk attributable to treatment. Given these challenges interpreting the epidemiological studies in aggregate, we tested the hypothesis that maternal SSRI exposure, independent of maternal stress, can modulate ASD-relevant behaviors in mammals. We report social communication and interaction deficits, as well as repetitive patterns of behavior in offspring of dams exposed to the SSRI FLX during pre- and postnatal development. We further showed that reexposure with FLX can ameliorate tactile hypersensitivity, yet further shift social dominance behaviors. These findings indicate that in the absence of other maternal manipulations or stressors, drug exposure alone is sufficient to induce in offspring long-term consequences to social and restrictive behaviors, some of which may be mediated by a disrupted $5-\mathrm{HT}$ system.

There is an established body of work in the rodent literature showing clear links between maternal SSRI exposure during pregnancy and a paradoxical increase in depressive- and anxiety-like behaviors in the mature offspring (Lisboa et al., 2007; Noorlander et al., 2008; Olivier et al., 2011; Avitsur et al., 2016; Boulle et al., 2016; Gobinath et al., 2016; Salari et al., 2016), but little analysis of the impact on social or repetitive behavioral circuits. The current study adds to the limited studies of dam SSRI exposure that have recently begun to focus on these 
types of behaviors in offspring, and is the first to fully characterize in this type of model behaviors relevant to the core symptoms of ASD, including multiple tasks within each distinct domain. We sought to examine in our mice various possible social disruptions and repetitive/restricted behaviors, including sensory sensitivities, that are observed in autistic individuals. We demonstrate the potential for maternal SSRI exposure alone to induce early social communication deficits, abnormal sociability, and altered social hierarchy behaviors, as well as perseveration and tactile hypersensitivity.

We did not find any phenotype common among all three exposure durations, suggesting FLX's influence on ASDrelated behaviors may depend on the duration of and developmental timeframe of exposure. Early pregnancy alone (E0-E16) was the least vulnerable developmental period examined. We observed increased submissive behaviors in adults in this exposure model, but typical behaviors in all other testing. Increased submissive behaviors were also observed in adult offspring that received FLX exposure through the entirety of gestation, or the rough equivalent in brain development to the first two trimesters of human pregnancy. In addition, this increased exposure duration induced early communicative deficits in the form of reduced USV production when isolated from the dam, as well as sociability disruptions. The Extended FLX exposure groups exhibited the greatest functional disruptions. The dampened USV production during development was coupled with social approach decreases and robust dominance behaviors suggesting this longer duration exposure to altered 5-HT activity most heavily impact social behavior circuitry. Only these mice demonstrated repetitive/restricted patterns of behavior. Complementing our findings on distinct effects of maternal FLX on dominance, recent work showed prenatal maternal FLX treatment decreased aggressive behaviors, while treatment extending postnatally increased aggressive behaviors in adult C57BL/6 male offspring (Kiryanova et al., 2016). However, another report showed increased aggression in male offspring of ICR dams exposed to only prenatal FLX (Svirsky et al., 2016). The discrepancies in aggression findings between these two studies may reflect strain $\times$ drug interactions. The distinct phenotypes of mice that received prenatal-only versus continued postnatal FLX exposure may be mediated by circuitry disruptions due to differences in 5-HT system development that occurs at these different periods. While 5-HT axons reach their targets by birth, terminal field development occurs postnatal (Maddaloni et al., 2017). Excess 5-HT during embryonic development acts to down-regulate 5-HT innervation through a negative feedback mechanism (Whitaker-Azmitia, 2005) and reduced 5-HT terminal processes has also been reported in rodents following postnatal SSRI treatment (Maciag et al., 2006). This suggests prenatal FLX exposure likely influences axonal innervation by $5-\mathrm{HT}$ neurons of the raphe, but continued postnatal exposure may have further reduced $5-\mathrm{HT}$ terminal fields, possibly meditating the increased dominance and perseverative behavior patterns observed in the Extended FLX cohort.
The social behavior disruptions observed in our study extend those previously reported following maternal FLX exposure to include sociability alterations and strong influences on social dominance. The majority of previous examinations of early SSRI exposure on social phenotypes focused only on aggression (Lisboa et al., 2007; Kiryanova et al., 2016; Svirsky et al., 2016), as a clear link between $5-\mathrm{HT}$ and aggression has been shown in both humans and animal models (Brown et al., 1982; Kaplan et al., 1994; Moeller et al., 1996; Reisner et al., 1996). We found sociability was dampened following FLX during pregnancy only, and that extended FLX exposure decreased total time investigating the social stimulus, but did not disrupt a social preference. This suggests we are observing a differential impact on sociability circuits based on timing of exposure. A previous report showed maternal FLX exposure limited to postnatal-only ages (P3-P21) had no effect on social approach behaviors in mice (Nakai et al., 2017). Together with our findings, this suggests in utero exposure may be the vulnerable period for sociability circuit formation. Tryptophan depletion diet has been shown to disrupt sociability behavior in adult C57BL/6 mice (Zhang et al., 2015). It is possible that early FLX exposure ultimately decreases 5-HT activity in key areas that mediate social preference. We did not find an influence of extended exposure on frequency of social behaviors observed during the juvenile interactions. Whether this is a result of the age at testing or that the unexposed partner could also initiate the interactions is unknown, and we are unaware of another study investigating unimpeded social interactions in a similar model.

Perhaps the most robust phenotype we observed was the change to social dominance. This is unsurprising given a link between low 5 -HT levels in the mature brain and dominance has been demonstrated in both human and animal research (Kaplan et al., 1994; Uchida et al., 2005). Tryptophan depletion was shown in an adult autistic patient to exacerbate symptoms including perseveration (McDougle et al., 1993), and adult mice fed a tryptophan-depleted diet exhibited increased dominance in the tube test (Uchida et al., 2005). If a decrease in activity of the $5-\mathrm{HT}$ system is mediating the dominance phenotypes observed in our mice, then we hypothesized increasing this activity would normalize this phenotype. Interestingly, we observed the opposite. Re-exposure with FLX during adulthood actually further enhanced the dominant phenotype induced by maternal FLX exposure. Within $30 \mathrm{~min}$ of exposure FLX increases extracellular 5-HT, dose-dependently, within the frontal cortex, hippocampus, and raphe (Malagié et al., 1995). Cortical and striatal 5-HT tissue levels are depleted with chronic (three weeks) exposure (Siesser et al., 2013; Bazhenova et al., 2017), but extracellular 5-HT levels seem to remain elevated (Jacobsen et al., 2016). Our data suggest the maternal FLX exposure altered the circuits mediating this social hierarchy behavior in a complex manner such that they no longer respond to 5-HT in a typical way. It is possible that other aspects of the 5-HT system, such as receptor densities or innervation patterns, were altered by 
maternal FLX exposure such that adult FLX treatment influences these circuits differently.

In addition to social behavior disruptions, maternal FLX exposure induced abnormalities related to the repetitive/ restricted patterns of behavior symptoms of ASD. Our results suggest continued postnatal exposure may be required to perturb these circuits. Most robust was the induction of tactile hypersensitivity. Sensory processing dysfunction is associated with multiple neurodevelopmental disorders, including the sensory sensitivity observed in ASD (Slobounov et al., 2006; Ross et al., 2007; Schneider et al., 2008; Lane et al., 2010; Ghanizadeh, 2011; Dar et al., 2012). 5-HT appears to play a role in regulating the balance between internal signals and sensory information from the environment (Lottem et al., 2016). Thus, fluctuations in the 5-HT system could tip that balance creating increased or decreased sensitivities. The high levels of $5-\mathrm{HT}$ required during neurodevelopment likely serve to increase the brain's responsiveness to the environment at that time required for plasticity and maturation. Adjusting those levels as we did through maternal FLX treatment may disrupt the 5-HT-mediated sensitivity required for proper circuit development. Our results suggest the circuits underlying tactile sensitivity were altered, perhaps made hyper-responsive. The partial rescue of the tactile hypersensitivity observed following adult FLX reexposure suggests the circuit disruptions are reversible and may be due to abnormal 5-HT activity levels. These data further support the therapeutic potential of SSRIs for sensory processing disorders.

As genetic factors are clearly an important causation of ASD (Geschwind, 2008), it is likely that environmental contributions to ASD risk interact with existing genetic susceptibility (Hertz-Picciotto et al., 2006; Klei et al., 2012). It has been suggested that environmental factors that might modulate social behavior or language could tip the balance toward ASD in children with genetic vulnerability (Geschwind, 2008). As we initially thought SSRI exposure alone might be a relatively modest factor, we exposed Celf6 mutant mice, which exhibit a subtle ASDlike phenotype (Dougherty et al., 2013), to maternal FLX and analyzed offspring behavior for possible potentiation of the ASD-like phenotype. We hypothesized a potentiation of deficits in Celf6 mutants with FLX exposure due to the effect each manipulation has on the 5-HT system. The Celf6 mutant exhibited subtle ASD-related deficits, specifically decreased early social communicative behavior and a resistance to change behavior patterns as well as reduced brain 5-HT levels patterns (Dougherty et al., 2013), making it an ideal model to examine the influence of FLX on a genetically vulnerable background and the impact of two hits to the 5-HT system on these behaviors. What we observed was both the Celf6 mutation and the FLX exposure independently reduced pup USVs, induced perseveration in the T-maze and reduced digging in the marble burying assay. These complementary behavioral disruptions suggest Celf6 loss and FLX exposure act in parallel on the circuits underlying these behaviors, possibly through similar influences on the 5-HT system. In contrast to our results is a similar study in the $15 q 11-13$ duplication model (15q-dup), which also shows reduced brain 5-HT levels (Tamada et al., 2010). Interactions between maternal FLX and the genetic duplication potentiated deficits in the 15q-dup mice: specifically, hypoactivity and anxiogenic behaviors (Nakai et al., 2017). Maternal FLX actually improved 15q-dup induced sociability, which was linked to restoration of extracellular 5-HT levels. The effect of FLX on the development of behavior circuitry appears to be in the opposite direction to that induced by $15 q-d u p$, such that it can have an ameliorating effect. However, the effect is likely in the same direction as Celf6 loss and similar enough that the effects are paralleled and not synergistic. Thus, we did not observe a potentiation of behaviors in the FLX-exposed Celf6 mutants or a restoration of deficits.

It is unclear why the Extended-exposure Celf6 ${ }^{+/+}$mice, which are on a C57BL/6J background, behaved differently than the C57BL/6J mice in marble burying. No difference was observed between the Celf6 ${ }^{+/+}$and C57 VEH-exposed mice, indicating the source of this difference is the maternal FLX exposure groups. A similar phenomenon was described in the Neuroligin-3 knockout mice showing deficits in sociability in both knock-out and WT littermates when housed together (Kalbassi et al., 2017). It is possible the reduced digging behavior expressed by the Celf6 $6^{--}$mice influences that of their WT littermates following maternal exposure to FLX. An alternative explanation is that perhaps digging behavior was influenced by the maternal behavior of Celf6 ${ }^{+/-}$versus C57BL/6J dams. The focus of this study was on the long-term consequences of exposure on offspring behavior, but we cannot rule out that some of our results may be influenced by SSRI mediated alterations of maternal behaviors in the nest. We chose not to cross-foster our pups because we wanted to continue FLX exposure into postnatal stages of brain development, and we wanted to avoid the confounding stress to both pups and dams of direct pup injections. Yet, because of this design, we cannot comment on the influence of FLX on maternal behavior in our litters, nor any long-term effects of maternal behavior changes on adult offspring phenotypes.

The potential influence of maternal care is complex, and worthy of an entire study of its own. Qualitatively, differences in maternal care have not been observed in Celf6 ${ }^{+/-}$ dams, yet this has not been thoroughly quantified. In addition, there may be an interaction between direct FLX exposure and heterozygous loss of Celf6 that affects maternal behavior and maternal care. The reciprocal influence of maternal care and pup USV on each other is complex. Greater maternal responsiveness has been shown to result in fewer calls emitted by the pups (D'Amato et al., 2005). However, decreased USV production by pups has also been shown to result in maternal neglect because the dams cannot locate the pups outside of the nest. This was identified in vocally impaired pups with genetic loss of motor neurons that transform breaths into calls (Hernandez-Miranda et al., 2017). It is possible in our FLX model that pup USV and maternal care are interacting in several ways. First, FLX could be directly impacting maternal care, and decreasing pup USVs. If this 
is the case in our mice, we would hypothesize based on previous research that the FLX increased maternal care and thus reduced pup USVs. We would further hypothesize this level of maternal care would likely not result in the long-term behavioral deficits observed in the adult offspring. However, the large magnitude of the reduction in USV we observed in FLX-exposed pups seems too robust for changes in maternal care to account for the underlying the pup phenotype. A second way in which maternal care and pup USV may be interacting is through a reduction to maternal care in response to the robustly reduced USV emitted by the pups exposed to FLX. This reduced maternal care has the potential to further disrupt neurodevelopment of the pup, and thus be a possible indirect influence on the later adult behaviors. Celf6 mutation harbored by the dam may also play into this scenario by altering dam or pup responses additively or synergistically. To our knowledge, the direct impact of SSRI exposure on maternal behaviors has not been examined; however increased latency to retrieve pups back to the nest has been demonstrated in adult female offspring exposed gestationally to FLX (Svirsky et al., 2016), suggesting transgenerational effects of gestational FLX exposure. Thus, we can conclude that FLX treatment to the dam during and immediately following pregnancy modulates progeny behaviors relevant to ASD; and that this is independent of maternal stress but possibly mediated by alterations to maternal care behaviors.

Despite a potential for increased risk from FLX exposure, untreated or undertreated depression and anxiety in pregnancy are themselves strongly associated with adverse outcomes (Grote et al., 2010), and we do not view this study as being sufficient cause to alter treatment decisions. Thus, while our findings are a contribution to our understanding of the consequences of developmental SSRI exposure, additional work needs to be done to understand the precise mechanisms by which SSRIs can alter circuit function. Our rescue experiment indicates that tactile sensitivity may be responsive to restoring $5-\mathrm{HT}$ levels via SSRI treatment, but that this could exacerbate other phenotypes. This also indicates these two phenotypes have distinct mechanisms. We believe the carefully characterized phenotype demonstrated here provides a clear paradigm for comparative analysis of different treatment options for their relative impact on offspring behavior, as well as a potential experimental manipulation for studies defining the circuits that control social and repetitive behaviors in the mammalian brain.

\section{References}

American Psychiatric Association (2013) Diagnostic and statistical manual of mental disorders: DSM-5, Ed 5. Arlington, VA: American Psychiatric Association Publishing.

Andrade SE, Raebel MA, Brown J, Lane K, Livingston J, Boudreau D, Rolnick SJ, Roblin D, Smith DH, Willy ME, Staffa JA, Platt R (2008) Use of antidepressant medications during pregnancy: a multisite study. Am J Obstet Gynecol 198:194.e1-e5. CrossRef

Angoa-Pérez M, Kane MJ, Briggs DI, Francescutti DM, Kuhn DM (2013) Marble burying and nestlet shredding as tests of repetitive, compulsive-like behaviors in mice. J Vis Exp 50978. Medline

Avitsur R, Grinshpahet R, Goren N, Weinstein I, Kirshenboim O, Chlebowski N (2016) Prenatal SSRI alters the hormonal and be- havioral responses to stress in female mice: possible role for glucocorticoid resistance. Horm Behav 84:41-49. CrossRef Medline

Azmitia EC, Singh JS, Whitaker-Azmitia PM (2011) Increased serotonin axons (immunoreactive to $5-\mathrm{HT}$ transporter) in postmortem brains from young autism donors. Neuropharmacology 60:13471354. CrossRef Medline

Bachmanov AA, Reed DR, Beauchamp GK, Tordoff MG (2002) Food intake, water intake, and drinking spout side preference of 28 mouse strains. Behav Genet 32:435-443. Medline

Bazhenova EY, Sinyakova NA, Kulikova EA, Kazarinova IA, Bazovkina DV, Gainetdinov RR, Kulikov AV (2017) No effect of C1473G polymorphism in the tryptophan hydroxylase 2 gene on the response of the brain serotonin system to chronic fluoxetine treatment in mice. Neurosci Lett 653:264-268. CrossRef Medline Benza N, Chugani DC (2015) Serotonin in autism spectrum disorder: insights from human studies and animal models. In: The molecular basis of autism (Fatemi SH, ed), pp 257-274. New York: Springer.

Boulle F, Pawluski JL, Homberg JR, Machiels B, Kroeze Y, Kumar N, Steinbusch HWM, Kenis G, van den Hove DLA (2016) Developmental fluoxetine exposure increases behavioral despair and alters epigenetic regulation of the hippocampal BDNF gene in adult female offspring. Horm Behav 80:47-57. CrossRef Medline

Branchi I, Santucci D, Vitale A, Alleva E (1998) Ultrasonic vocalizations by infant laboratory mice: a preliminary spectrographic characterization under different conditions. Dev Psychobiol 33:249256. Medline

Branchi I, Santucci D, Alleva E (2001) Ultrasonic vocalisation emitted by infant rodents: a tool for assessment of neurobehavioural development. Behav Brain Res 125:49-56. Medline

Brown GL, Ebert MH, Goyer PF, Jimerson DC, Klein WJ, Bunney WE, Goodwin FK (1982) Aggression, suicide, and serotonin: relationships of CSF amine metabolites. Am J Psychiatry 139:741-746. CrossRef Medline

Cabrera-Vera TM, Garcia F, Pinto W, Battaglia G (1997) Effect of prenatal fluoxetine (Prozac) exposure on brain serotonin neurons in prepubescent and adult male rat offspring. J Pharmacol Exp Ther 280:138-145. Medline

Chugani DC, Muzik O, Rothermel R, Behen M, Chakraborty P, Mangner T, da Silva EA, Chugani HT (1997) Altered serotonin synthesis in the dentatothalamocortical pathway in autistic boys. Ann Neurol 42:666-669. CrossRef Medline

Chugani DC, Muzik O, Behen M, Rothermel R, Janisse JJ, Lee J, Chugani HT (1999) Developmental changes in brain serotonin synthesis capacity in autistic and nonautistic children. Ann Neurol 45:287-295. Medline

Cohen J (1988) Statistical power analysis for the behavioral sciences, Ed 2. Hillsdale, NJ: Routledge.

Cooper WO, Willy ME, Pont SJ, Ray WA (2007) Increasing use of antidepressants in pregnancy. Am J Obstet Gynecol 196:544.e1e5. CrossRef Medline

Corbett A, McGowin A, Sieber S, Flannery T, Sibbitt B (2012) A method for reliable voluntary oral administration of a fixed dosage $(\mathrm{mg} / \mathrm{kg}$ ) of chronic daily medication to rats. Lab Anim 46:318-324. CrossRef

D'Amato FR, Scalera E, Sarli C, Moles A (2005) Pups call, mothers rush: does maternal responsiveness affect the amount of ultrasonic vocalizations in mouse pups? Behav Genet 35:103-112. CrossRef

Dar R, Kahn DT, Carmeli R (2012) The relationship between sensory processing, childhood rituals and obsessive-compulsive symptoms. J Behav Ther Exp Psychiatry 43:679-684. CrossRef Medline de Chaumont F, Coura RD-S, Serreau P, Cressant A, Chabout J, Granon S, Olivo-Marin J-C (2012) Computerized video analysis of social interactions in mice. Nat Methods 9:410-417. CrossRef Medline

Dobbing J, Sands J (1979) Comparative aspects of the brain growth spurt. Early Hum Dev 3:79-83. Medline

Dougherty JD, Maloney SE, Wozniak DF, Rieger MA, Sonnenblick L, Coppola G, Mahieu NG, Zhang J, Cai J, Patti GJ, Abrahams BS, 
Geschwind DH, Heintz N (2013) The disruption of Celf6, a gene identified by translational profiling of serotonergic neurons, results in autism-related behaviors. J Neurosci 33:2732-2753. CrossRef Medline

Freireich EJ, Gehan EA, Rall DP, Schmidt LH, Skipper HE (1966) Quantitative comparison of toxicity of anticancer agents in mouse, rat, hamster, dog, monkey, and man. Cancer Chemother Rep 50:219-244. Medline

Geschwind DH (2008) Autism: many genes, common pathways? Cell 135:391-395. CrossRef Medline

Ghanizadeh A (2011) Sensory processing problems in children with $A D H D$, a systematic review. Psychiatry Investig Psychiatry Investig 8:89-94. CrossRef Medline

Gobinath AR, Workman JL, Chow C, Lieblich SE, Galea LAM (2016) Maternal postpartum corticosterone and fluoxetine differentially affect adult male and female offspring on anxiety-like behavior, stress reactivity, and hippocampal neurogenesis. Neuropharmacology 101:165-178. CrossRef

Goeden N, Velasquez J, Arnold KA, Chan Y, Lund BT, Anderson GM, Bonnin A (2016) Maternal inflammation disrupts fetal neurodevelopment via increased placental output of serotonin to the fetal brain. J Neurosci 36:6041-6049. CrossRef

González-Burgos I, Olvera-Cortés E, Del Angel-Meza AR, FeriaVelasco A (1995) Serotonin involvement in the spontaneous alternation ability: a behavioral study in tryptophan-restricted rats. Neurosci Lett 190:143-145. Medline

Grote NK, Bridge JA, Gavin AR, Melville JL, lyengar S, Katon WJ (2010) A meta-analysis of depression during pregnancy and the risk of preterm birth, low birth weight, and intrauterine growth restriction. Arch Gen Psychiatry 67:1012-1024. CrossRef Medline

Haack B, Markl H, Ehret G (1983) Sound communication between parents and offspring. In: The auditory psychobiology of the mouse (Williot JF, ed), pp 57-97. New York: Psychology Press.

Hayashi S (1993) Development and diversity of social structure in male mice. J Ethol 11:77-82. CrossRef

Hernandez-Miranda LR, Ruffault P-L, Bouvier JC, Murray AJ, MorinSurun M-P, Zampieri N, Cholewa-Waclaw JB, Ey E, Brunet J-F, Champagnat J, Fortin G, Birchmeier C (2017) Genetic identification of a hindbrain nucleus essential for innate vocalization. Proc Natl Acad Sci USA 114:8095-8100. CrossRef Medline

Hertz-Picciotto I, Croen LA, Hansen R, Jones CR, van de Water J, Pessah IN (2006) The CHARGE study: an epidemiologic investigation of genetic and environmental factors contributing to autism. Environ Health Perspect 114:1119-1125. Medline

Hiemke C, Härtter S (2000) Pharmacokinetics of selective serotonin reuptake inhibitors. Pharmacol Ther 85:11-28. Medline

Holladay JW, Dewey MJ, Yoo SD (1998) Pharmacokinetics and antidepressant activity of fluoxetine in transgenic mice with elevated serum alpha-1-acid glycoprotein levels. Drug Metab Dispos 26:20-24. Medline

Hollander E, Phillips A, Chaplin W, Zagursky K, Novotny S, Wasserman S, lyengar R (2005) A placebo controlled crossover trial of liquid fluoxetine on repetitive behaviors in childhood and adolescent autism. Neuropsychopharmacology 30:582-589. CrossRef Medline

Holy TE, Guo Z (2005) Ultrasonic songs of male mice. PLoS Biol 3. CrossRef

Jacobsen JP, Rudder ML, Roberts W, Royer EL, Robinson TJ, Oh A, Spasojevic I, Sachs BD, Caron MG (2016) SSRI augmentation by 5-Hydroxytryptophan slow release: mouse pharmacodynamic proof of concept. Neuropsychopharmacology 41:2324-2334. CrossRef Medline

Kalbassi S, Bachmann SO, Cross E, Roberton VH, Baudouin SJ (2017) Male and female mice lacking neuroligin-3 modify the behavior of their wild-type littermates. eNeuro 4. CrossRef

Kaplan JR, Shively CA, Fontenot MB, Morgan TM, Howell SM, Manuck SB, Muldoon MF, Mann JJ (1994) Demonstration of an association among dietary cholesterol, central serotonergic activity, and social behavior in monkeys. Psychosom Med 56:479-484. Medline

Kiryanova V, Meunier SJ, Vecchiarelli HA, Hill MN, Dyck RH (2016) Effects of maternal stress and perinatal fluoxetine exposure on behavioral outcomes of adult male offspring. Neuroscience 320: 281-296. CrossRef Medline

Klei L, Sanders SJ, Murtha MT, Hus V, Lowe JK, Willsey AJ, MorenoDe-Luca D, Yu TW, Fombonne E, Geschwind D, Grice DE, Ledbetter DH, Lord C, Mane SM, Martin CL, Martin DM, Morrow EM, Walsh CA, Melhem NM, Chaste P, et al. (2012) Common genetic variants, acting additively, are a major source of risk for autism. Mol Autism 3:9. CrossRef Medline

Lane AE, Young RL, Baker AEZ, Angley MT (2010) Sensory processing subtypes in autism: association with adaptive behavior. $J$ Autism Dev Disord 40:112-122. CrossRef

Levitt P (2003) Structural and functional maturation of the developing primate brain. J Pediatr 143:S35-S45. CrossRef

Lisboa SFS, Oliveira PE, Costa LC, Venâncio EJ, Moreira EG (2007) Behavioral evaluation of male and female mice pups exposed to fluoxetine during pregnancy and lactation. Pharmacology 80:4956. CrossRef

Lottem E, Lörincz ML, Mainen ZF (2016) Optogenetic activation of dorsal raphe serotonin neurons rapidly inhibits spontaneous but not odor-evoked activity in olfactory cortex. J Neurosci 36:7-18. CrossRef

Lucki I (1998) The spectrum of behaviors influenced by serotonin. Biol Psychiatry 44:151-162. Medline

Maciag D, Simpson KL, Coppinger D, Lu Y, Wang Y, Lin RC, Paul IA (2006) Neonatal antidepressant exposure has lasting effects on behavior and serotonin circuitry. Neuropsychopharmacology 31: 47-57. CrossRef Medline

Maddaloni G, Bertero A, Pratelli M, Barsotti N, Boonstra A, Giorgi A, Migliarini S, Pasqualetti M (2017) Development of serotonergic fibers in the post-natal mouse brain. Front Cell Neurosci 11. CrossRef

Malagié I, Trillat A-C, Jacquot C, Gardier AM (1995) Effects of acute fluoxetine on extracellular serotonin levels in the raphe: an in vivo microdialysis study. Eur J Pharmacol 286:213-217. CrossRef

Maloney SE, Chandler KC, Anastasaki C, Rieger MA, Gutmann DH, Dougherty JD (2018) Characterization of early communicative behavior in mouse models of neurofibromatosis type 1. Autism Res 11:44-58. CrossRef Medline

Marken PA, Munro JS (2000) Selecting a selective serotonin reuptake inhibitor: clinically important distinguishing features. Prim Care Companion J Clin Psychiatry 2:205-210. Medline

Matrisciano F, Tueting P, Dalal I, Kadriu B, Grayson DR, Davis JM, Nicoletti F, Guidotti A (2013) Epigenetic modifications of GABAergic interneurons are associated with the schizophrenia-like phenotype induced by prenatal stress in mice. Neuropharmacology 68:184-194. CrossRef Medline

McDougle CJ, Naylor ST, Goodman WK, Volkmar FR, Cohen DJ, Price LH (1993) Acute tryptophan depletion in autistic disorder: a controlled case study. Biol Psychiatry 33:547-550. Medline

McDougle CJ, Naylor ST, Cohen DJ, Volkmar FR, Heninger GR, Price LH (1996) A double-blind, placebo-controlled study of fluvoxamine in adults with autistic disorder. Arch Gen Psychiatry 53:10011008. Medline

Mezzacappa A, Lasica P-A, Gianfagna F, Cazas O, Hardy P, Falissard B, Sutter-Dallay A-L, Gressier F (2017) Risk for autism spectrum disorders according to period of prenatal antidepressant exposure: a systematic review and meta-analysis. JAMA Pediatr 171:555-563.

Mickle AD, Shepherd AJ, Loo L, Mohapatra DP (2015) Induction of thermal and mechanical hypersensitivity by parathyroid hormonerelated peptide through upregulation of Trpv1 function and trafficking. Pain 156:1620-1636. CrossRef Medline

Miranda R, Nagapin F, Bozon B, Laroche S, Aubin T, Vaillend C (2015) Altered social behavior and ultrasonic communication in the dystrophin-deficient mdx mouse model of Duchenne muscular dystrophy. Mol Autism 6. CrossRef

Misri S, Burgmann A, Kostaras D (2000) Are SSRls safe for pregnant and breastfeeding women? Can Fam Physician 46:626-628, 631633. 
Moeller FG, Dougherty DM, Swann AC, Collins D, Davis CM, Cherek DR (1996) Tryptophan depletion and aggressive responding in healthy males. Psychopharmacology (Berl) 126:97-103. Medline

Moy SS, Nadler JJ, Perez A, Barbaro RP, Johns JM, Magnuson TR, Piven J, Crawley JN (2004) Sociability and preference for social novelty in five inbred strains: an approach to assess autistic-like behavior in mice. Genes Brain Behav 3:287-302. CrossRef Medline

Muller CL, Anacker AM, Rogers TD, Goeden N, Keller EH, Forsberg CG, Kerr TM, Wender CL, Anderson GM, Stanwood GD, Blakely $\mathrm{RD}$, Bonnin A, Veenstra-VanderWeele J (2016) Impact of maternal serotonin transporter genotype on placental serotonin, fetal forebrain serotonin, and neurodevelopment. Neuropsychopharmacology 42:427-436.

Nakai N, Nagano M, Saitow F, Watanabe $Y$ Kawamura $Y$, Kawamoto A, Tamada K, Mizuma H, Onoe $\mathrm{H}$, Watanabe $\mathrm{Y}$, Monai $\mathrm{H}$, Hirase $\mathrm{H}$, Nakatani J, Inagaki H, Kawada T, Miyazaki T, Watanabe M, Sato Y, Okabe S, Kitamura K, et al. (2017) Serotonin rebalances cortical tuning and behavior linked to autism symptoms in 15q11-13 CNV mice. Sci Adv 3:e1603001. CrossRef Medline

Noorlander CW, Ververs FFT, Nikkels PGJ, van Echteld CJA, Visser GHA, Smidt MP (2008) Modulation of serotonin transporter function during fetal development causes dilated heart cardiomyopathy and lifelong behavioral abnormalities. PLoS One 3:e2782. CrossRef

Nordquist N, Oreland L (2010) Serotonin, genetic variability, behaviour, and psychiatric disorders - a review. Ups J Med Sci 115:2-10. CrossRef Medline

Oberlander T, Warburton W, Misri S, Aghajanian J, Hertzman C (2006) Neonatal outcomes after prenatal exposure to selective serotonin reuptake inhibitor antidepressants and maternal depression using population-based linked health data. Arch Gen Psychiatry 63:898-906. CrossRef Medline

Olivier JD, Vallès A, van Heesch F, Afrasiab-Middelman A, Roelofs JJ, Jonkers M, Peeters EJ, Korte-Bouws GA, Dederen JP, Kiliaan AJ, Martens GJ, Schubert D, Homberg JR (2011) Fluoxetine administration to pregnant rats increases anxiety-related behavior in the offspring. Psychopharmacology (Berl) 217:419-432. CrossRef

Orefice LL, Zimmerman AL, Chirila AM, Sleboda SJ, Head JP, Ginty DD (2016) Peripheral mechanosensory neuron dysfunction underlies tactile and behavioral deficits in mouse models of ASDs. Cell 166:299-313. CrossRef Medline

Palanisamy A, Baxter MG, Keel PK, Xie Z, Crosby G, Culley DJ (2011) Rats exposed to isoflurane in utero during early gestation are behaviorally abnormal as adults. Anesthesiology 114:521-528. CrossRef Medline

Peñagarikano O, Abrahams BS, Herman El, Winden KD, Gdalyahu A, Dong H, Sonnenblick LI, Gruver R, Almajano J, Bragin A, Golshani P, Trachtenberg JT, Peles E, Geschwind DH (2011) Absence of CNTNAP2 leads to epilepsy, neuronal migration abnormalities, and core autism-related deficits. Cell 147:235-246. CrossRef Medline

Rai D, Lee BK, Dalman C, Newschaffer C, Lewis G, Magnusson C (2017) Antidepressants during pregnancy and autism in offspring: population based cohort study. BMJ 358:j2811. Medline

Ramos É, St-André M, Rey É, Oraichi D, Bérard A (2008) Duration of antidepressant use during pregnancy and risk of major congenital malformations. Br J Psychiatry 192:344-350. CrossRef Medline

Reisner IR, Mann JJ, Stanley M, Huang YY, Houpt KA (1996) Comparison of cerebrospinal fluid monoamine metabolite levels in dominant-aggressive and non-aggressive dogs. Brain Res 714: 57-64. Medline

Rieger MA, Dougherty JD (2016) Analysis of within subjects variability in mouse ultrasonic vocalization: pups exhibit inconsistent, state-like patterns of call production. Front Behav Neurosci 10: 182. CrossRef

Ross LA, Saint-Amour D, Leavitt VM, Molholm S, Javitt DC, Foxe JJ (2007) Impaired multisensory processing in schizophrenia: deficits in the visual enhancement of speech comprehension under noisy environmental conditions. Schizophr Res 97:173-183. CrossRef Medline
Salari A-A, Fatehi-Gharehlar L, Motayagheni N, Homberg JR (2016) Fluoxetine normalizes the effects of prenatal maternal stress on depression- and anxiety-like behaviors in mouse dams and male offspring. Behav Brain Res 311:354-367. CrossRef Medline

Schizophrenia Working Group of the Psychiatric Genomics Consortium (2014) Biological insights from 108 schizophrenia-associated genetic loci. Nature 511:421-427. CrossRef

Schneider ML, Moore CF, Gajewski LL, Larson JA, Roberts AD, Converse AK, DeJesus OT (2008) Sensory processing disorder in a primate model: evidence from a longitudinal study of prenatal alcohol and prenatal stress effects. Child Dev 79:100-113. CrossRef

Siesser WB, Sachs BD, Ramsey AJ, Sotnikova TD, Beaulieu J-M, Zhang X, Caron MG, Gainetdinov RR (2013) Chronic SSRI treatment exacerbates serotonin deficiency in humanized Tph2 mutant mice. ACS Chem Neurosci 4:84-88. CrossRef Medline

Slobounov S, Tutwiler R, Sebastianelli W, Slobounov E (2006) Alteration of postural responses to visual field motion in mild traumatic brain injury. Neurosurgery 59:134-139, discussion 134-139. CrossRef

Smythies J (2005) Serotonin system. In: The neuromodulators, Sec V, Ed 1, pp 217-268. San Diego: Academic Press.

Sodhi MS, Sanders-Bush E (2004) Serotonin and brain development. Int Rev Neurobiol 59:111-174. CrossRef Medline

Svirsky N, Levy S, Avitsur R (2016) Prenatal exposure to selective serotonin reuptake inhibitors (SSRI) increases aggression and modulates maternal behavior in offspring mice. Dev Psychobiol 58:71-82. CrossRef Medline

Tamada K, Tomonaga S, Hatanaka F, Nakai N, Takao K, Miyakawa T, Nakatani J, Takumi T (2010) Decreased exploratory activity in a mouse model of $15 \mathrm{q}$ duplication syndrome; implications for disturbance of serotonin signaling. PLoS One 5:e15126. CrossRef

Uchida S, Kitamoto A, Umeeda H, Nakagawa N, Masushige S, Kida $S$ (2005) Chronic reduction in dietary tryptophan leads to changes in the emotional response to stress in mice. J Nutr Sci Vitaminol (Tokyo) 51:175-181. Medline

Unceta N, Ugarte A, Sánchez A, Gómez-Caballero A, Goicolea M, Barrio R (2010) Development of a stir bar sorptive extraction based HPLC-FLD method for the quantification of serotonin reuptake inhibitors in plasma, urine and brain tissue samples. J Pharm Biomed Anal 51:178-185. CrossRef

Viktorin A, Uher R, Reichenberg A, Levine SZ, Sandin S (2017) Autism risk following antidepressant medication during pregnancy. Psychol Med 47:2787-2796. CrossRef Medline

Wang F, Zhu J, Zhu H, Zhang Q, Lin Z, Hu H (2011) Bidirectional control of social hierarchy by synaptic efficacy in medial prefrontal cortex. Science 334:693-697. CrossRef Medline

Whitaker-Azmitia PM (2005) Behavioral and cellular consequences of increasing serotonergic activity during brain development: a role in autism? Int J Dev Neurosci 23:75-83. CrossRef

Whitaker-Azmitia PM (2010) Serotonin and development. In: Handbook of behavioral neuroscience, handbook of the behavioral neurobiology of serotonin, Chap 3.1 (Jacobs BL, Muller CP, eds), pp 309-323. New York: Elsevier.

Whitaker-Azmitia PM, Druse M, Walker P, Lauder JM (1996) Serotonin as a developmental signal. Behav Brain Res 73:19-29. CrossRef

Wöhr M, Dahlhoff M, Wolf E, Holsboer F, Schwarting RKW, Wotjak CT (2008) Effects of genetic background, gender, and early environmental factors on isolation-induced ultrasonic calling in mouse pups: an embryo-transfer study. Behav Genet 38:579-595. CrossRef

Zhang WQ, Smolik CM, Barba-Escobedo PA, Gamez M, Sanchez JJ, Javors MA, Daws LC, Gould GG (2015) Acute dietary tryptophan manipulation differentially alters social behavior, brain serotonin and plasma corticosterone in three inbred mouse strains. Neuropharmacology 90:1-8. CrossRef Medline

Zhao ZQ, Chiechio S, Sun YG, Zhang KH, Zhao CS, Scott M, Johnson RL, Deneris ES, Renner KJ, Gereau RW, Chen ZF (2007) Mice lacking central serotonergic neurons show enhanced inflammatory pain and an impaired analgesic response to antidepressant drugs. J Neurosci 27:6045-6053. CrossRef Medline 